Seleção supervisionada de características por ranking para processar consultas por similaridade em imagens médicas

Gabriel Efrain Humpire Mamani 



\section{Seleção supervisionada de características por ranking para processar consultas por similaridade em imagens médica}

\section{Gabriel Efrain Humpire Mamani}

Orientadora: Profa. Dra. Agma Juci Machado Traina

Dissertação apresentada ao Instituto de Ciências Matemáticas e de Computação - ICMC-USP, como parte dos requisitos para obtenção do título de Mestre em Ciências - Ciências de Computação e Matemática Computacional. VERSÃO REVISADA 
Ficha catalográfica elaborada pela Biblioteca Prof. Achille Bassi e Seção Técnica de Informática, ICMC/USP, com os dados fornecidos pelo(a) autor(a)

\begin{tabular}{|c|c|}
\hline \multirow[t]{3}{*}{ H926s } & $\begin{array}{l}\text { Humpire-Mamani, Gabriel Efrain } \\
\text { Seleção Supervisionada de Características por } \\
\text { Ranking para Processar Consultas por Similaridade em } \\
\text { Imagens Médicas / Gabriel Efrain Humpire-Mamani; } \\
\text { orientadora Agma Juci Machado Traina. -- São Carlos, } \\
2012 \text {. } \\
\quad 77 \text { p. }\end{array}$ \\
\hline & $\begin{array}{l}\text { Dissertação (Mestrado - Programa de Pós-Graduação en } \\
\text { Ciências de Computação e Matemática Computacional) -- } \\
\text { Instituto de Ciências Matemáticas e de Computação, } \\
\text { Universidade de São Paulo, } 2012 \text {. }\end{array}$ \\
\hline & $\begin{array}{l}\text { 1. Seleção de Características. 2. Extração de } \\
\text { Características. 3. Recuperação de Imagens Baseado em } \\
\text { Conteúdo.4. Imagens Médicas. I. Machado Traina, } \\
\text { Agma Juci, orient. II. Título. }\end{array}$ \\
\hline
\end{tabular}


"When a writer conceives an idea he concives it in a form of words. That form of words constitutes his style, and it is absolutely governed by the idea. The idea can only exist in words, and it can only exist in one form of words. You cannot say exactly the same thing in two different ways. Slightly alter the expression, and you slightly alter the idea".

- Arnold Bennett 



\section{Agradecimentos}

À minha orientadora, Profa. Dra. Agma J. M. Traina pelo apoio, paciência, sabedoria e especialmente pelos conselhos que me apresentou para tornar possível esse trabalho.

Aos meus pais, "Bertita" e Fermin, e irmãos Saúl, Maritza e Elsa pelo incessante incentivo e apoio nesta etapa na minha vida. Às minhas sobrinhas Alondrita e Kami, e às minhas sobrinhas e sobrinhos, que estão por chegar e que com certeza trarão muita alegria na minha Família.

Aos meus amigos Fernando e Jorge "conchán”, e em especial a Karina por ter me ensinado muito nesta vida e pelos gratos momentos que passamos. Aos meus amigos da "Republica.PE".

Aos meus colegas, do ICMC e do GBdI que me apoiaram ao longo do mestrado. Agradecimentos especiais ao Alceu, Daniel Mario, Felipe, Newton e a Ândrea que ajudaram muito com a revisão desta dissertação.

Ao CNPq pelo suporte financeiro 

Obter uma representação sucinta e representativa de imagens médicas é um desafio que tem sido perseguido por pesquisadores da área de processamento de imagens médicas com o propósito de apoiar o diagnóstico auxiliado por computador (Computer Aided Diagnosis - CAD). Os sistemas CAD utilizam algoritmos de extração de características para representar imagens, assim, diferentes extratores podem ser avaliados. No entanto, as imagens médicas contêm estruturas internas que são importantes para a identificação de tecidos, órgãos, malformações ou doenças. É usual que um grande número de características sejam extraídas das imagens, porém esse fato que poderia ser benéfico, pode na realidade prejudicar o processo de indexação e recuperação das imagens com problemas como a maldição da dimensionalidade. Assim, precisa-se selecionar as características mais relevantes para tornar o processo mais eficiente e eficaz. Esse trabalho desenvolveu o método de seleção supervisionada de características FSCoMS (Feature Selection based on Compactness Measure from Scatterplots) para obter o ranking das características, contemplando assim, o que é necessário para o tipo de imagens médicas sob análise. Dessa forma, produziu-se vetores de características mais enxutos e eficientes para responder consultas por similaridade. Adicionalmente, foi desenvolvido o extrator de características $k$-Gabor que extrai características por níveis de cinza, ressaltando estruturas internas das imagens médicas. Os experimentos realizados foram feitos com quatro bases de imagens médicas do mundo real, onde o $k$-Gabor sobressai pelo desempenho na recuperação por similaridade de imagens médicas, enquanto o FSCoMS reduz a redundância das características para obter um vetor de características menor do que os métodos de seleção de características convencionais e ainda com um maior desempenho em recuperação de imagens.

Palavras-chave: Seleção de Características; CBIR; CAD; Extração de Características; 

Obtaining a representative and succinct description of medical images is a challenge that has been pursued by researchers in the area of medical image processing to support Computer-Aided Diagnosis (CAD). CAD systems use feature extraction algorithms to represent images. Thus, different extractors can be evaluated. However, medical images contain important internal structures that allow identifying tissues, organs, deformations and diseases. It is usual that a large number of features are extracted the images. Nevertheless, what appears to be beneficial actually impairs the process of indexing and retrieval of images, revealing problems such as the curse of dimensionality. Thus, it is necessary to select the most relevant features to make the process more efficient and effective. This dissertation developed a supervised feature selection method called FSCoMS (Feature Selection based on Compactness Measure from Scatterplots) in order to obtain a ranking of features, suitable for medical image analysis. Our method FSCoMS had generated shorter and efficient feature vectors to answer similarity queries. Additionally, the $k$-Gabor feature extractor was developed, which extracts features by gray levels, highlighting internal structures of medical images. The experiments performed were performed on four real world medical datasets. Results have shown that the $k$-Gabor boosts the retrieval performance, whereas the FSCoMS reduces the subsets' redundancy to produce a more compact feature vector than the conventional feature selection methods and even with a higher performance in image retrieval.

Keywords: Feature Selection; CBIR; CAD; Feature Extraction; 

Resumo ix

Abstract $\quad$ xi

Sumário $\quad$ xiii

\begin{tabular}{lll}
\hline & Introdução Geral & 1
\end{tabular}

1.1 Motivação para o Desenvolvimento da Pesquisa . . . . . . . . . . . . . . . . 1

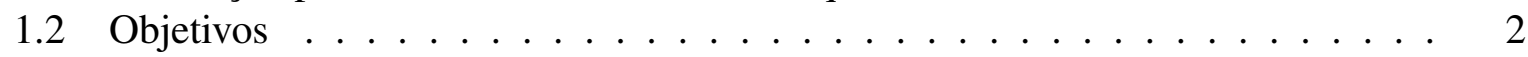

1.3 Organização do Documento . . . . . . . . . . . . . . . . 2

2 Conceitos Necessários para Recuperação de Imagens Baseada em Conteúdo 5

2.1 Extração de Características $\ldots \ldots \ldots \ldots \ldots \ldots$

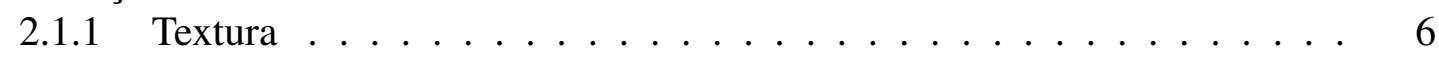

2.1 .2 Forma $\mathrm{e}$ Cor $\ldots \ldots \ldots \ldots \ldots$

2.1 .3 Dimensão Fractal . . . . . . . . . . . . . . . . . . . . . . . . . . . . . 11

2.2 Seleção de Características . . . . . . . . . . . . . . . . . . . . 13

2.2.1 Processos de um método de seleção de características . . . . . . . . . . . 14

2.2 .2 Métodos de seleção de características . . . . . . . . . . . . . . 16

2.3 Consultas por Similaridade . . . . . . . . . . . . . . . . . . . . 21

2.4 Considerações Finais $\ldots \ldots \ldots \ldots$. . . . . . . . . . . . . 22

3 Extração de Características pelo Método $k$-Gabor 23

3.1 O Extrator de Características $k$-Gabor . . . . . . . . . . . . . . . . . 24

$3.1 .1 \quad$ Clusterização com $k$-means . . . . . . . . . . . . . . . . 25

3.1.2 Obtendo o Vetor de Características . . . . . . . . . . . . . . . . 26

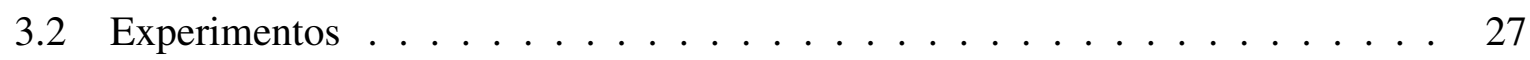

3.2.1 Experimento \#1: Base de Imagens Lung ROI-3258. . . . . . . . . . . . . . 28

3.2.2 $\quad$ Experimento \#2: Base de Imagens 944Body . . . . . . . . . . . . . . . . 30

3.2.3 Experimento \#3: Base de Imagens DDSM . . . . . . . . . . . . . . . . . 31

3.2 .4 Experimento \#4: Base de Imagens IRMA . . . . . . . . . . . . . 32 
3.3 Conclusões . . . . . . . . . . . . . . . . . . . . . . . . . 34

4 Seleção de Características pelo Método FSCoMS 37

$4.1 \quad$ O método Feature Selection Based on Compactness Measure from Scatterplots 38

4.1 .1 Compactness Measure from ScatterPlots. . . . . . . . . . . . . . . . . 40

$4.1 .2 \quad$ Ranking de ScatterPlots . . . . . . . . . . . . . . . . . . . . . . 41

4.1 .3 Ranking de Características . . . . . . . . . . . . . . . . . 43

4.2 Discussão de Experimentos . . . . . . . . . . . . . . . . . . . . . . . . 44

4.2 .1 Geração de Subconjuntos . . . . . . . . . . . . . . . . . . . . . . 46

4.2.2 Análise de Relevância de Subconjuntos em Dimensionalidade . . . . . 47

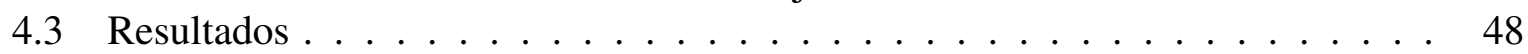

$4.3 .1 \quad$ Experimento \#1: Base de Imagens 944-Body . . . . . . . . . . . . . . 50

4.3.2 Experimento \#2: Base de Imagens Lung CT ROIs . . . . . . . . . . . . 53

$4.3 .3 \quad$ Experimento \#3: Base de Imagens DDSM . . . . . . . . . . . . . . . . . 55

4.3 .4 Experimento \#4: Base de Imagens IRMA . . . . . . . . . . . . . . . . 58

4.4 Considerações Finais $\ldots \ldots \ldots \ldots$. . . . . . . . . . . . . 60

5 Conclusões Gerais e Linhas de Pesquisas Futuras 65

5.1 Linhas de Pesquisas Futuras $\ldots \ldots \ldots \ldots 6$

\begin{tabular}{|lll}
\hline A Apêndice A & 69
\end{tabular}

\begin{tabular}{|l|l|}
\hline Referências Bibliográficas & 73 \\
\hline
\end{tabular} 


\section{Lista de Figuras}

2.1 Exemplo de cinco imagens com diferentes texturas. . . . . . . . . . . . . . 7

2.2 Exemplo de matriz de co-ocorrência . . . . . . . . . . . . . . 8

2.3 Elaboração do filtro de Gabor. . . . . . . . . . . . . . . . . . . . . . 9

2.4 Amostras do banco de filtros de Gabor. . . . . . . . . . . . . . . . . . . . . 10

2.5 Histograma de uma imagem médica. . . . . . . . . . . . . . . . . . . . . . . . . . . . . . . . . . .

2.6 Triângulo de Sierpinski. . . . . . . . . . . . . . . . . . . . . . . 11

2.7 Diagrama do extrator SFTA. . . . . . . . . . . . . . . . . . . . . 13

2.8 Processo geral de um método de seleção de características. . . . . . . . . . . . 14

2.9 Os tipos de consultas $k \mathrm{NN}$ e por abrangência $\ldots \ldots \ldots \ldots$. . . . . . . 21

$3.1 \quad$ O diagrama do método $k$-Gabor usando $k=3$. . . . . . . . . . . . 25

$3.2 \quad$ Casamento de pixels entre a máscara $M_{k}$ e I para a obtenção de $I_{k}^{*}$. . . . . . . . 26

3.3 Exemplo de saídas do algoritmo $k$-means para a base de imagens Lung ROI-3258. 28

$3.4 \quad$ Amostras da base de imagens Lung ROI 3258. . . . . . . . . . . . . . . . . . . 29

3.5 Gráfico de Precisião e Revocação para a imagem "Lung ROI-3258". . . . . . . 29

3.6 Amostras da base de imagens "944Body". . . . . . . . . . . . . . . . . . 30

3.7 Gráfico de P\&R para a base de imagens "944Body" usando $k=2$ para $k$-Gabor. $\quad 31$

3.8 Amostras da base de imagens "DDSM" . . . . . . . . . . . . . 31

3.9 Gráfico de Precisão e Revocação para a base de imagens "DDSM". . . . . . . . . 32

3.10 Amostras da base de imagens IRMA, mostrando uma imagem por cada classe. $\quad 33$

3.11 Gráfico de Precisão e Revocação para a base de imagens "IRMA". . . . . . . . . 33

3.12 Sumarização dos resultados de precisão dos extratores de características. . . . . 35

4.1 Diagrama geral do método de seleção de características FSCoMS. . . . . . . . 40

4.2 Exemplo de uma análise de ScatterPlot . . . . . . . . . . . . . . . . . 42

4.3 Diagrama dos processos para os métodos de seleção de características por ranking. 45

$4.4 \quad$ Diagrama da análise da dimensionalidade para os métodos $X^{2}$, IG e FSCoMS..$~ 46$

4.5 Obtenção do valor de relevância para um subconjunto $S_{i}$. . . . . . . . . . . . . 48

4.6 Amostras da base de imagens médicas 944-Body. . . . . . . . . . . . . . . 50

$4.7 \quad$ Análise de relevância de subconjuntos para a base de imagens 944Body. . . . . . 51

$4.8 \quad$ Gráfico P\&R para a base de imagens 944Body e consultas $k$ NN com $k=15$. . $\quad 52$ 
$4.9 \quad$ Amostras da base de imagens Lung CT ROIs. . . . . . . . . . . . . . . . . . . 53

4.10 Análise de relevância de subconjuntos para a base de imagens Lung CT ROIs. . 54

4.11 Gráfico de P\&R para a base de imagens Lung $C T$ e consultas $k \mathrm{NN}$ com $k=20$. 55

4.12 Amostras da base de imagens "DDSM" . . . . . . . . . . . . 56

4.13 Análise de relevância de subconjuntos para a base de imagens DDSM. . . . . . 56

4.14 Gráfico de P\&R para a base de imagens $D D S M$ e consultas $k \mathrm{NN}$ com $k=15$. . . $\quad 57$

4.15 Amostras da base de imagens IRMA com oito classes. . . . . . . . . . . . . 58

4.16 Análise de relevância de subconjuntos para a base IRMA. . . . . . . . . . . . 59

4.17 Gráfico de P\&R para a base de imagens IRMA e consultas $k$ NN $\operatorname{com} k=15$. . 60

4.18 Diagrama radar do desempenho do (a)FSCoMS e (b)IG em cada Base de imagens. 62

4.19 Diagrama radar do desempenho do Fisher e gramSchmidt em cada Base de

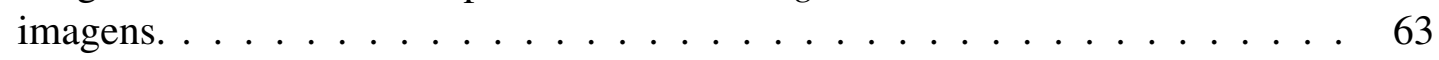

4.20 Diagrama radar do desempenho do T-test e o $X^{2}$ em cada Base de imagens. . . 63

4.21 Diagrama radar do desempenho do StarMiner e o CFS em cada Base de imagens. 64

4.22 Diagrama radar do desempenho do FCBF em cada Base de imagens. . . . . . . 64 


\section{Lista de Tabelas}

3.1 Sumarização dos resultados de precisão dos extratores de características. . . . . 34

4.1 Tabela de símbolos . . . . . . . . . . . . . . . . . . . . . . . . . . . 39

\begin{tabular}{|l|l|l|l|l|}
\hline 4.2 & Exemplo de valores de relevância do ranking usando a Equação & 4.6 & $\operatorname{com} A=2$.
\end{tabular}

4.3 Métodos de extração de características usados nos experimentos. . . . . . . . . 49

\begin{tabular}{|lll}
\hline 4.4 & Tabela comparativa de dimensionalidade das quatro bases de imagens avaliadas. & 61
\end{tabular} 



\section{Introdução Geral}

\subsection{Motivação para o Desenvolvimento da Pesquisa}

Atualmente os hospitais têm equipamentos de imageamento que podem gerar imagens de alta qualidade com altos níveis de detalhes em tempo real. No entanto, requer muitos especialistas para atender todos os casos clínicos atuais. Nos centros hospitalares há ainda muita informação não processada por falta de especialistas. Assim, os casos clínicos que já foram analisados e laudados podem ser uma fonte de conhecimento necessário para que o computador, pelo meio de pré-processamento de imagens, possa obter sugestões de diagnósticos considerando a similaridade entre os casos clínicos que ainda não foram atendidos.

Os sistemas de Diagnóstico Auxiliado por Computador (CAD - do inglês Computer Aided Diagnosis) apoiam os médicos especialistas na tarefa de diagnóstico apresentando-lhes sugestões de possíveis diagnósticos. Entre os principais objetivos dos sistemas CAD estão $(i)$ melhorar a acurácia do diagnóstico, e (ii) melhorar a consistência da interpretação das imagens médicas. No entanto, os sistemas CAD continuam em desenvolvimento e ainda demandam melhorias. Uma das principais técnicas utilizadas pelos sistemas CAD é a Content Based Image Retrieval (CBIR), que por sua vez é composta por algoritmos que fornecem informação relevante segunda uma imagem de consulta. Assim, para o cálculo das imagens mais similares é necessário um processo de extração de características que possa representar numericamente uma imagem do modo mais sucinto possível. No entanto, obter abundante informação das ima- 
gens gera problemas, como a redundância, devido ao número elevado de características. Assim, são aplicados métodos de seleção de atributos (características) para descartar informação pouco relevante ou redundante. Por consequência, consegue-se reduzir o tempo de resposta do sistema CBIR. Finalmente, aumentar a taxa de precisão e a eficiência dos sistemas CAD é a principal motivação deste projeto de mestrado.

\subsection{Objetivos}

O objetivo deste projeto de mestrado é desenvolver um algoritmo supervisionado que permita selecionar e ponderar as características mais importantes utilizando algoritmos de visualização e projeção de dados de alta dimensionalidade. Desse modo, um sistema de recuperação de imagens por conteúdo, que apoie consultas por similaridade em um tipo específico de imagens, poderá se beneficiar da escolha mais apropriada das melhores características.

Como elementos de experimentação da técnica a ser desenvolvida, foram utilizadas bases de imagens médicas do mundo real, que são bases com laudos e que se encontram disponibilizadas para o Grupo de Bases de Dados e de Imagens (GBdI) pelo Centro de Ciências de Imagens e Física Médica do Hospital das Clínicas de Ribeirão Preto.

\subsection{Organização do Documento}

O presente projeto de mestrado apresentou no primeiro capítulo as considerações iniciais para o entendimento do trabalho apresentado nesta dissertação, a motivação do desenvolvimento desta proposta e a organização do documento. O conteúdo do trabalho está estruturado da seguinte maneira:

- No Capítulo 2 são abordados: (i) métodos de extração de características relacionados com a proposta desta dissertação, (iii) os principais métodos de seleção de características da literatura que foram utilizados na área médica, e (iii) consultas por similaridade em sistemas CBIR.

- O Capítulo 3 mostra detalhadamente o extrator de características $k$-Gabor, que é parte da proposta neste projeto de mestrado. Além disso, são apresentados os experimentos realizados com quatro bases de imagens médicas do mundo real. 
- O Capítulo 4 descreve o método de seleção de características proposto nesta dissertação, o Feature Selection based on Compactness Measure from Scatterplots (FSCoMS). Os experimentos realizados usaram as mesmas bases de imagens usadas no Capítulo 3 e apresenta uma discussão de resultados que ressalta as contribuições de ambos Capítulos (3 e 4).

- Finalmente, o Capítulo 5 sumariza as conclusões desta dissertação, apontando as principais contribuições (os métodos $k$-Gabor e FSCoMS), e linhas de pesquisas futuras. 

CAPÍTULO

\section{2}

\section{Conceitos Necessários para} Recuperação de Imagens Baseada em Conteúdo (CBIR)

O problema de gerenciar e extrair informações relevantes de grandes quantidades de imagens médicas (mamografias, tomografias, raios X, ultra-som, entre outros), as quais são diariamente coletadas por hospitais e centros médicos, tem motivado a pesquisa nos sistemas CBIR. Assim, algoritmos de processamento de imagens eficazes e eficientes são o principal objetivo de grupos de pesquisa para obter a essência da imagem em relação a um critério específico. Normalmente as aplicações mudam segundo as restrições e os objetivos do sistema CBIR, por conseguinte, não existe um sistema CBIR com resultados ideais para todos os casos. Dessa forma, é necessária uma análise dos algoritmos que serão utilizados no sistema CBIR para aprimorar tanto quanto for possível o desempenho e qualidade em recuperação.

A literatura define os sistemas CBIR como uma tecnologia que ajuda o gerenciamento de imagens pelo seu conteúdo visual (Datta et al., 2008). No entanto, existe uma diferença entre o conteúdo visual (percepção humana) e a representação digital (numérica) de uma imagem (representação computarizada), esse problema é chamado de gap semântico. Como solução para lidar com o gap semântico, foram desenvolvidos extratores de características específicos para a área médica (García-Gómez, 2009, Ghosh et al., 2011). Por outro lado, o funcionamento 
geral de um sistema CBIR é sumarizado da seguinte maneira "dado uma imagem de consulta $I$, retornar as $k$ imagens mais similares/relevantes segundo seu conteúdo" (Deselaers et al., 2007).

\subsection{Extração de Características}

Uma imagem engloba grande quantidade de informações, que precisam ser organizadas para permitir interpretar e compreender seu conteúdo. A primeira ideia para obter informação relevante de um objeto é basear-se na percepção humana, que usa principalmente a forma e a cor para distinguir entre os objetos primários, assim, quanto mais complexos os objetos, mais complexas suas características. No entanto, muitos dos extratores de características não podem ser interpretados graficamente, mas têm significado semântico. Usualmente a informação extraída (característica) é resultado de uma análise global da imagem. No entanto, os extratores de características capturam informações numéricas e relevantes para distinguir/separar as imagens de nosso interesse, que indicam qual grupo de imagens pertence à mesma classe. As características serão mais robustas se apresentarem independência às transformações geométricas (translação, rotação e escala) (Arimura et al., 2009). Assim, as $m$ características obtidas são organizadas em um vetor de características, podendo ser interpretado como um ponto $m$-dimensional em um espaço vetorial (Guyon, 2006).

A extração de características é um problema que refere-se também ao domínio das imagens que serão classificadas (Deserno, 2010). Assim, cada base de imagens muda o contexto do conteúdo que quer representar. Por exemplo, se temos imagens médicas, possivelmente o objetivo seja identificar tumores. Considere que os tumores mudam muito entre a cabeça, costas, mamografia, e outros, assim, o contexto muda muito segundo os requerimentos do sistema CBIR. Em consequência, precisa-se analisar o desempenho dos extratores de características para determinar qual deles é o mais adequado para cada contexto.

$\mathrm{Na}$ literatura há muitos extratores de características, cada um deles com vantagens, desvantagens e restrições. Os extratores de características mais comuns empregados em sistemas CBIR são divididos em três classes primitivas: cor, textura e forma. A seguir apresentaremos os principais métodos de extração de características que são comumente usados com imagens médicas.

\subsubsection{Textura}

Imagens de água, grama, madeira ou objetos feitos pelo homem contém exemplos de texturas, cada uma diferente da outra. No entanto, a textura é difícil de descrever em termos qualitativos (Manjunath and Ma, 2002). Não existe uma definição formal da textura que seja universalmente 
aceita. Assim, (Saipullah and Kim, 2011) definem a textura como uma propriedade intrínseca da imagem que representa a rugosidade e as características estatísticas de variações locais de brilho entre pixels vizinhos.

A textura nos sistemas CBIR é uma das principais características representativas dos objetos da natureza, sendo que muda por cada material do objeto representado na imagem. A Figura 2.1 contém cinco amostras de texturas diferentes, pode-se distinguir a madeira, pedras, folhas, tecido e água. Cada uma dessas texturas representa objetos diferentes e tem um padrão de uma região de interesse. Os principais extratores baseados em textura encontrados na literatura serão apresentados nas seguintes sub-seções.
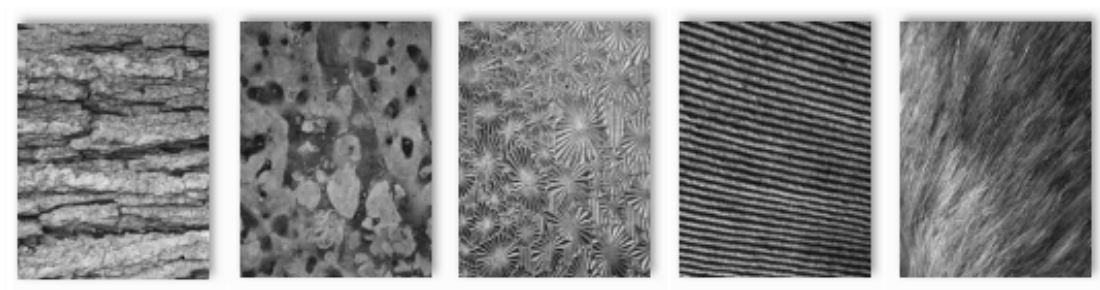

Figura 2.1: Exemplo de cinco imagens com diferentes texturas.

\section{Haralick}

O extrator de características Haralick (Haralick et al., 1973) é um dos extratores mais usados nos sistemas CBIR por representar os principais conceitos genéricos de textura como autocorrelação, brilho, contraste, entropia, homogeneidade, entre outros.

As características de Haralick são extraídas calculando medidas estatísticas da matriz de co-ocorrência da imagem. A principal vantagem da matriz de co-ocorrência (Albregtsen and Others, 1995) é representar a distribuição de intensidades de tons de cinza de uma imagem. Ao usar níveis de cinza (limiares), a matriz de co-ocorrência reduz o tempo de processamento. Na literatura são considerados $d=8$ níveis de cinza para gerar a matriz de dimensão $8 * 8$. Assim, as intensidades correspondentes aos deslocamentos nos eixos $X$ e $Y$ preenchem a matriz de co-ocorrência. Sendo que os valores para os deslocamentos nos eixos representam as orientações em ângulos, por exemplo: $45^{\circ}, 90^{\circ}, 135^{\circ}, \ldots$, etc. A Equação 2.1 mostra formalmente o cálculo da matriz de co-ocorrência, considerando $I$ a imagem e $p(i, j)$ o valor da matriz de co-ocorrência no ponto $(i, j) \operatorname{com} i=1, \ldots, d$ e $j=1, \ldots, d$, as variáveis $\Delta x$ e $\Delta y$ são os deslocamentos nos eixos $x$ e $y$ respectivamente. Um exemplo gráfico de como calcular a matriz 
de co-ocorrência é apresentado na Figura 2.2.

$$
p(i, j)=\sum_{x=0}^{(x-\Delta x)} \sum_{y=0}^{(y-\Delta y)} 1, \operatorname{Se}(I(x, y)=i) \mathrm{e}(I(x+\Delta x, y+\Delta y)=j)
$$

As características são extraídas da matriz de co-ocorrência em um total de 22 características.

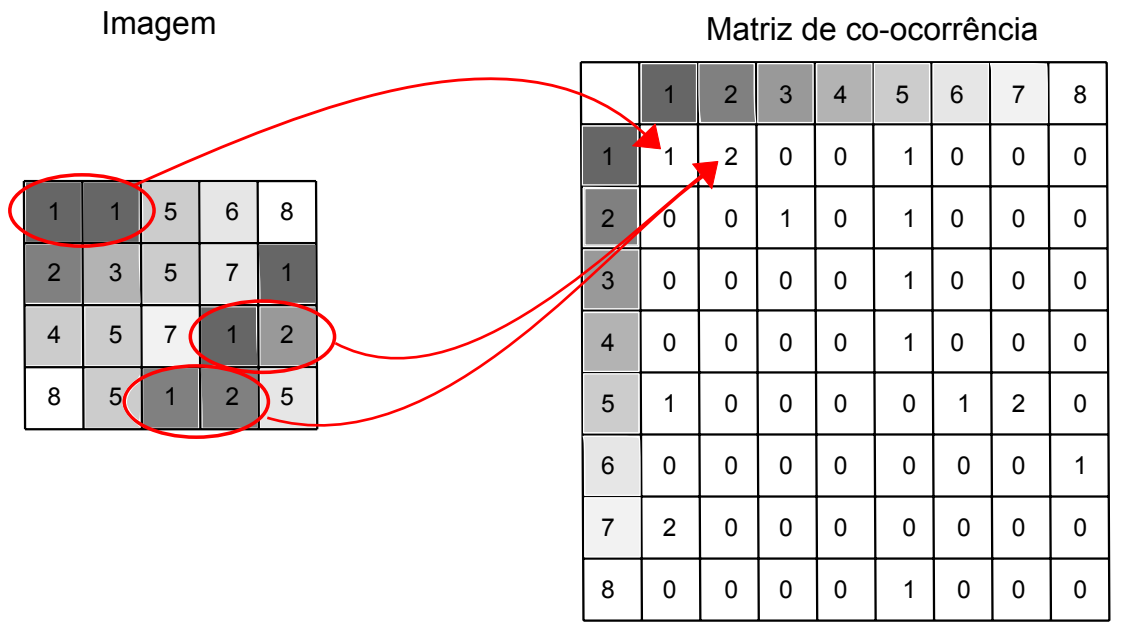

Figura 2.2: Exemplo de matriz de co-ocorrência com deslocamentos no eixo $x=1$ e $y=0$, adaptado de wWw. mathworks. com.

As equações para calcular as características são detalhadas no Anexo $\mathrm{A}$

\section{Gabor}

O extrator Gabor (ou Banco de Filtros de Gabor) (Manjunath, 1996); (Movellan, 2002) é amplamente usado em sistemas CBIR por ter características robustas e independentes de transformações geométricas. Gabor trabalha com parâmetros de orientação e escala que influem no cálculo dos filtros. Cada um dos filtros é aplicado na imagem de entrada para obter a média e o desvio padrão em cada região.

O filtro de Gabor atua independentemente da escala, rotação e translação da imagem por meio de um limite de escalas e rotações atribuídas como parâmetros. Formalmente a função complexa de Gabor (ou filtro de Gabor) apresenta a seguinte equação:

$$
g(x, y)=\left(\frac{1}{2 \pi \sigma_{x} \sigma_{y}}\right) \exp \left[-\frac{1}{2}\left(\frac{R_{1}^{2}}{\sigma_{x}^{2}}+\frac{R_{2}^{2}}{\sigma_{y}^{2}}\right)\right] \exp \left(\frac{2 \pi i R_{1}}{\lambda}\right)
$$




$$
\begin{aligned}
& R_{1}=x \cos \phi-y \sin \phi \\
& R_{2}=x \sin \phi+y \cos \phi
\end{aligned}
$$

Considerando $\phi$ como a orientação do filtro, $\gamma$ como a razão de aspecto do filtro, $\sigma$ é o desvio padrão da Gaussiana segundo cada eixo, $\lambda$ é a largura de onda da função sinusoidal, e finalmente $\psi$ é o deslocamento da fase. As variáveis $\lambda, \sigma$, e $\theta$ podem assumir valores diversos. Para obter um melhor desempenho do extrator Gabor, (Cope et al. 2010) propõe valores padrões para $\sigma, \lambda$ e $\phi$, baseados em $m$ o número de escalas e $n$ o número de rotações com $\sigma=1.5 * 1.2^{m-1}$, $\lambda=\frac{\sigma * \pi}{2} \mathrm{e} \phi=\frac{n * \pi}{16}$.

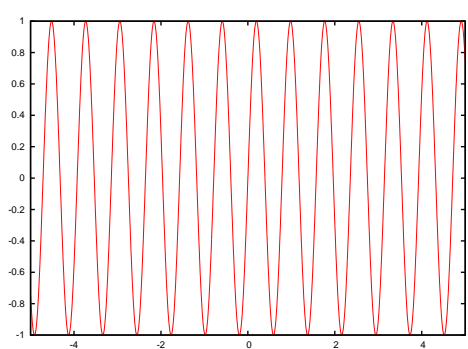

(a) Função sinusoidal.

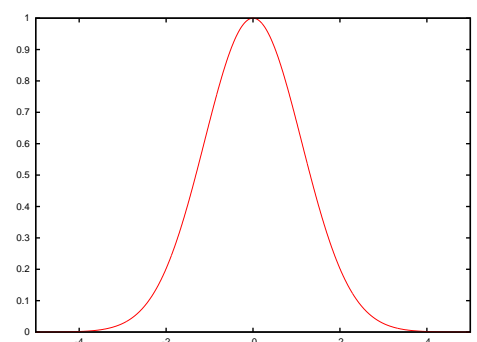

(b) Função gaussiana.

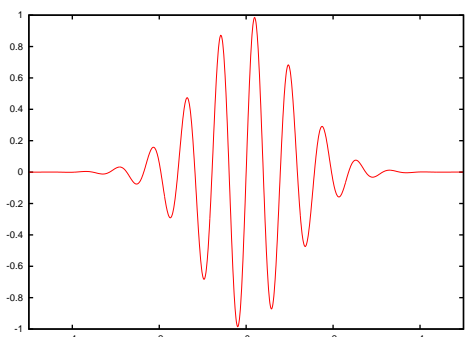

(c) Filtro de Gabor.

Figura 2.3: Elaboração do filtro de Gabor.

Na Figura 2.3 são ilustradas três imagens que explicam a geração do filtro de Gabor baseados na teoria da transformada de Fourier. A imagem 2.3 a) é um sinal gerado por um função senoidal, a imagem 2.3 (b) é gerada pela função do filtro Gaussiano e finalmente a imagem 2.3 (c) é a multiplicação das sinais $(a) *(b)$. A Figura 2.4 mostra algumas amostras do banco de filtros gerados pela Equação 2.2. O Banco de Filtros de Gabor tem sido usado em muitas aplicações na área médica, em (Buciu and Gacsadi, 2009) Gabor é usado para a detecção de tumores malignos e benignos em mamografias, em (Tahmoush, 2009) é utilizada para a detecção de câncer de mama. Além disso, os filtros de Gabor também são usados em aplicações de reconhecimento de padrões (Wang et al., 2005b).

\subsubsection{Forma e Cor}

A forma é uma das mais importantes características de baixo nível nos sistemas CBIR sendo muitas vezes utilizada para representar mais proximamente a percepção humana (Mingqiang et al., 2008). A identificação de objetos pela forma é uma das técnicas mais efetivas para a identificação de objetos primários. Na área médica as características de forma são usadas para a identificação de tumores, órgãos ou regiões de interesse com forma bem definida. A maioria 

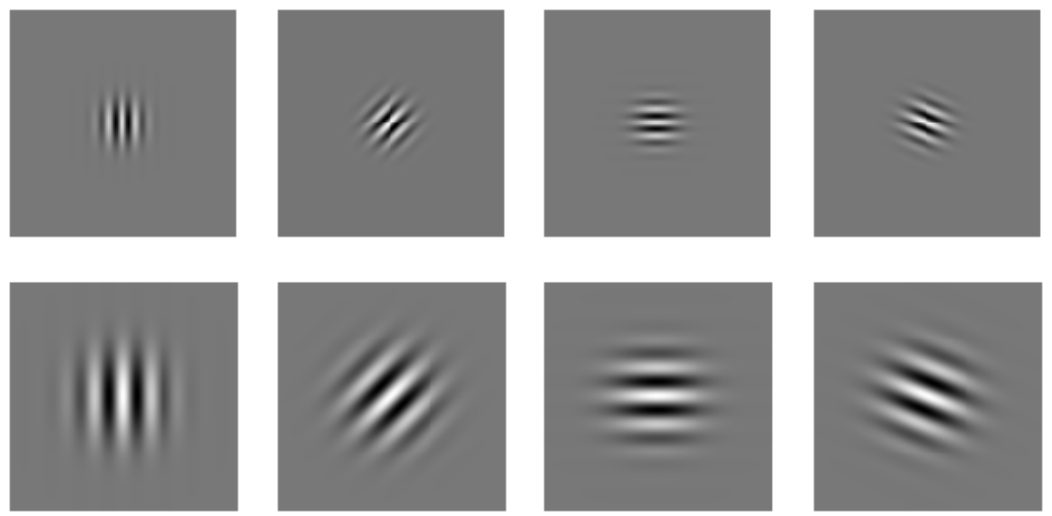

Figura 2.4: Amostras do banco de filtros de Gabor.

de extratores baseados em forma precisam do contorno da região de interesse para obter suas características. Assim, um primeiro passo é usar métodos de segmentação sob a imagem de entrada para a identificação da região de interesse e depois obter seu contorno. Além disso, os extratores de forma apresentam diversidade de aplicações como medicina, biologia, robótica, entre outros. Por outro lado, as características baseadas na cor são usadas pela principal vantagem de representar conteúdo visual de imagens com custo computacional baixo nos sistemas CBIR.

Os principais extratores baseados em forma e cor encontrados na literatura serão apresentados a seguir.

\section{Características Geométricas}

Usualmente o contorno de uma região de interesse é utilizado para poder obter valores geométricos como: curvatura, excentricidade, área, entre outros. Em (Cho, 2010), mostra-se que diversos órgãos e estruturas biológicas têm formas identificáveis e inclusive não mudam muito de pessoa para pessoa, como por exemplo: o cérebro, os ossos e o coração. Desse modo, variações ou desvios nas formas usuais podem identificar casos anormais em órgãos ou estruturas presentes nas imagens de exames médicos.

\section{Histogramas}

O histograma (Swain and Ballard, 1991) é a maneira mais fácil de representar a distribuição da cor na imagem com custo computacional linear. Os histogramas são considerados como uma contagem do número de vezes de cada cor nos pixels da imagem.A Figura 2.5 apresenta uma imagem médica (cranio sagital) e seu respectivo histograma. Os histogramas são usados 
amplamente na área médica pela independência das transformações geométricas. Além disso, alterações leves na imagem não mudam muito os resultados (Deselaers et al., 2007). No entanto, a principal desvantagem é que imagens distintas podem ter histogramas iguais ou similares.

Imagem

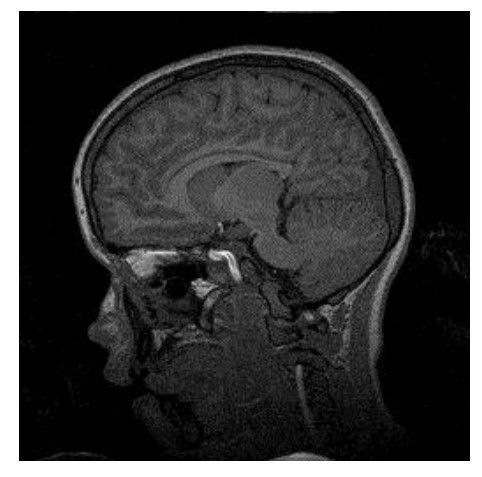

Histograma

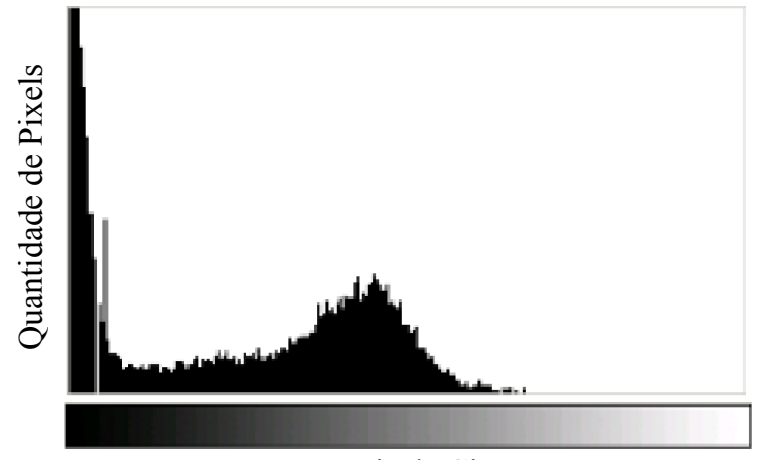

Níveis de Cinza

Figura 2.5: Histograma de uma imagem médica, mostra-se a imagem de entrada e o histograma obtido com a quantidade de pixels encontrados na imagem por níveis de cinza.

\subsubsection{Dimensão Fractal}

Os fractais são estruturas que apresentam certo grau de auto-semelhança em escala, ou seja, um objeto é composto por partes similares ao fractal como um todo (Balan et al., 2005). O fractal mais conhecido é o triângulo de Sierpinski, ilustrado na Figura 2.6, que apresenta triângulos equiláteros com cada esquina no ponto médio de cada lado de um triângulo maior. Assim, as imagens também podem apresentar auto-similaridade para definir a região de interesse atual. A seguir, são apresentados alguns métodos de extração de características baseados na dimensão fractal.

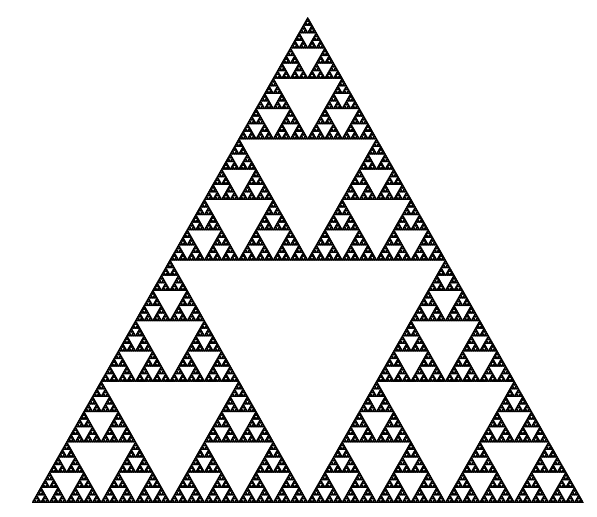

Figura 2.6: O triângulo de Sierpinski apresenta a auto-similaridade, neste caso, cada triângulo contém mais triângulos. 


\section{Fast Fractal Stack (FFS)}

O extrator Fast Fractal Stack ou FFS (Costa et al., 2011) baseia-se na dimensão fractal de bandas das imagens, obtidas por sua decomposição por limiares, e foi validado com imagens de pulmão obtendo destaque na capacidade de recuperar imagens em tempo linear. O FFS considera uma imagem de entrada em tons de cinza. Inicialmente a imagem é decomposta em $t$ limiares usando o algoritmo proposto no mesmo trabalho para decomposição de pilha binária (binary stack decomposition algorithm), como mostra a Equação 2.5.

$$
I_{b}(x, y)=\left\{\begin{array}{l}
1 \text { se } I(x, y) \geq t \\
0, \text { caso contrário. }
\end{array}\right.
$$

O algoritmo Fast Fractal Stack (FFS) aproveita os limiares para ressaltar os contornos das regiões encontradas em cada nível, e calcula a dimensão fractal usando o algoritmo Box counting (Abraham, 1994) para cada nível. A Equação 2.6 mostra como calcular os limiares $t_{i}$.

$$
t_{i}=\left\lfloor\frac{n_{l}}{n_{t}+1} \cdot i\right\rfloor, i=1,2, \ldots, n_{t}
$$

onde $n_{t}$ é um parâmetro definido pelo usuário que corresponde ao número de limiares. $\mathrm{O}$ autor propõe usar empiricamente o valor $n_{t}$ em 8 . No entanto, a principal vantagem do método FFS é seu custo computacional linear com relação ao tamanho da imagem.

\section{Surfaces Feature Texture Analysis (SFTA)}

O extrator Surfaces Feature Texture Analysis ou SFTA (Costa et al. 2012), é um método baseado na decomposição da imagem de entrada em um conjunto de imagens para ressaltar características internas. A imagem é decomposta usando o algoritmo proposto no mesmo trabalho Two Threshold Binary Decomposition (TTDB), que baseia-se no algoritmo Otsu multi-nível (Huang and Wang, 2009) para encontrar os pares de thresholds a serem aplicados na imagem. De cada imagem decomposta são extraídas três características no total, duas características de textura (média e desvio padrão), e a dimensão fractal calculada das bordas da imagem decomposta. Todas as características são colocadas no mesmo vetor de características do extrator SFTA, como ilustra a Figura 2.7 
Imagem Binária

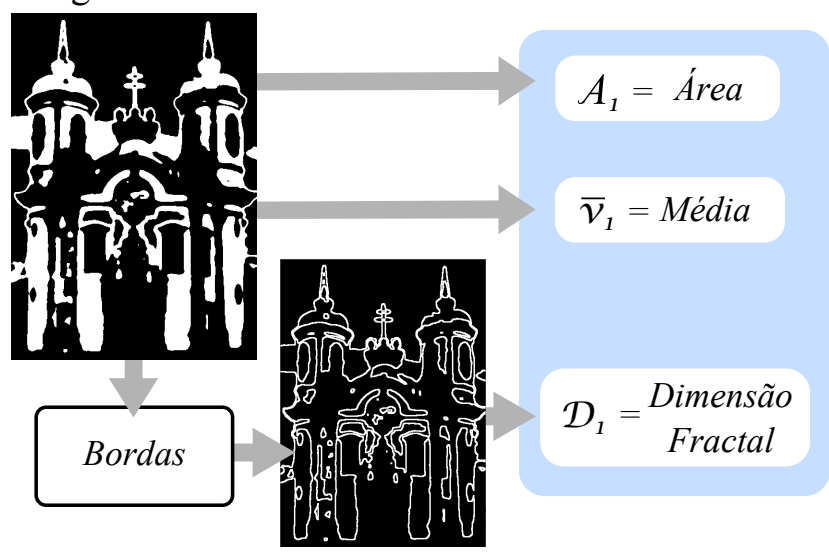

Figura 2.7: Diagrama do extrator SFTA.

\subsection{Seleção de Características}

Os métodos de seleção de características recebem um único vetor de características como entrada. É assim que os vetores de características dos extratores apresentados na Seção 2.1 serão compostos para obter o vetor $J_{f v}$, que é a entrada para os métodos de seleção de características. Integrar as características fornecidas por $n$ extratores de características com dimensionalidades $d_{1}, d_{2}, \ldots, d_{n}$ em um único vetor geraria um vetor de dimensionalidade $d_{f}$ resultante da soma das dimensionalidades $d_{f}=d_{1}+d_{2}+\cdots+d_{n}$. O fato de ter uma maior dimensionalidade não implica em uma maior precisão nos resultados do CBIR. Ao contrário, isso pode influenciar negativamente nas etapas posteriores. Esse problema é chamado de maldição da dimensionalidade (Hinneburg and Keim, 1999; Pagel et al., 2000) onde a precisão do sistema diminui conforme o vetor de características aumenta.

A seleção de características é uma área de pesquisa importante nas áreas de reconhecimento de padrões, estatística, e mineração de dados com o objetivo de escolher um subconjunto de características que aprimore a precisão do sistema CBIR (Wang et al., 2005a) pela eliminação de características pouco preditivas (Kim and Street, 2007).

Assim, o subconjunto escolhido pode ser: (i) o subconjunto de características com um tamanho específico que otimiza seu desempenho, e (ii) o subconjunto com o melhor equilíbrio entre e o desempenho de recuperação/classificação.

Relevância Segundo definição em (Yu and Liu, 2004), uma característica pode ser estatisticamente relevante por duas razões: ( $i$ ) está fortemente correlacionado com a classe, ou (ii) é parte de um subconjunto com outras características e o subconjunto é fortemente correlacionado com a classe. Existem 3 níveis de relevância: forte, fraca e irrelevante. 
Redundância Uma característica é redundante se no subconjunto de características existe mais de uma característica com semântica similar ou com as mesmas propriedades (Guyon, 2006). A redundância de características influi também no desempenho do subconjunto, normalmente com uma quantidade maior de características ou diminuindo o desempenho na recuperação de imagens.

\subsubsection{Processos de um método de seleção de características}

Um método de seleção de características (Reunanen, 2012) apresenta a estrutura ilustrada na Figura 2.8, e é composto das seguintes etapas: geração de subconjuntos, avaliação, critério de parada e a validação do subconjunto final. Formalmente, o processo de validação não é parte de um método de seleção de características, mas sua função é validar a qualidade do subconjunto.

Um método de seleção de características pode retornar: $(i)$ um único subconjunto, obtendo $S=\left\{f_{1}, f_{2}, \ldots, f_{n}\right\}$ com $n<m$ sendo $n$ e $m$ as dimensionalidades do vetor de características selecionado e do vetor de características original respectivamente, ou $(i i)$ um ranking de características ordenados por relevância, ou seja, o método não retorna um subconjunto de características. Então, no caso (ii) precisa-se gerar subconjuntos baseados no ranking de características para encontrar o subconjunto com melhor desempenho. Os subconjuntos serão gerados da seguinte maneira: $S=\left\{S_{1}, S_{2}, \ldots, S_{m}\right\}$, sendo que $S_{1}=\left\{f_{1}\right\}, S_{2}=\left\{f_{1}, f_{2}\right\}, \ldots$, $S_{m}=\left\{f_{1}, f_{2}, \ldots, f_{m}\right\}$. Além disso, a característica $f_{i}$ é mais relevante do que a característica $f_{i+1}$. Estas etapas serão descritas a seguir.

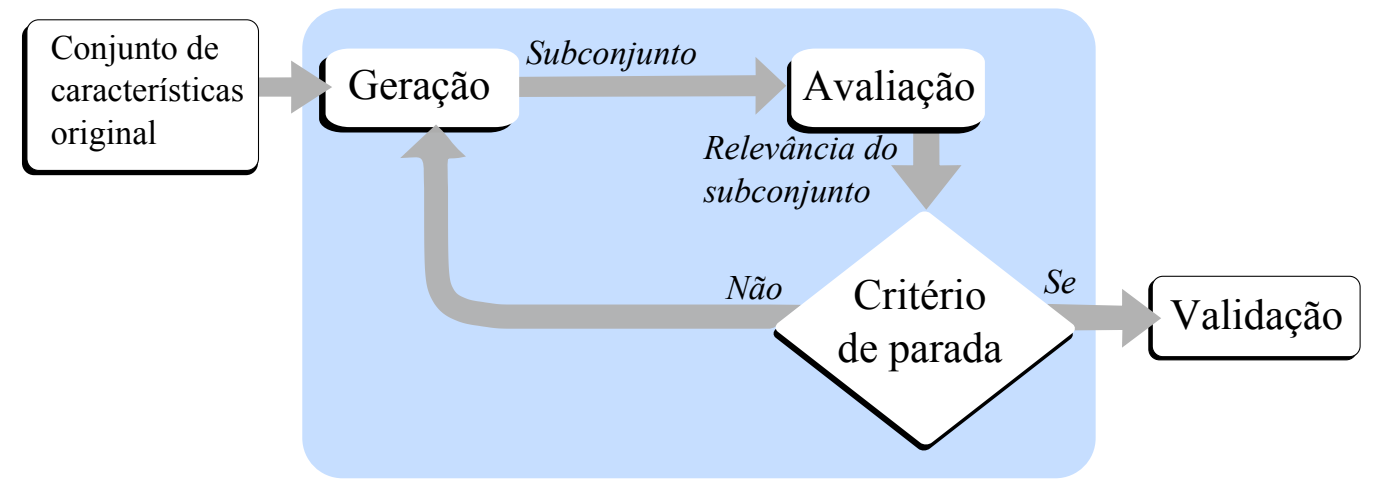

Figura 2.8: Processo geral de um método de seleção de características, Figura adaptada de (Duchesnay et al., 2011).

\section{Geração}

A etapa de Geração cria um subconjunto de características para depois avaliá-lo. A etapa de geração de subconjuntos é repetitiva até encontrar um subconjunto que satisfaça algum critério 
de parada. Assim, para gerar um novo subconjunto pode-se optar por três das seguintes opções: adicionar características relevantes ao subconjunto, remover características irrelevantes do subconjunto, ou ambos. No entanto, são três as abordagens para a geração de todos os subconjuntos:

1. Completo - Examina todos os subconjuntos possíveis. Apesar de encontrar a melhor solução, o custo computacional é exponencial e se o número de características for grande, torna-se uma solução computacionalmente intratável.

2. Heurístico - Seleciona subconjuntos sob alguns critérios de geração de subconjuntos. Produz resultados rápidos mas não garante o melhor resultado.

3. Aleatório - Gera subconjuntos sem uma ordem de relevância. O subconjunto ótimo depende da quantidade de gerações realizadas. Além disso, depende muito do critério de parada para não cair na abordagem de geração completa (força bruta).

A primeira geração do subconjunto de características pode ser feita seguindo as seguintes abordagens:

Forward selection : Começa sem características e as adiciona uma a uma. Em cada passo adiciona uma característica para reduzir o erro. Adiciona uma a uma até que o erro não seja afetado significativamente.

Backward selection : Começa com todas as características e as remove uma a uma, cada passo da eliminação reduz o erro ou o incrementa um pouco, até que outra característica removida altere o erro de forma significativa.

\section{Avaliação}

A etapa de Avaliação calcula o valor de relevância do subconjunto escolhido na etapa de Geração. Existem muitas maneiras de avaliar um subconjunto e depende do que se precisar nos testes. De maneira geral, as medidas de avaliação são representadas pela função $J$ no Algoritmo 1. sendo que Rvalue contém a avaliação numérica do subconjunto. Assim, o Algoritmo 1 encontra o melhor subconjunto de características do vetor.

\section{Critério de parada}

O Critério de Parada determina o subconjunto calculado. No entanto, sem uma adequada condição de parada o processo de seleção de características pode rodar exaustivamente. $\mathrm{O}$ 


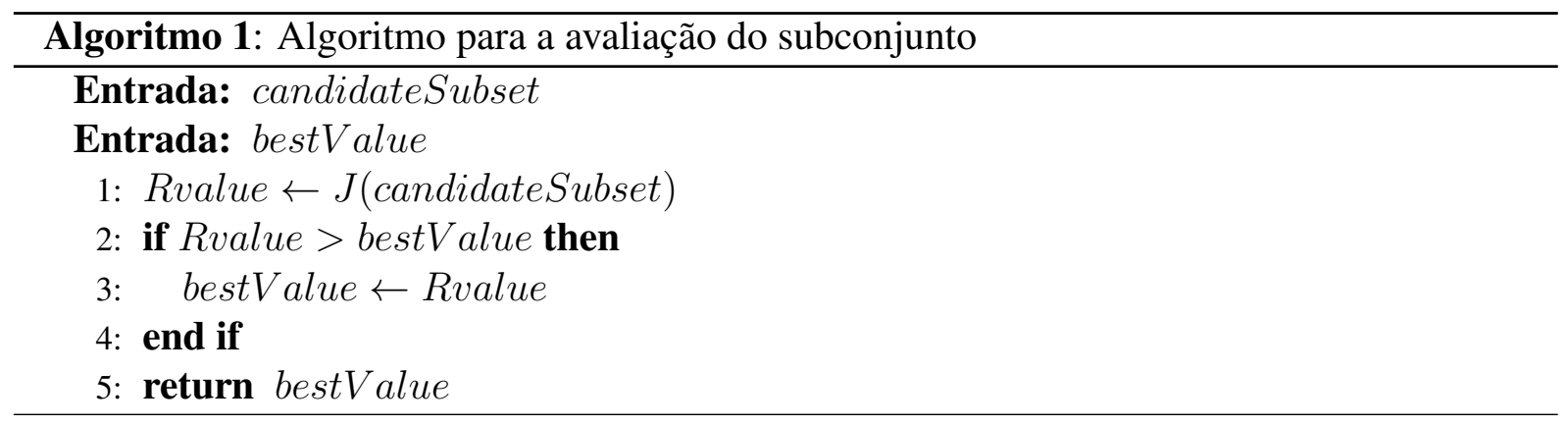

critério de parada é normalmente definido pelos processos de avaliação com a soma máxima de precisão obtida pelo novo subconjunto (Duchesnay et al., 2011).

\subsubsection{Métodos de seleção de características}

\section{Ganho de Informação - IG}

A seleção de características por Ganho de Informação (Information Gain Ratio - IG) (Mukras et al., 2007; Saeys et al., 2007; Zhao et al., 2010) é um dos métodos mais populares para a seleção de características. $\mathrm{O}$ ganho de informação representa a dependência entre a característica e a classe. Assim, este método ordena as características segundo a capacidade discriminativa das classes. Dada a característica $X$ e a classe $Y$, o ganho de informação é calculado como mostra a Equação 2.7 .

$$
\begin{aligned}
I G(X, Y) & =H(X)-H(X \mid Y) \\
\text { Entropia }: H(X) & =-\sum_{i} P\left(x_{i}\right) \log _{2}\left(P\left(x_{i}\right)\right) \\
H(X \mid Y) & =-\sum_{j} P\left(y_{j}\right) \sum_{i} P\left(x_{i} \mid y_{j}\right) \log _{2}\left(P\left(x_{i} \mid y_{j}\right)\right)
\end{aligned}
$$

\section{Estatística Chi-squared - $\mathbf{X}^{2}$}

O Algoritmo Chi-squared ou $X^{2}$ para seleção de características (Liu, 1997; Liu and Setiono, 1995) aplica a estatística de $X^{2}$ (Equação 2.10) para todas as características, medindo a relação entre a característica e a categoria. O Algoritmo $X^{2}$ consiste de duas etapas:

1. Calcula o valor de $X^{2}$ (Equação 2.10) e para cada par de intervalos adjacentes.

2. Junta os pares de intervalos adjacentes com os valores mais baixos de $X^{2}$. 


$$
\chi^{2}=\sum_{i=1}^{m} \sum_{j=1}^{k} \frac{\left(A_{i j}-E_{i j}\right)^{2}}{E_{i j}}
$$

onde $k$ é o número de classes, $m$ é o número de intervalos, $A_{i j}$ é o número de padrões no i-ésimo intervalo da j-ésimo classe, e:

$$
\begin{aligned}
E_{i j} & =\frac{R_{i} * C_{j}}{N} \text { frequência esperada de } A_{i j} \\
R_{i} & =\sum_{j=1}^{k} A_{i j}, \text { número de padrões no i-ésimo intervalo } \\
C_{j} & =\sum_{i=1}^{2} A_{i j}, \text { número de padrões na j-ésima classe } \\
N & =\sum_{i=1}^{2} R_{i}, \text { número total de padrões }
\end{aligned}
$$

\section{Seleção de Características Baseada na Correlação (CFS)}

O método de Seleção de Características Baseada na Correlação (Correlation-based feature selection - CFS) (Hall and Smith, 1999; Zhao et al., 2010) é completamente automático, ou seja, não precisa de alguma especificação do usuário de algum threshold ou de alguma quantidade de características selecionadas. O método CFS, baseia-se na hipótese de que um bom subconjunto de características contém características altamente correlacionadas à classe (Huang and Liao. 2003).

$$
\text { Merit }_{S}=\frac{k \overline{r_{c f}}}{\sqrt{k+k(k-1) r \overline{f f}}}
$$

onde:

$$
\begin{aligned}
k & =\text { número de características } \\
C & =\text { número de classes } \\
\overline{r_{c f}} & =\sum_{f_{i} \in S} \frac{1}{k} \sum\left(f_{i}, c\right) \text { a média das características da classe de correlação. } \\
\overline{r_{f f}} & =\text { a média da intercorrelação de características. }
\end{aligned}
$$

A Equação 2.11 representa a função de mérito achada de maneira heurística do subconjunto $S$ que contém $k$ características. Este método de seleção de características é do tipo forward 
selection, ou seja, o algoritmo começa sem características e as adiciona segundo a análise de mérito (Equação 2.11).

\section{StarMiner - Mineração de Regras de Associação Estatísticas}

O algoritmo StarMiner (Ribeiro, 2008) é um modelo de classificação supervisionada que melhora a precisão de recuperação por conteúdo das imagens médicas fornecendo regras estatísticas de mineração, e realimentação por relevância (feedback relevance). Essencialmente, as regras de associação obtém relações entre as classes dos padrões e as características (Bugatti and Traina, 2008). Assim, as características são denotadas como $f_{i}$, enquanto as classes dos padrões estão denotadas como $Y=\left\{y_{1}, y_{2}, \ldots, y_{m}\right\}$, onde $m$ é a quantidade de classes. $\mathrm{O}$ algoritmo StarMiner encontra regras de associação do tipo $y_{j} \rightarrow f_{i}$, cada uma das regras pode ser interpretada da seguinte maneira: A característica $f_{i}$ deve ter um comportamento em imagens da categoria $y_{j}$ diferente do seu comportamento em imagens das demais categorias da base. Além disso, a característica $f_{i}$ apresenta um comportamento uniforme para todas as imagens da classe $y_{j}$. No entanto, para as características serem selecionadas têm que cumprir as seguintes condições:

$$
\begin{aligned}
\mu_{f_{i}}(V) & =\frac{\sum_{k \in V}\left(f_{i_{k}}\right)}{|V|} \\
\sigma_{f_{i}}(V) & =\sqrt{\frac{\sum_{k \in V}\left(f_{i_{k}}-\mu_{f_{i}}(V)\right)^{2}}{|V|}} \\
\mu_{f_{i}}\left(T_{y_{j}}\right)-\mu_{f_{i}}\left(T-T_{y_{j}}\right) & \geq \Delta \mu_{\min } \\
\sigma_{f_{i}}\left(T_{y_{j}}\right) & \leq \sigma_{\max }
\end{aligned}
$$

Hipótese de rejeição $H_{0}: \mu_{f_{i}}\left(T_{y_{j}}\right)=\mu_{f_{i}}\left(T-T_{y_{j}}\right)$

onde: $\Delta \mu_{\text {min }}$ é a mínima diferença das médias da característica $f_{i}$ no subconjunto de imagens $V, \sigma_{\text {max }}$ é o máximo desvio padrão para a característica $f_{i}$, e $\gamma_{\text {min }}$ é a mínima confiança para rejeitar a hipótese $H_{0}$.

\section{Fast Correlation-Based Filter (FCBF)}

O método de seleção de características Fast Correlation-Based Filter ou FCBF (Yu, 2003) é baseado na medida de qualidade Symmetrical Uncertainty (SU) representada pela Equação 2.21 . A medida SU é baseada no IG e na entropia $\mathrm{H}$, e ajuda a decidir se uma características é relevante para uma classe ou não. Além disso, usa a correlação das características e a classe para decidir se uma característica é relevante ou redundante para o subconjunto de características. 
Além disso, o FCBF define dois conceitos chamados predominant correlation para definir uma característica como predominante na predição de uma classe.

$$
S U(X, Y)=2 *\left[\frac{I G(X \mid Y)}{H(X)+H(Y)}\right]
$$

Se o SU entre uma características e uma classe é 1 significa que essa característica está bem relacionada com a classe. Por outro lado, se o SU é 0, a característisca é irrelevante para essa classe (Duangsoithong and Windeatt, 2010). Assim, este método se sobressai pela sua rapidez e pelas baixas dimensionalidades dos seus subconjuntos selecionados (saídas). No entanto, para remover as características redundantes, o FCBF utiliza três heurísticas que garantem obter um vetor de características enxuto. No artigo (Yu, 2003), o FCBF foi avaliado com dez bases de imagens, uma delas de imagens médicas obtendo resultados promissores.

\section{Fisher Score}

O método Fisher Score (Gu et al., 2010) é um dos métodos de seleção de características supervisionados mais usados na literatura. Assim, uma característica obterá um alto Fisher Score discriminativo, se e somente se a característica tem valores similares na mesma classe e valores muito diferentes nas outras classes. Assim, o Fisher Score é calculado como apresenta a Equação 2.22.

$$
F_{r}=\frac{\sum_{i=1}^{c} n_{i}\left(\mu_{i}-\mu\right)^{2}}{\sum_{i=1}^{c} n_{i} \sigma_{i}^{2}}
$$

- $n_{i}=$ número de amostras na classe $i$.

- $\mu$ = média dos valores da característica.

- $\mu_{i}=$ média dos valores da característica na classe $i$.

- $\sigma_{i}=$ desvio padrão dos valores das características na classe $i$.

- $C=$ número de classes.

Assim, quando $\mu$ é muito diferente de cada $\mu_{i}$, ou quando cada $\sigma_{i}$ é bem pequeno, o valor do Fisher Score torna-se bem maior (Lo et al., 2009). 


\section{T-test}

O algoritmo T-test (Ghurye, 1949) ou Student T-Test, foi amplamente usado com dados de microarrays (Suy et al., 2003). No entanto, o T-test original é limitado para apenas duas classes (Wang et al., 2007);(Zhou and Wang, 2007). Por outro lado, para problemas multi-classe calcula-se o valor t-statistics (Tibshirani et al., 2002) em solução à limitação do T-test original. O t-statistics calcula a diferença da média da classe e a média de todas as classes, onde, a diferença é padronizada pelo desvio padrão do within-class $S_{i}$ apresentado na Equação 2.24 . Os experimentos nesta dissertação serão do tipo multi-classe, assim, precisa-se calcular o valor t-statistics apresentada na Equação 2.23 .

$$
\begin{aligned}
t_{i c} & =\frac{\bar{x}_{i c}-\bar{x}_{i}}{M_{c}\left(S_{i}+S_{0}\right)} \\
S_{i}^{2} & =\frac{1}{N-C} \sum_{c=1}^{C} \sum_{j \in c}\left(x_{i j}-\bar{x}_{i c}\right)^{2} \\
M_{c} & =\sqrt{1 / n_{c}+1 / N}
\end{aligned}
$$

onde $\mathrm{N}$ é o número de amostras, $\mathrm{C}$ o número de classes, e $x_{i j}$ refere-se à $i$-ésima características da $j$-ésima amostra, $\bar{x}_{i}$ representa a média da $i$-ésima características de todas as classes, e o $S_{0}$ representa a mediana dos $S_{i}$ para todas as características.

\section{Gram-Schmidt}

O Gram-Schmidt orthogonalization (Bjorck, 1967) é um conceito matemático, que é usado em computação na área de aprendizado de maquinas, especificamente nas redes de Função de Base Radial (RBF). No entanto, a variação do algoritmo para seleção de características fornece um ranking das características. O processo de seleção consiste em encontrar o vetor de características que projete melhor ao conjunto de características (Stoppiglia and Dreyfus, 2003). Ao ser um conceito de ortogonalização, se geram ângulos das projeções dos subconjuntos. Assim, o menor ângulo de um subconjunto ajuda na identificação das características relevantes e reduz o erro médio quadrático de redundância do subconjunto de saída. O cálculo do menor ângulo é apresentado na Equação 2.26

$$
\cos ^{2}\left(x^{k}, y\right)=\frac{\left(x^{k} * y\right)^{2}}{\left\|x^{k}\right\|^{2} *\|y\|^{2}}, k=1 \text { até } n
$$

onde $n$ é o número de características, $P$ é o número de amostras no conjunto de dados, e $y$ representa as classes das $P$ amostras. Assim, o $x^{i}=\left[x_{1}^{i}, x_{2}^{i}, \ldots, x_{P}^{i}\right]$ denota ao vetor de valores 
da característica $i$ das $P$ amostras. Por consequência a matriz $X(P, Q)=\left[x^{1}, x^{2}, \ldots, x^{n}\right]$ representa o conjunto de amostras $N$ com as $Q$ características.

\subsection{Consultas por Similaridade}

As consultas por similaridade consistem na recuperação de imagens semelhantes à imagem de consulta. Assim, os critérios baseados na igualdade $(<,>,=)$ são inadequados para dados multimídia como as imagens, esse tipo de dados não apresenta relação de ordem total, pois não faz sentido realizar consultas do tipo: "Obtenha as imagens com tumores no cérebro iguais à imagem de consulta". O critério mais adequado para os casos desse tipo são as consultas por similaridade. Assim, a consulta anterior faria mais sentido como: "Obtenha as imagens com tumores no cérebro semelhantes à imagem de consulta". Para obter este tipo de resultados existem duas abordagens de consultas por similaridade, uma é conhecida como "consulta por abrangência"(range query) e a outra é chamada "consultas aos k vizinhos mais próximos"( $k$-nearest neighbor query - $k N N)$.

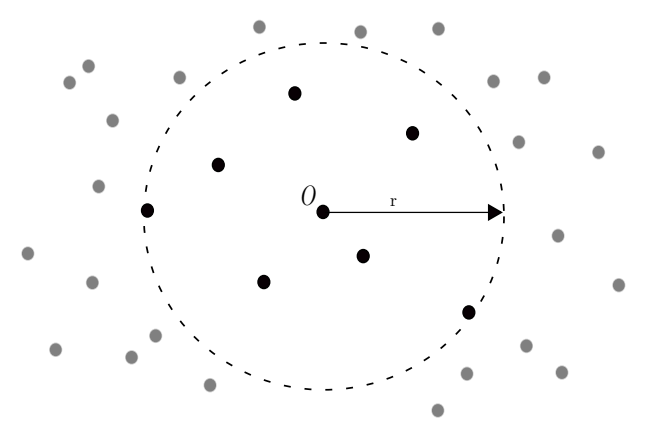

(a) Consulta por abrangência

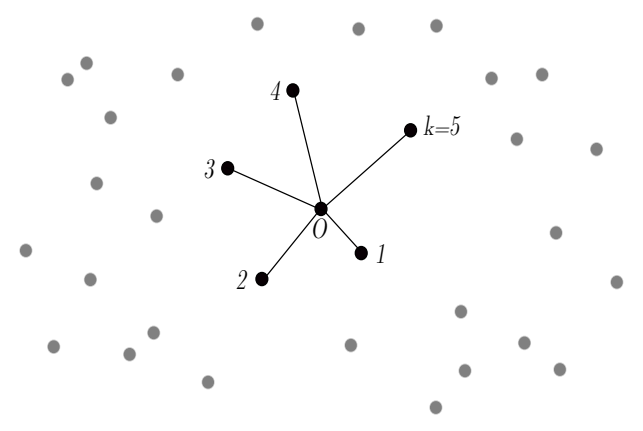

(b) Consulta do tipo $k N N$

Figura 2.9: Os tipos de consultas, (a) Exemplo de uma consulta por abrangência onde o conjunto de resposta contém 7 elementos sendo que ' $O$ ' não faz parte do resultado, e (b) Exemplo de uma consulta do tipo $k N N$ onde o conjunto de resposta contém 6 elementos(' $\mathrm{O}^{\prime}$ faz parte do conjunto).

\section{Consultas por abrangência (range query)}

A consulta por abrangência (range query) precisa de um objeto de referência $Q$ (query center) e um raio de cobertura $r$ para obter os objetos mais similares ao ponto $Q$. A Equação 2.27 apresenta o conjunto resposta $R_{r q}$ que inclui todos os elementos $S$ da base que se encontram a uma distância menor ou igual a $r$ do elemento $Q$. A Figura 2.9a apresenta um exemplo de 
consulta por abrangência no domínio bidimensional, onde o conjunto de resposta contém sete elementos.

$$
R_{r q}=\{S \mid d(S, Q) \leq r\}
$$

\section{Consulta aos k vizinhos mais próximos ( $k$ NN query)}

A consulta $k \mathrm{NN}$ precisa de um objeto de referência $Q$ (query center), e um número inteiro $k$. $\mathrm{O}$ valor de $k$ representa o número de elementos mais próximos do elemento $Q$ que se deseja obter como conjunto de resposta. Formalmente é apresentada na Equação 2.28, onde $\Omega$ representa o conjunto de todos os elementos. A Figura $2.9 \mathrm{~b}$ representa um exemplo de consulta do tipo $k N N$ para $k=5$ no espaço bi-dimensional, onde o conjunto de resposta contém cinco elementos.

$$
R_{k N N}=\left\{S\left|\forall P \in\left\{\Omega-R_{k N N}\right\}, d(Q, S) \leq d(Q, P),\right| R_{k N N} \mid=k\right\}
$$

\subsection{Considerações Finais}

Este Capítulo apresentou uma breve revisão e discussão sobre métodos de extração e seleção de características que foram selecionados por serem apropriados ao domínio de imagens médicas. Além disso foram apresentados os tipos de consulta por similaridade. Tal discussão visou apresentar o embasamento principal e conceitos necessários ao desenvolvimento deste trabalho e também para sua compreensão. 


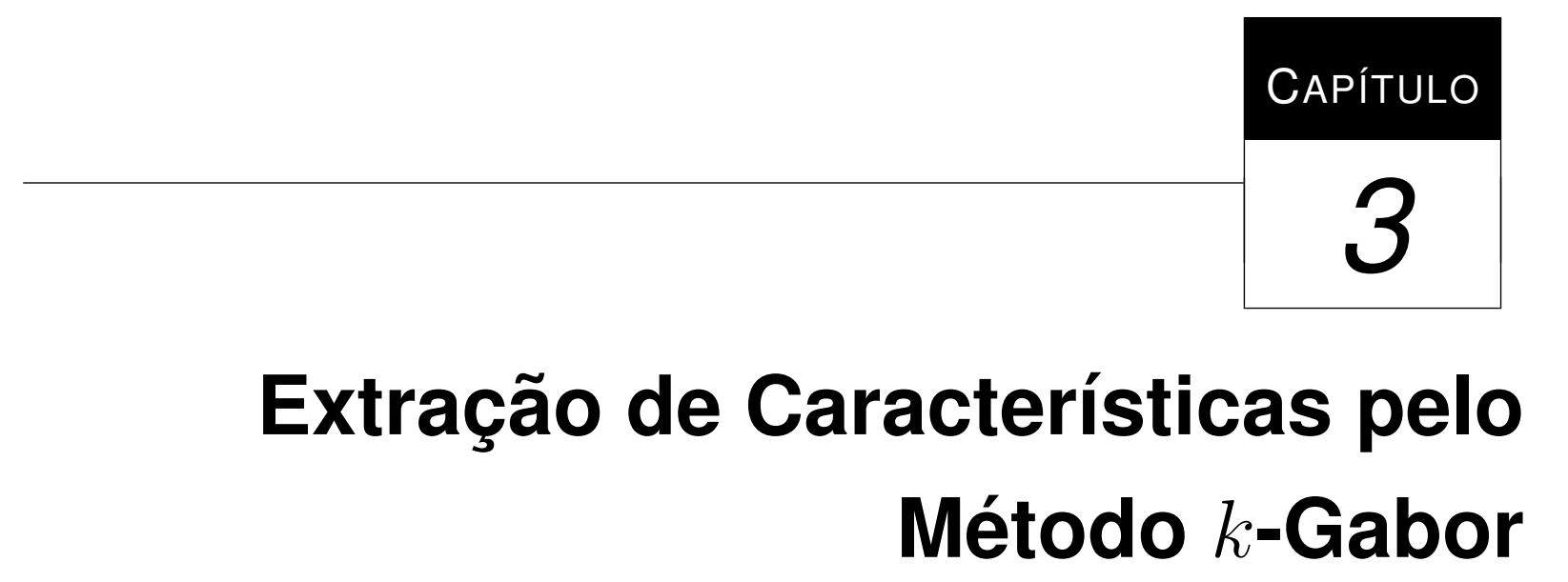

Neste capítulo é descrito um novo método de extração de características desenvolvido durante este projeto de Mestrado: o $k$-Gabor. O algoritmo de extração de características consiste na decomposição da imagem de entrada para ressaltar o conteúdo da imagem médica. As imagens decompostas, ou máscaras, contêm informação semanticamente similar, sendo que, cada máscara contém só uma parte da informação da imagem de entrada, ou seja, a informação entre máscaras é diferente. Este método aproveita essa abordagem para extrair características por cada máscara e ressaltar características que não eram perceptíveis na imagem de entrada. $\mathrm{O}$ $k$-Gabor precisa do parâmetro $k$ para extrair características, onde $k$ pode ter os seguintes valores $\{2,3, \ldots, 10\}$. O valor $k$ representa a quantidade de clusters que o algoritmo de clustering $k$-means vai gerar a partir da imagem. Assim, o vetor de características final forma-se pela união das características de Gabor extraídas dos $k$ clusters. Os resultados obtidos com o método de extração de características $k$-Gabor foram publicados no evento IEEE Computer-Based Medical System (CBMS2012), que ocorreu em Roma, na Itália (Humpire et al., 2012b). 


\subsection{O Extrator de Características $k$-Gabor}

Gerenciar e extrair informação útil de dados multimídia, e mais ainda de imagens médicas reais, tem motivado a pesquisa na criação de novos algoritmos para sistemas de Recuperação de Imagens baseado no Conteúdo - CBIR (do inglês Content Based Image Retrieval). Assim, os métodos de extração de características são o componente principal dos sistemas CBIR por fornecer informação relevante da imagem. Essa informação é representada por vetores de características com uma dimensionalidade fixa, assim, os vetores de características são usados nas consultas por similaridade usando uma medida de dissimilaridade. Existem três tipos principais de extratores de características baseados na forma, cor, e textura. Porém, é necessário testar diferentes extratores de características para encontrar aquele extrator com a melhor performance em consultas por similaridade. O método proposto $k$-Gabor está baseado na obtenção de formas (máscaras) da imagem de entrada usando um algoritmo de clustering para obter características de textura cada uma dessas máscaras. Essa abordagem permite dar uma maior semântica às características extraídas.

O método de extração de características proposto é composto por duas etapas: $(i)$ cada imagem de entrada em tons de cinza é clusterizada considerando os valores dos seus pixels usando o algoritmo $k$-means, resultando um novo conjunto de imagens. Assim, para cada imagem de entrada se obtém $k$ novas imagens clusterizadas. Posteriormente, cada imagem clusterizada gera uma nova imagem para a análise. (ii) Características de Gabor são extraídas de cada imagem gerada na primeira etapa. Finalmente, todas as características extraídas do conjunto de imagens clusterizadas compõem o vetor de características final, construindo o vetor de características do extrator $k$-Gabor.

Uma adequada separação dos níveis de cinza das imagens ajudam a ressaltar a informação relevante da imagem de consulta. Níveis específicos ou clusters da imagem podem ajudar na identificação de tecidos, características de regiões de interesse e/ou descartar informação redundante, assim como o background. O extrator de características Gabor foi selecionado para aproveitar as texturas de imagem. Vale notar que os filtros de Gabor trabalham com rotações e escalas, fazendo uma análise usando diferentes filtros e extraindo características por cada filtro aplicado. Assim, o extrator $k$-Gabor faz uma análise das estruturas internas em cada um dos níveis da imagem de entrada, obtendo características mais fortes e robustas. Assim, pelo clustering das regiões da imagem, o $k$-Gabor aproveita a forma das características dessas regiões. Portanto, a proposta integra duas (textura e forma) das três principais características ao analisar as imagens, detectando os componentes mais relevantes de cada imagem. 
Imagem de Entrada
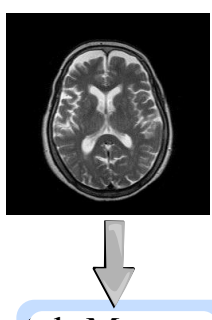

k-Means clusteriza pixels
pelo seu valor pelo seu valor
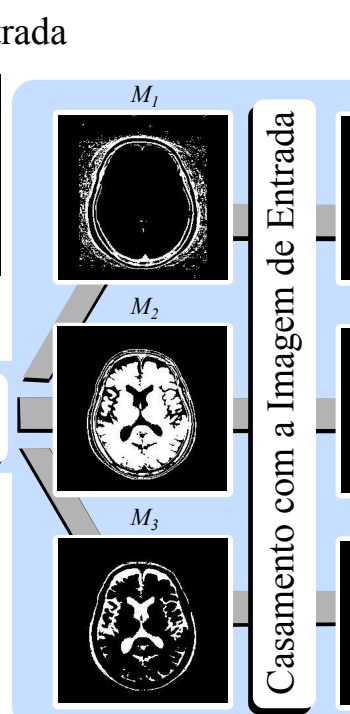

Vetor de Características

Final

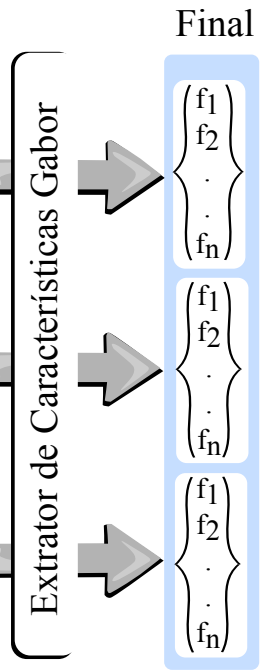

Figura 3.1: $\mathrm{O}$ diagrama do método $k$-Gabor usando $k=3$, onde a imagem de entrada é decomposta em três máscaras $M_{*}$. $\mathrm{O}$ casamento de pixels entre a imagem de entrada e $M_{*}$ gera uma imagem $I^{*}$ para assim extrair características.

\subsubsection{Clusterização com $k$-means}

Os métodos de clusterização de dados são também aplicados para clusterizar os pixels das imagens. Tais métodos agrupam os pixels da imagem em $k$ grupos considerando os seus valores em tons de cinza. $\mathrm{O}$ algoritmo de clusterização $k$-means é usado como um processo de segmentação (He et al. 2011) para ajudar a melhorar os resultados de outros métodos. O algoritmo $k$-means precisa de $k$ centroides para agrupar os valores dos pixels mais próximos. A Equação 3.1 mostra como é calculado o centroide $u_{k}$ para cada grupo. A imagem de entrada em tons de cinza $I$ tem pixels representados por $I_{i, j}$, onde $I_{i, j} \in\{0,1, \ldots, 255\}$.

$\mathrm{O}$ valor $k$ define o número de imagens de saída, onde cada imagem de saída é uma máscara $M_{k}$ com o mesmo tamanho da imagem de entrada $I$, mas com apenas duas cores: preto e branco. Nesta dissertação considera-se $2 \leq k \leq 10$ para trabalhar com vetores de características de até centenas de elementos.

Os pixels brancos representam a máscara atual selecionada pelo algoritmo $k$-means, e os pixels pretos o background. Esta máscara será aplicada para o casamento de pixels entre a máscara e os pixels da imagem de entrada $I$. Formalmente, a Equação 3.1 e 3.2 mostram como obter a máscara $M_{k}$. 


$$
\begin{aligned}
\mu_{k} & =k * \eta /(k+1) \\
M_{k} & =\operatorname{argmin} \sum_{i} \sum_{j}\left\|I_{i, j}-\mu_{k}\right\|
\end{aligned}
$$

onde $\mu_{k}$ representa o centroide do cluster $k, \eta$ é o máximo valor dos pixels na imagem, que deve ser menor ou igual a 255 .

\subsubsection{Obtendo o Vetor de Características}

O método Gabor gera um vetor de características considerando cada imagem clusterizada criado pelo algoritmo $k$-means com a seguinte configuração: 6 orientações e 4 escalas. Uma vez que temos $k$ máscaras (clusters) da imagem, o tamanho do vetor de características será $k * 6 * 4 *$ número de características capturadas por cada subespaço de Gabor. Como características do subespaço de Gabor, nós estamos calculando a média e o desvio padrão, (número de características $=2$ ).

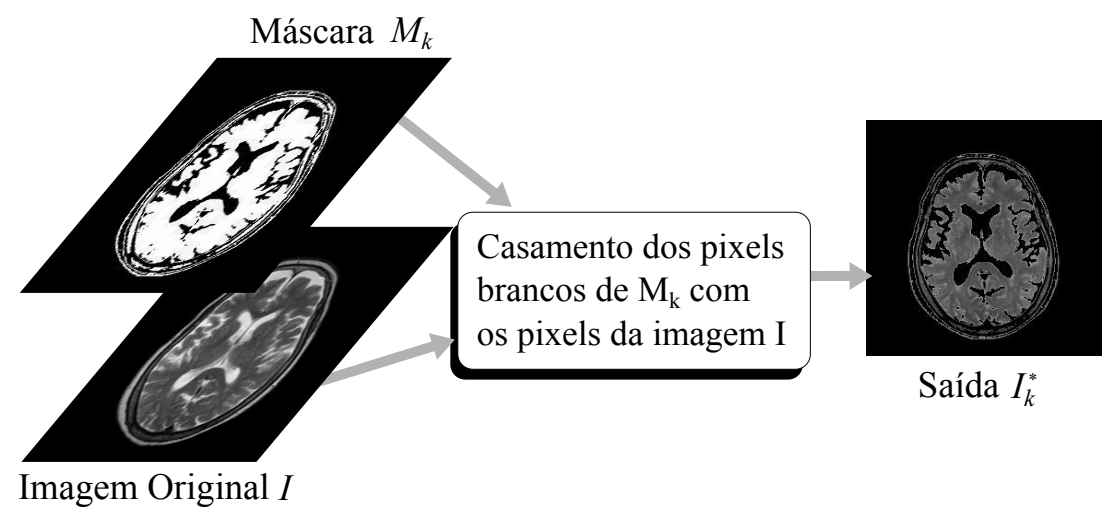

Figura 3.2: Casamento dos pixels brancos da máscara $M_{k}$ com os pixels da imagem I para obter $I_{k}^{*}$.

O casamento de pixels realizado entre a imagem de entrada $I$ e cada máscara $M_{k}$ gera uma nova imagem $I_{k}^{*}$. Na imagem $I_{k}^{*}$, cada pixel branco é substituída pelos valores dos pixels da imagem $I$, como é ilustrado na Figura 3.2. Este processo é sumarizado na Equação 3.3 .

$$
I_{k_{(i, j)}}^{*}= \begin{cases}0, & \text { se } M_{k_{(i, j)}}=\text { Preto } \\ I_{i, j}, & \text { se } M_{k_{(i, j)}}=\text { Branco }\end{cases}
$$


A dimensionalidade do vetor de características é $k$ vezes o número de características de Gabor e é obtido como mostra a Equação 3.4

$$
\text { FeatVect }=\bigcup_{i=1}^{k} \operatorname{Gabor}\left(I_{i}^{*}\right)
$$

onde $\operatorname{Gabor}\left(I_{i}^{*}\right) \rightarrow\left\{f_{1}, f_{2}, \ldots, f_{n}\right\}$ é a função que obtém as características de Gabor; $n$ é a dimensionalidade do vetor de características gerado pelo método Gabor.

\subsection{Experimentos}

Temos comparado a eficácia da proposta $k$-Gabor com outros extratores de características da literatura: os tradicionais Histogramas, o método FFS, o convencional Gabor, e Haralick. As dimensões dos vetores de características são 256, 8, 22 e 13 respectivamente. A dimensionalidade do vetor de características gerado pelo método $k$-Gabor depende do parâmetro $k$, que será detalhado nas discussões sobre os resultados obtidos.

Com o propósito de avaliar a eficiência dos extratores de características, temos usado os gráficos de Precision\&Recall (P\&R) (Baeza-Yates et al., 1999) como uma medida de eficiência, por ser amplamente usada e conhecida por pesquisadores em CBIR para medir a capacidade de recuperação do método. Os valores de Precisão e Revocação estão definidos a seguir:

$$
\begin{aligned}
\text { Precisão } & =\frac{\text { O número de imagens relevantes recuperadas }}{\text { O número de imagens recuperadas }} \\
\text { Revocação } & =\frac{\text { O número de imagens relevantes recuperadas }}{\text { O número de imagens relevantes na base }}
\end{aligned}
$$

Uma regra de ouro para entender os gráficos de $P \& R$ é a seguinte: enquanto a curva fique mais perto da parte superior do gráfico, melhor é o desempenho de recuperação do método. Uma imagem é considerada relevante quando sua classe é a mesma classe da imagem de consulta. As curvas de Precisão e Revocação foram construídas pela média das curvas resultantes de cada consulta. Para cada consulta, as $\kappa$ imagens mais similares foram recuperadas usando as consultas $\kappa$-nearest neighbor $(\kappa \mathrm{NN})$. Assim, usando a abordagem leave-one-out cross-validation (Yuan et al. 2010), cada imagem da base de imagens é usada como centro de consulta e comparada com as outras imagens usando a função de distância Euclidiana. Todas as características foram normalizadas usando a abordagem MinMax com valores entre 0 e 1 , a normalização de características evita a distorção dos dados. 
A fim de ter uma comparação justa entre os métodos, a configuração dos extratores de características foram definidas com os valores padrões: para o Haralick, os parâmetros de deslocamento de valores no eixo $\delta_{x}$ e $\delta_{y}$ foram definidos como 1 e 0 respectivamente. Para o FFS, a quantidade de stacks é de $s=8$. Para o Gabor convencional, foram usadas 4 escalas e 6 rotações, a mesma configuração para o $k$-Gabor. Adicionalmente o método $k$-Gabor tem mais um parâmetro, o valor $k$ muda segundo a base de imagens, e especificamente muda de acordo à estrutura interna das imagens. Os valores entre $2 \leq k \leq 10$ foram encontrados através de testes empíricos para definir o valor adequado de $k$ em cada base de imagens. O valor apropriado de $k$ ajuda para obter o melhor desempenho do método. Finalmente, todos os extratores de características foram implementados na mesma plataforma Matlab.

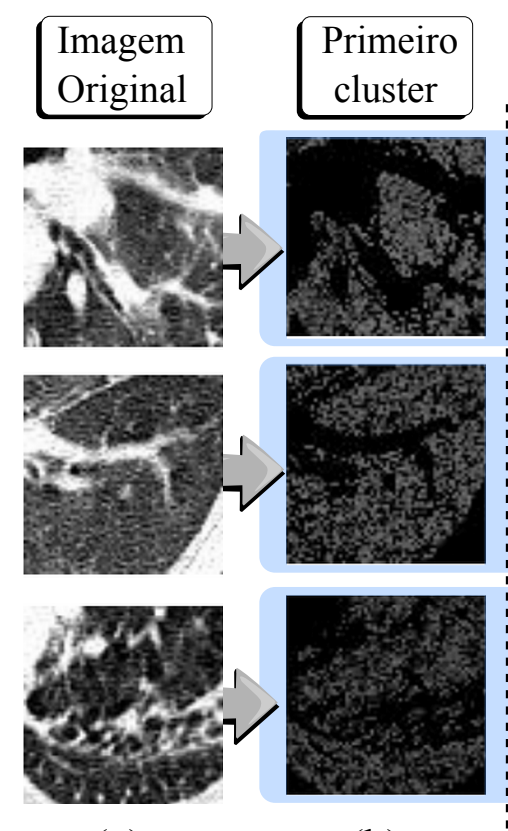

(a)

(b)

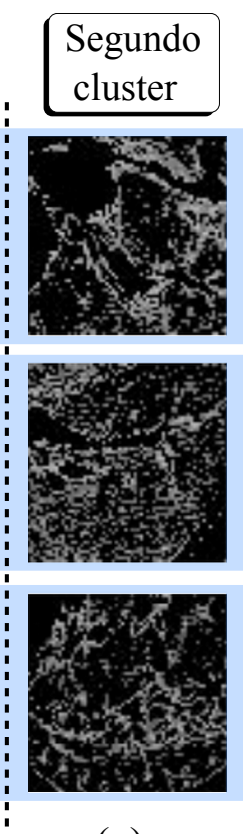

(c)

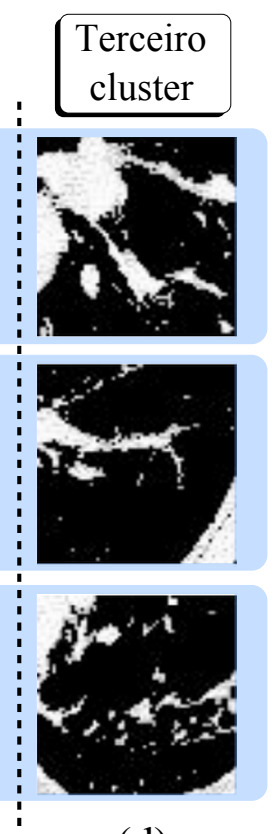

(d)

Figura 3.3: Exemplo de saídas do algoritmo $k$-means para a base de imagens Lung ROI-3258. (a): Amostras das imagens médicas de pulmão; (b)(c)(d): São as saídas do algoritmo $k$-means considerando $k=3$.

\subsubsection{Experimento \#1: Base de Imagens Lung ROI-3258}

A base de imagens Lung CT ROIs contém tomografias computadorizadas (CT) de pulmão. Essa base de imagens foi fornecida pelo Hospital das Clínicas de Ribeirão Preto da Universidade de São Paulo. Esta base contém seis classes, uma do pulmão normal (sem doenças) e cinco com casos clínicos no pulmão como: consolidação, enfisema, espessamento, favo de mel e vidro fosco com 451, 502, 590, 530, 590 e 595 imagens respectivamente, somando 3258 imagens 
na base de imagens. Cada imagem contém uma Region of Interest (ROI) de 64x64 pixels. A Figura 3.4 mostra cada uma das classes contidas nesta base de imagens. Enquanto a Figura 3.3 (a) apresenta três amostras da base de imagens, assim cada uma dessas imagens são as entradas para algoritmo $k$-means para gerar as saídas. No exemplo três saídas são mostradas nas Sub-figuras 3.3 (b)(c)(d) do primeiro, segundo e terceiro cluster respectivamente.

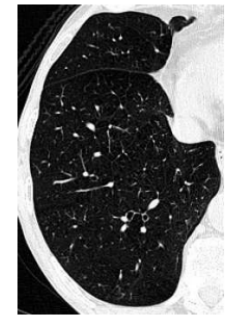

(a) Normal

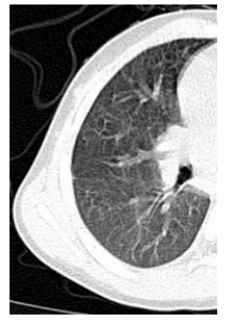

(b) Consolidation

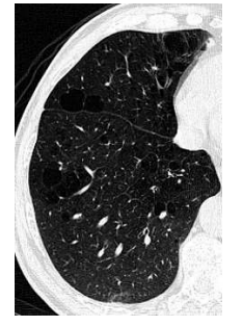

(c) Emphysema

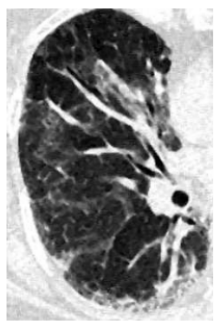

(d) Thicknening

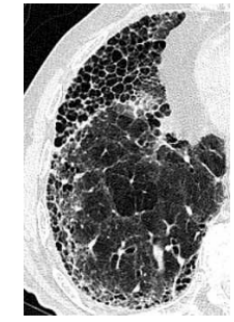

(e) Honeycombing

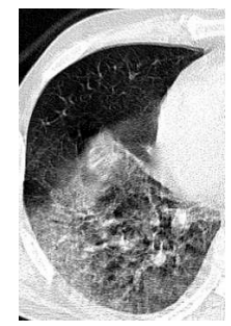

(f) Ground glass

Figura 3.4: Amostras da base de imagens Lung ROI 3258 usada no experimeto \#1, mostrando uma imagem por classe.

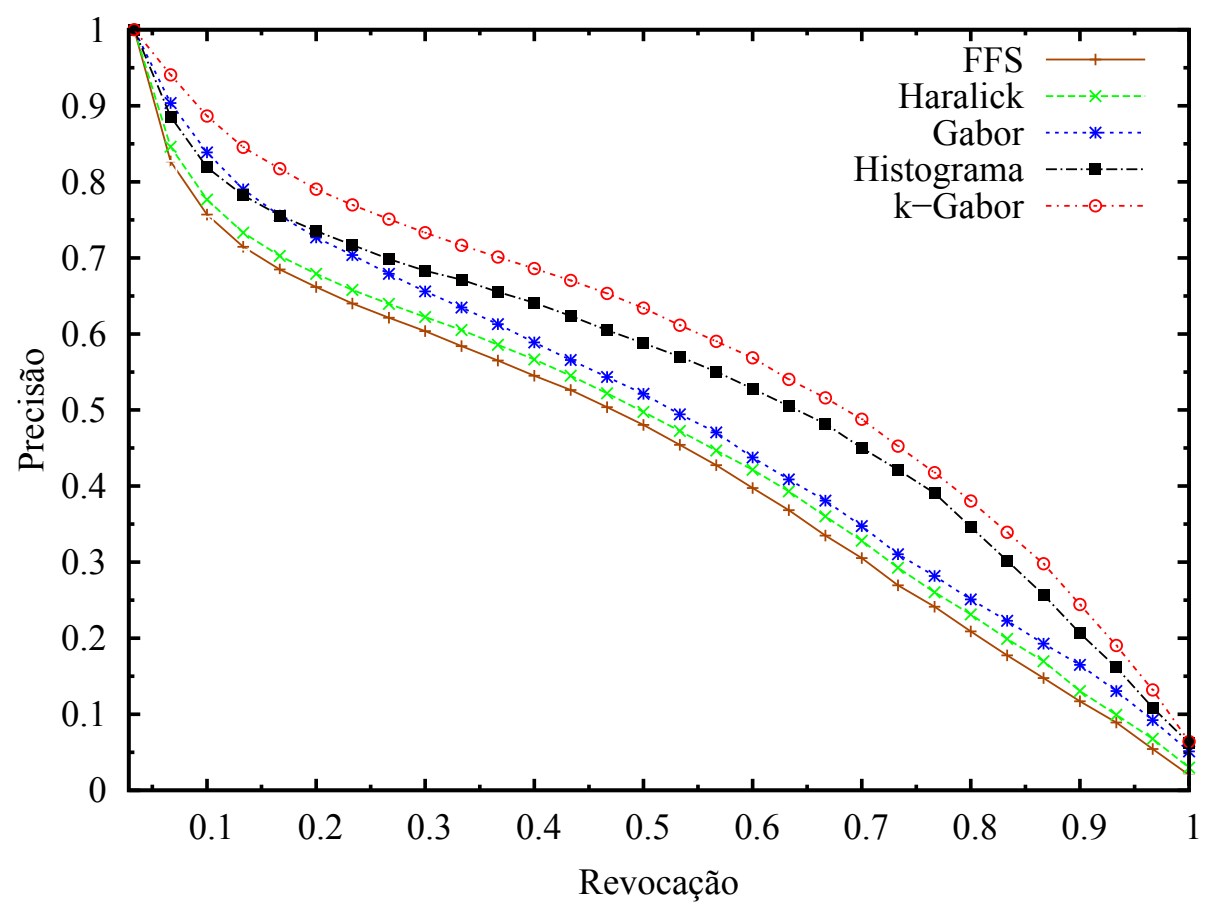

Figura 3.5: Gráfico de P\&R para a base de imagens "Lung ROI-3258" usando $k=3$ para construir o vetor de características extraído pelo método $k$-Gabor.

A Figura 3.5 mostra o gráfico $\mathrm{P} \& \mathrm{R}$ onde compara-se o método proposto ( $k$-Gabor) com os outros extratores de características representativos da literatura. $\mathrm{O} k$-Gabor (linha vermelha e sinais $\circ$ ) produz a melhor precisão sobre os outros métodos, sendo estável em todas as imagens relevantes usando $k=3$ (o número de clusters para o algoritmo $k$-means). O segundo 
melhor extrator de características é o extrator Histogramas (linha preta com sinais $\mathbf{\square}$ ), apesar da sua simplicidade, apresenta bons resultados nesta base de imagens. O extrator de características seguinte no gráfico é o extrator Gabor (linha azul com sinais *) que está acima do extrator Histogramas só até o 0.17 de revocação onde começa a cair em precisão mais do que os Histogramas. Os extratores FFS e Haralick produziram resultados similares, mas ambos produziram resultados menores em precisão do que o $k$-Gabor. Em consequência de ter usado $k=3$, e considerando que a dimensionalidade do extrator Gabor é de 48 (6 orientações, 4 escalas e 2 características: média e desvio padrão), a dimensionalidade do $k$-Gabor é de 144 para este experimento.

\subsubsection{Experimento \#2: Base de Imagens 944Body}

Este experimento usou a base de imagens fornecida pelo Hospital das Clinicas de Ribeirão Preto da Universidade de São Paulo. Esta base contém 944 imagens divididas em seis classes que descrevem regiões do corpo como abdômen coronal, angiografia, cabeça axial, cabeça coronal, cabeça sagital e coluna vertebral com 23, 36, 200, 236, 293 e 155 imagens respectivamente. Algumas amostras são mostradas na Figura 3.6 .
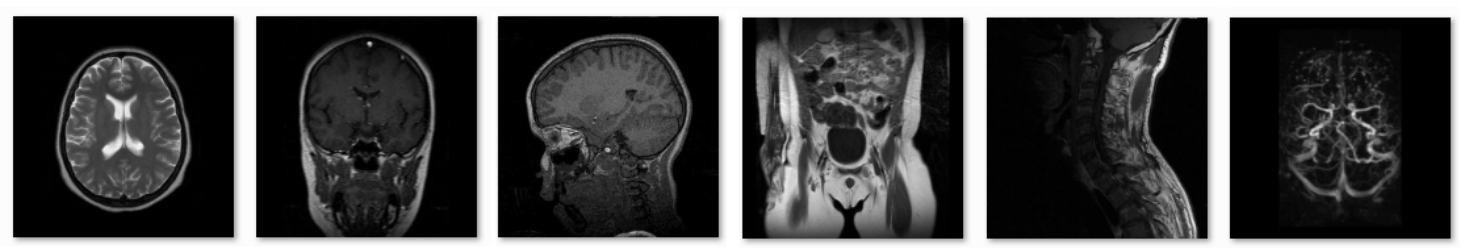

Figura 3.6: Amostras da base de imagens "944Body", é mostrada uma imagem de cada classe usado no experimento \#2.

A Figura 3.7 mostra os resultados no gráfico $P \& R$ dos extratores de características. $O$ $k$-Gabor (linha vermelha com sinais o) produz a melhor precisão sobre todos os métodos e se mantém acima dos outros extratores de características em todas as imagens relevantes (revocação) considerando $k=2$ como parâmetro. O extrator Gabor (linha azul com sinais *) produz inicialmente resultados comparáveis com o $k$-Gabor, mas ele decai mais rápido do que o $k$-Gabor quando o valor de revocação aumenta. Enquanto os métodos FFS (linha café com sinais + ) e Haralick (linha verde e sinais $\times$ ) obtiveram um desempenho similar. O extrator Histogramas (linha preta com sinais $\boldsymbol{\square}$ ) obteve nesta base de imagens os valores mais baixos de precisão, só na parte final, aproximadamente no 0.87 de revocação é que torna-se melhor do que Haralick. A dimensionalidade do vetor de características extraído pelo método $k$-Gabor para esta base de imagens é de $(48 * 2)=96$, por ter usado $k=2$. 


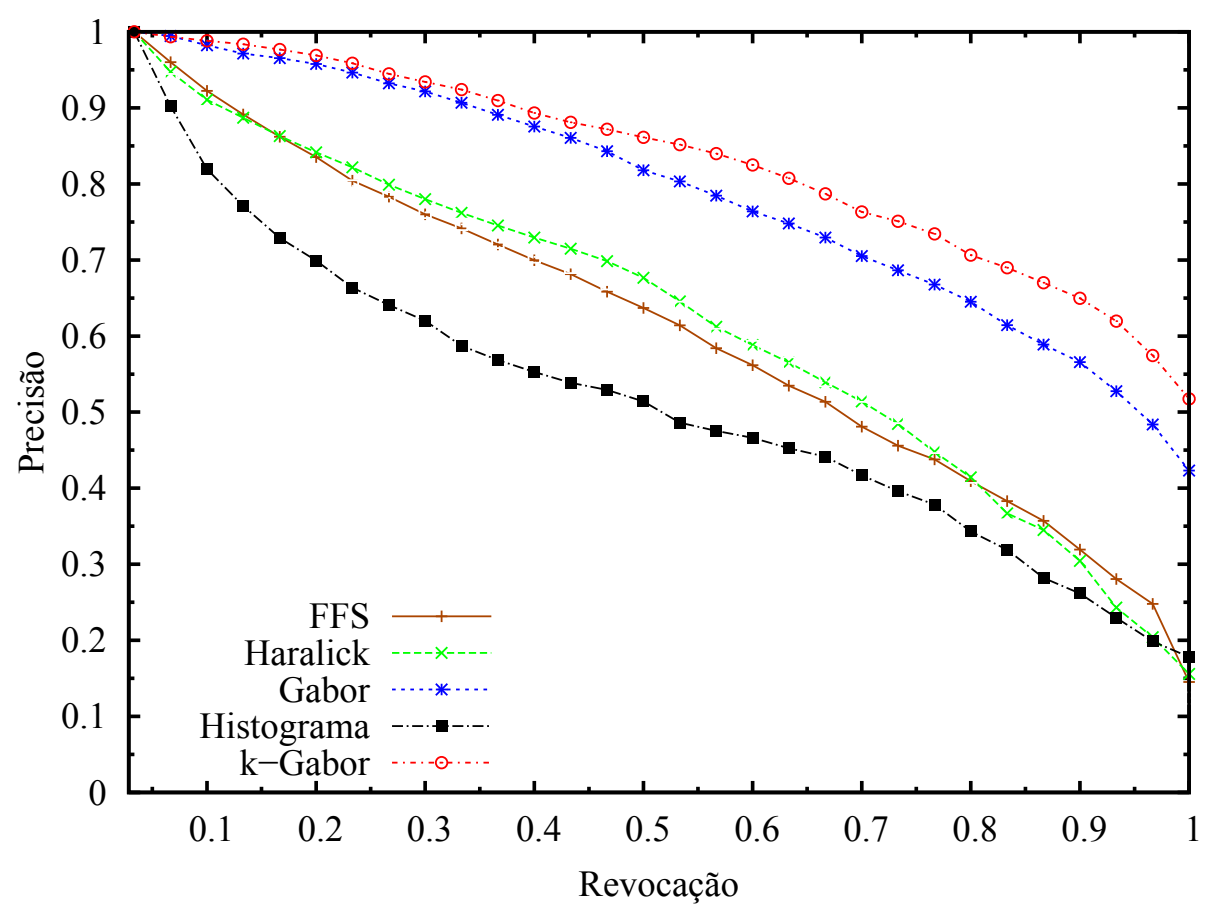

Figura 3.7: Gráfico de P\&R para a base de imagens "944Body" usando $k=2$ para extrair as características do $k$-Gabor.

\subsubsection{Experimento \#3: Base de Imagens DDSM}

Esta base de imagens Digital Database for Screening Mammography (DDSM) contém 250 ROIs de mamografias que foram capturadas pela University of South Carolina (disponível no site http://marathon.csee.usf.edu/Mammography). Esta base de imagens tem duas classes: massas benignas e malignas com 99 e 151 imagens respectivamente.
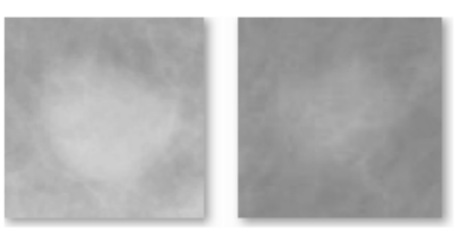

(a) Benigno
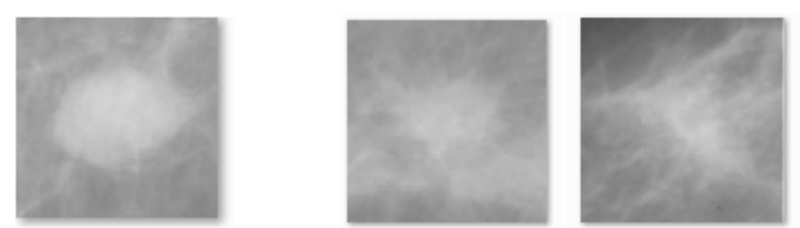

(b) Maligno

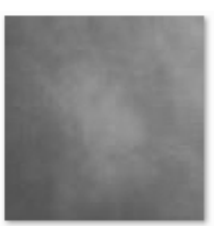

Figura 3.8: Amostras da base de imagens "DDSM" mostrando as duas classes: (a) benigno com 99 imagens e (b) a classe malignas com 151 imagens.

A Figura 3.9 mostra o gráfico de $\mathrm{P} \& \mathrm{R}$ com os resultados comparativos dos extratores de características. Neste experimento, o método $k$-Gabor (linha vermelha com sinais $\circ$ ) está ainda no topo do gráfico, embora bem próximo ao método FFS (linha café com sinais + ). Além disso, é importante ressaltar que ambos ( $k$-Gabor e o FFS) estão construídas considerando informações 


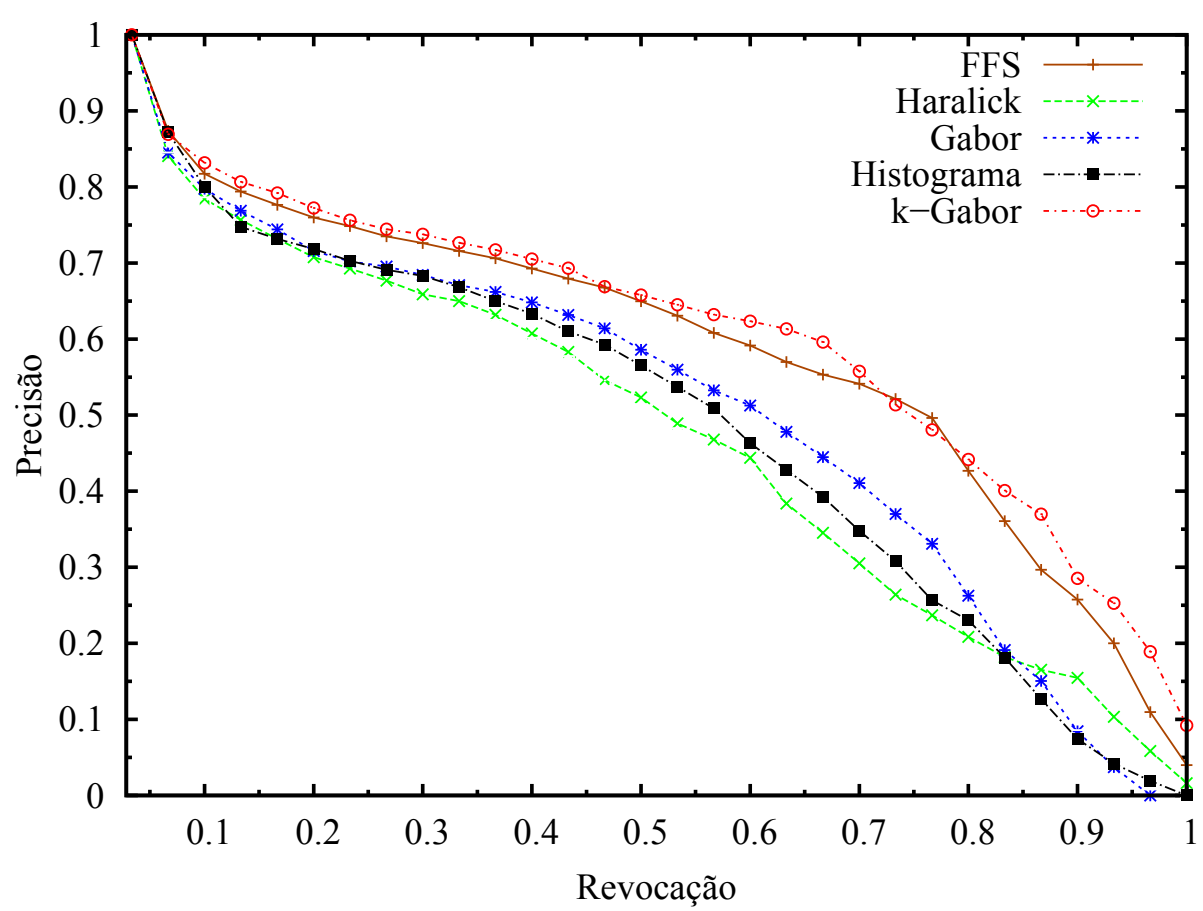

Figura 3.9: Gráfico de P\&R para a base de imagens "DDSM" usando $k=10$ para construir o vetor de características extraído pelo método $k$-Gabor.

baseadas nas regiões da imagem. Assim, a dimensionalidade do $k$-Gabor para esta base de imagens é de 480 por ter usado $k=10$.

Trata-se de uma base de imagens bastante difícil de classificar, devido à natureza da imagem. De fato, neste caso o extrator Gabor (linha azul com sinais *) não obteve uma boa diferença dos outros métodos, enquanto nas outras bases de imagens, Gabor normalmente obtém resultados muito bons. Nesta base de imagens os resultados obtidos por Gabor são comparáveis com os resultados obtidos pelo extrator Histogramas (linha preta com sinais $\mathbf{\square}$ ).

\subsubsection{Experimento \#4: Base de Imagens IRMA}

A base de imagens Image Retrieval for Medical Applications (IRMA) é de domínio público e foi obtida do site www. irma-project.org. Esta base de imagens foi fornecida pela RWTH Aachen University (Lehmann and Thies, 2003). Esta base de imagens contém 12,069 imagens divididas em oito classes descrevendo diferentes partes do corpo: abdômen, braço, peito, cranio, perna, mama, pélvis e coluna vertebral. As imagens mudam de tamanho, ou seja, não tem a mesma dimensionalidade. $\mathrm{O}$ extrator de características $k$-Gabor usa o parâmetro $k=3$ para esta base de imagens. Amostras da base de imagens são mostradas na Figura 3.10 .

A Figura 3.11 mostra o gráfico de $\mathrm{P} \& \mathrm{R}$ com os resultados comparativos dos extratores de 

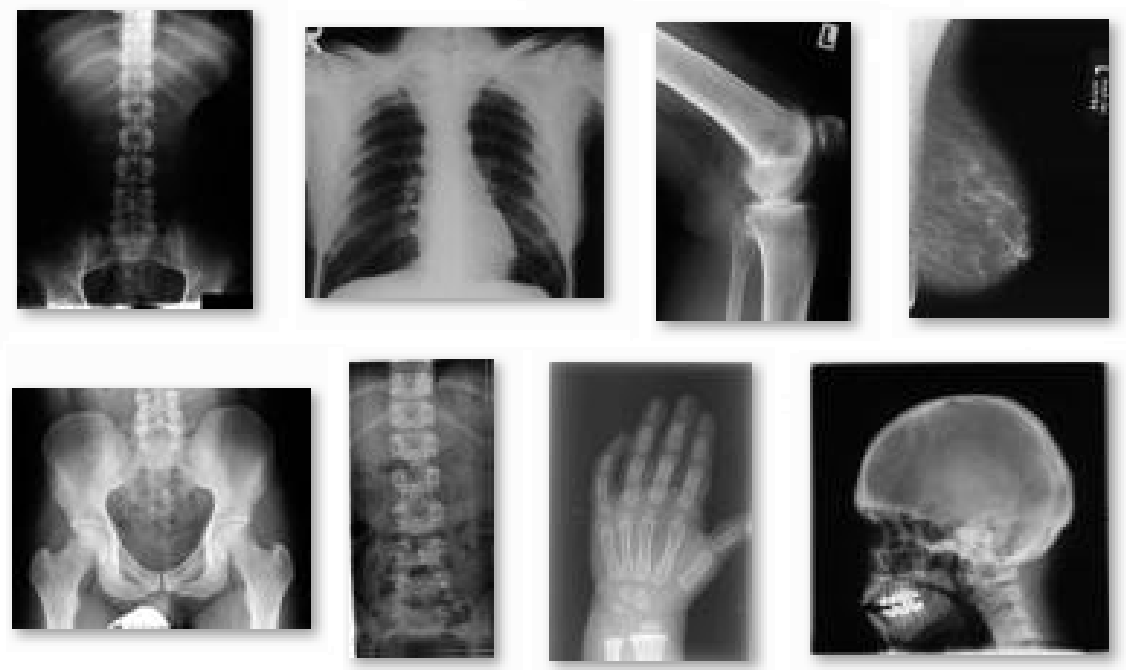

Figura 3.10: Amostras da base de imagens IRMA, mostrando uma imagem por cada classe.

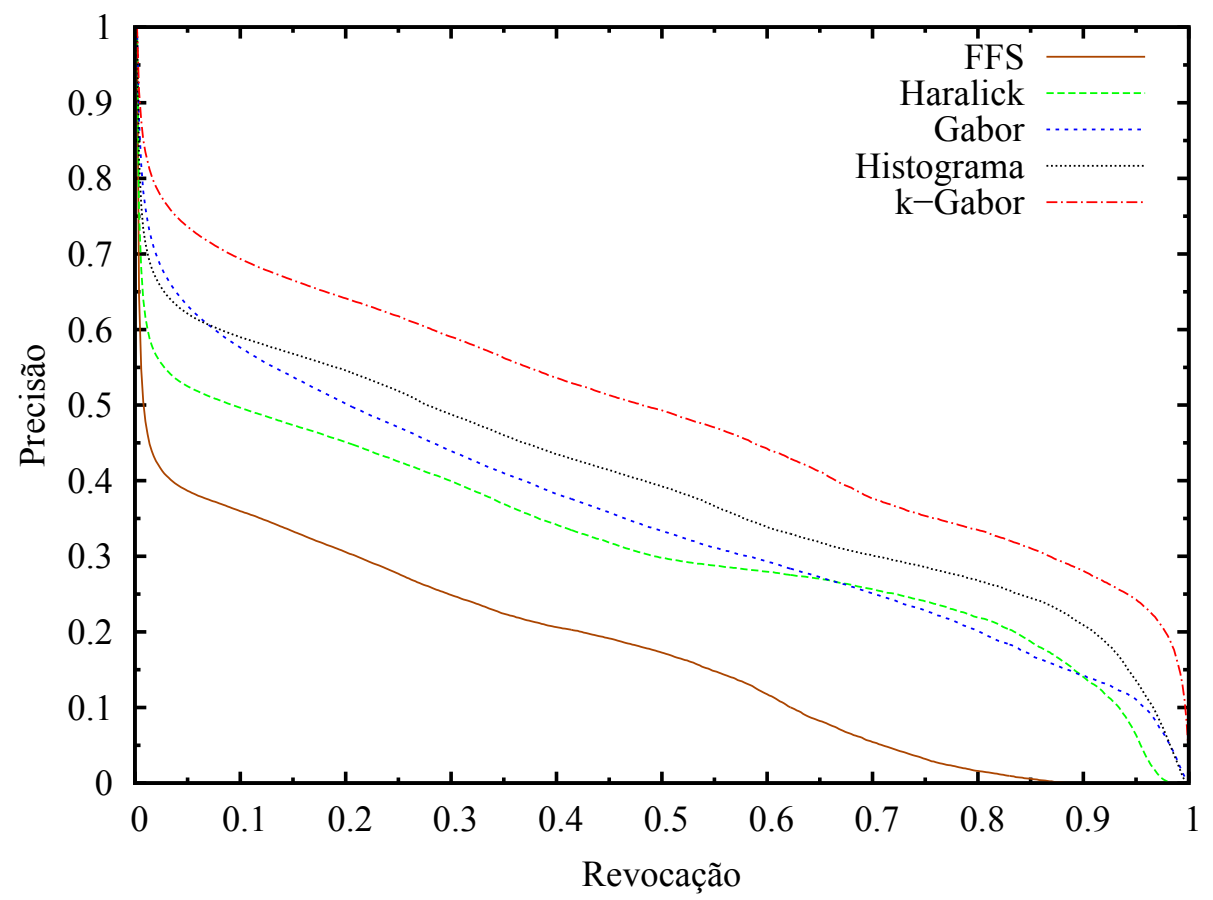

Figura 3.11: Gráfico de P\&R para a base de imagens "IRMA" usando $k=3$ para construir o vetor de características extraído pelo método $k$-Gabor. Este gráfico foi gerado considerando as 500 imagens mais relevantes nas consultas $k \mathrm{NN}$

características.Diferentemente das outras bases de imagens, a base IRMA tem uma quantidade maior de imagens, assim, o número de imagens relevantes consideradas para as consultas $k \mathrm{NN}$ mudou neste experimento de 30 para 500. O gráfico de P\&R mostra o método $k$-Gabor (linha vermelha) com uma ampla diferença sobre os outros extratores de imagens. Inicialmente o 
extrator Gabor (linha azul) começa a obter bons resultados até chegar em 0.08 de revocação onde o extrator Histogramas (linha preta) se torna melhor do que o Gabor até o final do gráfico. O extrator seguinte é o método Haralick (linha verde).

\subsection{Conclusões}

Neste capítulo foi apresentado um novo método de extração de características que é parte da proposta deste trabalho de mestrado, chamado $k$-Gabor, por usar o algoritmo de clustering $k$-means para agrupar os pixels da imagem em regiões de interesse. Essas regiões estão baseadas em tecidos ou estruturas internas da imagem, gerando $k$ novas imagens clusterizadas. Os filtros de Gabor são aplicados sobre cada imagem clusterizada para extrair informação da textura e assim compor o vetor de características to extrator $k$-Gabor. $\mathrm{O}$ valor $k$ pode variar segundo a base de imagens, considerando o grau de detalhe demandado na aplicação. Nos experimentos, os valores $k$ foram atribuídos empiricamente com $k=2,3,10$ para as três bases de imagens médicas. Temos comparado o método $k$-Gabor com vários extratores bem conhecidos na literatura, e os resultados mostram que a proposta apresenta a melhor precisão em recuperação de imagens ao responder consultas por similaridade.

Porém, o tempo de extração de características pode crescer muito para valores grandes de $k$. Se for necessário usar um valor grande de $k$, o método pode ser facilmente paralelizado, já que os filtros de Gabor são aplicados independentemente para cada imagem clusterizada.

Tabela 3.1: Sumarização dos resultados de precisão dos extratores de características.

\begin{tabular}{l|cccc}
\hline & Lung & 944Body & DDSM & IRMA \\
\hline FFS & 0.4443 & 0.6093 & 0.5848 & 0.1707 \\
Haralick & 0.4627 & 0.6202 & 0.4738 & 0.3176 \\
Gabor & 0.4919 & 0.7867 & 0.5043 & 0.3503 \\
Histogramas & 0.5407 & 0.5153 & 0.4860 & 0.3934 \\
$k$-Gabor & $\mathbf{0 . 5 8 0 9}$ & $\mathbf{0 . 8 2 9 2}$ & $\mathbf{0 . 6 0 5 7}$ & $\mathbf{0 . 4 8 7 6}$ \\
\hline
\end{tabular}

A Tabela 3.1 apresenta as médias dos resultados dos extratores de características para todas as bases de imagens usadas nestes experimentos, referentes à precisão obtida. Assim, quanto mais alto o valor melhor é o método. Temos usado os resultados dos gráficos $\mathrm{P} \& \mathrm{R}$ apresentados nas Figuras 3.5, 3.7, 3.9 e 3.11 para calcular a média desses valores por extrator em cada base de imagem. A Tabela 3.1 ressalta também que o $k$-Gabor apresenta significativamente maiores valores de precisão do que os outros extratores de características. A Figura 3.12 é uma representação gráfica da Tabela 3.1. Onde o método $k$-Gabor (barras laranjas) mostra-se superior 
aos outros extratores, e mais amplamente nas bases de imagens 944Body e IRMA. O método Gabor (barras verdes) sempre está entre as três primeiras posições nas quatro bases de imagens, e até consegue ser o segundo na base de imagens 944Body. O extrator seguinte é o Histogramas (barras ciano) também obtém a segunda posição em duas bases de imagens (Lung e IRMA), sendo que nas outras bases de imagens está na terceira posição. O próximo extrator a discutir é o FFS, que obtém baixos valores de precisão na base de imagens IRMA, um comportamento regular em outras duas, mas na base de imagens DDSM obtém a segunda posição com apenas oito características. Além disso, é necessário ressaltar a rapidez do método FFS para calcular as características.

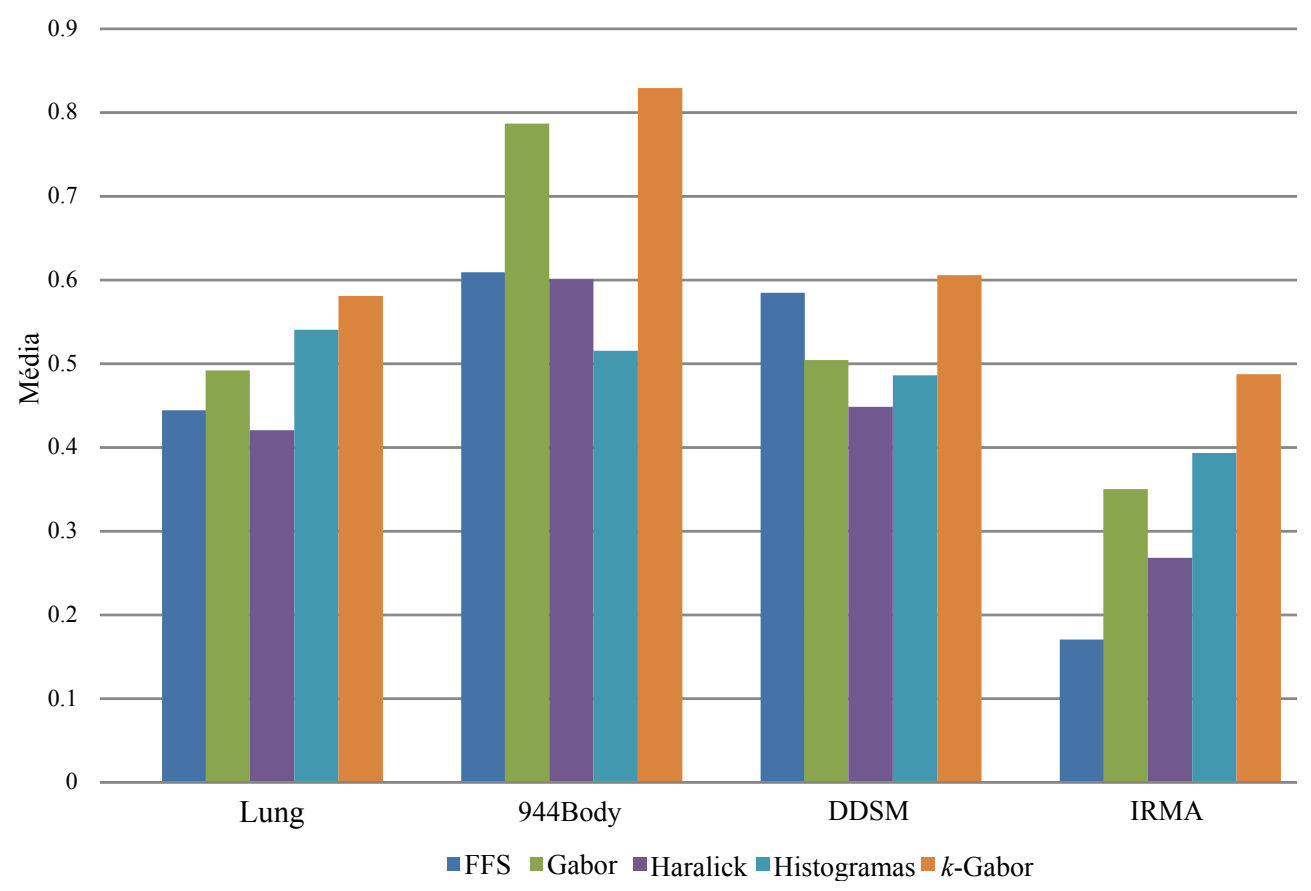

Figura 3.12: Representação gráfica da sumarização dos resultados de precisão (média) dos extratores de características para todas as bases de imagens. Esta figura é detalhada na Tabela 3.1 . 



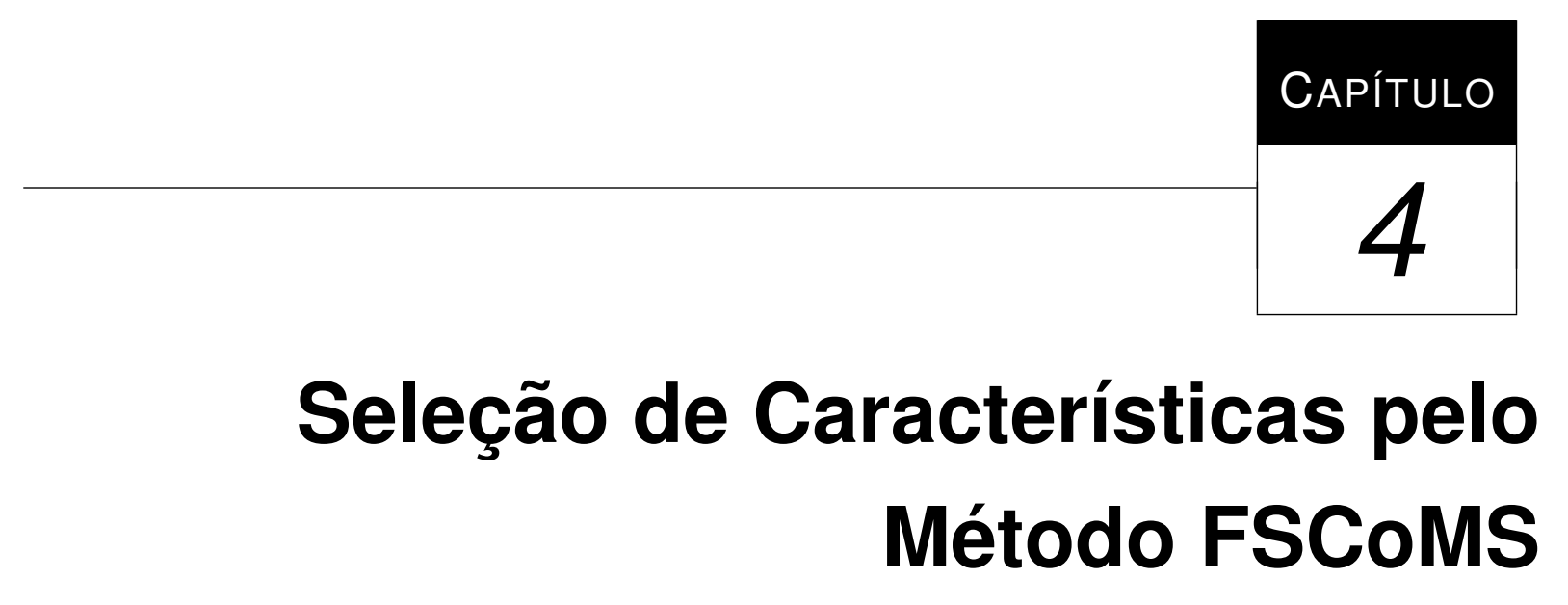

Neste capítulo é descrito um novo método de seleção de características desenvolvido durante este projeto de Mestrado: o Feature Selection based on Compactness Measure from Scatterplots, ou FSCoMS. Este método baseia-se na análise das projeções bidimensionais (ScatterPlots) das características para associar valores de relevância a cada uma das características. Assim, este método produz um peso para cada característica, permitindo gerar um ranking e identificar a característica mais relevante. Além do ranking que considera a relevância de cada característica, é preciso obter um subconjunto que permita reduzir o número de características consideradas. Para se obter um subconjunto de características é necessária uma análise de dimensionalidade. Esta análise de dimensionalidade é feita por meio de uma heurística que gera subconjuntos candidatos baseada no ranking das características. Desta forma, o método FSCoMS proposto produz um subconjunto de características menor que os métodos tradicionais, além de melhorar o desempenho/precisão do vetor de características. Os resultados obtidos em três das quatro bases de imagens testadas nesta dissertação foram publicados no evento The second IEEE Conference on Healthcare Informatics, Imaging, and Systems Biology (HISB2012) que ocorreu em setembro na Califórnia, Estados Unidos (Humpire et al., 2012a). 


\subsection{O método Feature Selection Based on Compactness Measure from Scatterplots (FSCoMS)}

A visualização de dados de alta dimensionalidade é uma tarefa complicada. No entanto, há diversos métodos baseados em heurísticas e projeções que permitem visualizar os dados. A visualização dos dados pode dar uma maior confiabilidade visual das características que serão consideradas e, portanto, podem evitar problemas como a correlação ou redundância de características. Uma análise sobre os métodos de visualização pode dar uma maior percepção dos critérios tomados pelos métodos de seleção de características. Por exemplo, os ScatterPlots (Sips et al., 2009; Ward, 1994) são os métodos mais usados para visualização de dados de alta dimensionalidade em duas dimensões. O método ScatterPlot calcula $n *(n-1) / 2$ projeções, onde $n$ é o número de características. Usualmente, cada classe em um ScatterPlot é representada com diferentes "sinais" ou cores. Assim, os métodos de visualização são apropriados para descrever e entender os dados de alta dimensionalidade (vetor de características)

Os métodos populares de seleção de características tiram proveito de medidas estatísticas e heurísticas para selecionar um subconjunto de características que mantenha ou melhore a qualidade da informação do conjunto de características original. As principais propriedades esperadas do novo subconjunto de características são:

1. Prover o melhor desempenho possível para separar as classes.

2. Obter um vetor de características com dimensionalidade menor do que a do vetor original.

Métodos como Correlation-based Feature Selection (CFS) (Huang and Liao, 2003), Chi-Squared ( $\left.X^{2}\right)$ (Liu and Setiono, 1995) e Ganho de Informação (IG) (Mukras et al., 2007) baseiam-se em valores estatísticos como a teoria da entropia (Geng et al., 2007) ou regras heurísticas para associar um valor de relevância às características. A entropia $H(X)$ é considerada uma medida da incerteza de um incidente de forma aleatória (Ding et al., 2011). Assim, valores pequenos de entropia aumentam os níveis de separação das diferentes classes. A entropia é definida pela Equação 4.1:

$$
H(X)=-\sum_{i=1}^{n} P\left(x_{i}\right) \log _{2}\left(P\left(x_{i}\right)\right)
$$

onde, $P\left(x_{i}\right) \geq 0, \sum_{i=1}^{n} P\left(x_{i}\right)=1, i=1,2, \ldots n$ e $x_{i}$ o valor da variável atual.

Por outro lado, a mineração de regras de associação é abordagem diferente por gerar relações do tipo $f_{i} \rightarrow C_{k}$ onde $f_{i}$ é uma característica e $C_{k}$ uma classe. Essa regra pode ser interpretada como uma relação da característica $f_{i} \operatorname{com} C_{k}$ por atender às restrições dos métodos 
de mineração de regras. Assim, métodos de mineração de regras como o StarMiner (Ribeiro, 2008) podem ser usados como métodos de Seleção de Características.

Tabela 4.1: Tabela de símbolos

\begin{tabular}{c|l}
\hline Símbolo & Definição \\
\hline$n$ & Número de características. \\
$m$ & Número de classes. \\
$f_{i}$ & Característica unitária. \\
$S_{i}$ & Subconjunto com $i$ características. \\
$S^{*}$ & Conjunto dos subconjuntos $S_{i}$. \\
$S_{i}^{*}$ & Subconjunto com relevância adequada. \\
$C_{i}$ & Classe $i$. \\
$\left|C_{i}\right|$ & Número de elementos na classe $C_{i}$. \\
$\delta_{k}\left(f_{i} f_{j}\right)$ & Medida de compacidade entre $f_{i}$ e $f_{j}$ para a classe $k$. \\
$\Psi_{\left(f_{i} f_{j}\right)}$ & Ranking para o $S c a t t e r P l o t$ gerado por $f_{i}$ e $f_{j}$. \\
$F_{j}$ & Vetor de características gerado pelo extractor $j$. \\
$J_{f v}$ & União dos vetores de características dos extractores $\left\{F_{1}, F_{2}, \ldots, F_{j}\right\}$. \\
$\triangleright$ & Ordem de relevância entre características. \\
$A$ & Parâmetro para a função de relevância.
\end{tabular}

Na Seção 2.2.2 foram apresentados métodos de seleção de características baseados em heurísticas e valores estatísticos, além do StarMiner que baseia-se em regras de associação. O FSCoMS, por sua vez, é baseado na análise automática dos Scatter Plots para gerar um ranking de características por relevância e usa os símbolos apresentados na tabela 4.1 para sua definição. O FSCoMS está dividido em três conceitos principais que são sumarizados a seguir:

Compactness Measure from ScatterPlots (CMS) : É uma medida que avalia a compacidade da classe $C_{k}$ nos Scatter Plots e é representado como $\delta_{k}\left(f_{i} f_{j}\right)$, onde $f_{*}$ é uma característica. O CMS realiza consultas $k$-NN usando o centroide de cada classe $C_{m}$ como centro de consulta.

Ranking de ScatterPlot : Representa a relevância de um ScatterPlot. Usa o valor $\delta_{m}$ para gerar a variável $S R a n k$, onde $m$ é o número de classes. O Algoritmo 2 detalha o processo a ser realizado para calcular o valor do ranking de um ScatterPlot.

Ranking de características : Recebe como entrada o valor SRank para dar um valor de relevância a cada característica.

O método FSCoMS está baseado na geração do Ranking de ScatterPlot, que auxilia na separação das classes. Mede-se a compacidade de cada classe considerando pares de características. 


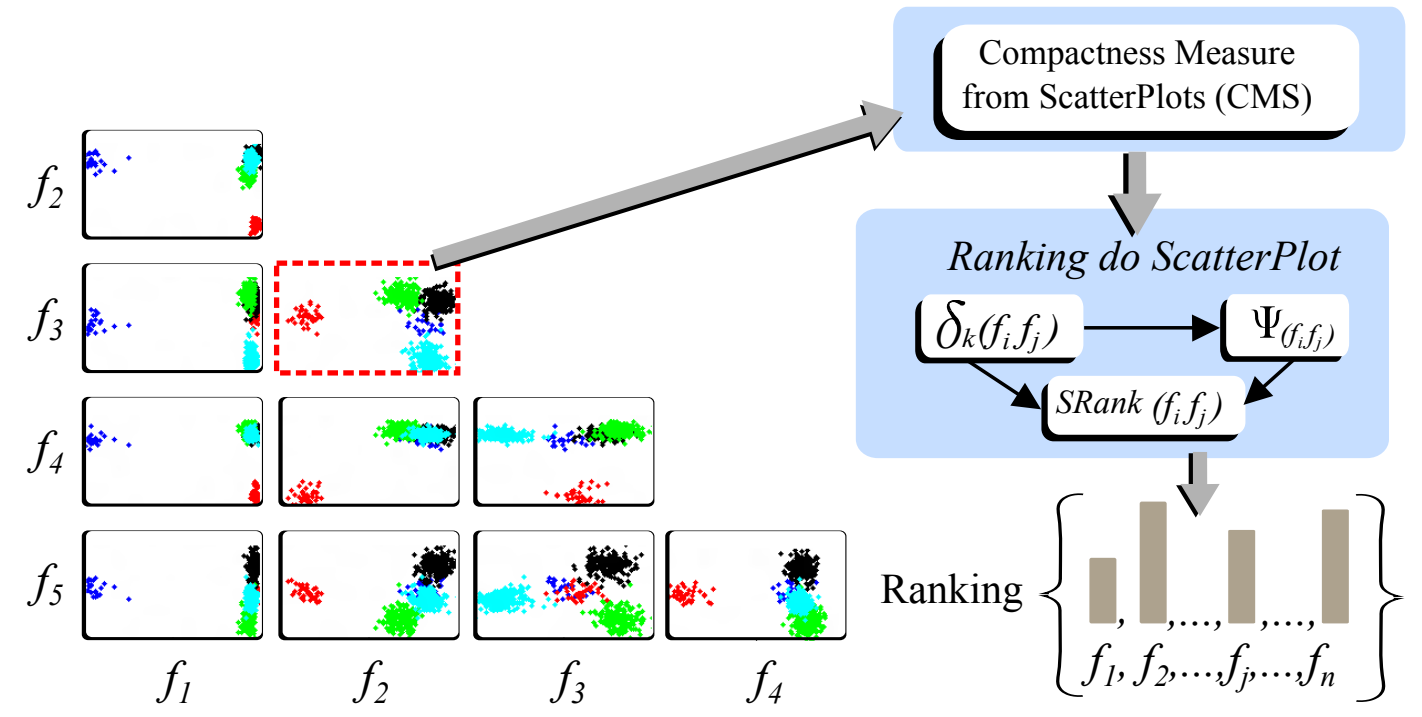

Figura 4.1: Diagrama geral do método FSCoMS que mostra os processos requeridos para obter o ranking de características. Inicialmente são gerados todos os ScatterPlots para calcular a CMS $\left(\delta_{k}\right)$. Este valor se apoia do valor $\Psi$ para obter um ranking de Scatter Plots . Por fim, o exemplo mostra a obtenção do ranking de cinco características.

Para obter esses valores usamos os centroides de cada classe como centro de consulta para as consultas $k \mathrm{NN}$. A obtenção do valor CMS ajuda a diminuir o grau de redundância entre características para predizer uma classe específica $C_{k}$. Altos valores de redundância entre características geram um ScatterPlot com classes sobrepostas devido à similaridade e alta correlação da informação. Por outro lado, valores baixos de redundância entre características implicam um ScatterPlot com melhores taxas de separabilidade entre classes. A Figura 4.1 ilustra os procedimentos gerais para obter o ranking das características baseados na análise dos ScatterPlots.

\subsubsection{Compactness Measure from ScatterPlots (CMS)}

Na literatura, há diversos trabalhos baseados na obtenção de medidas dos Scatter Plots (Sips et al., 2009); (Albuquerque and Eisemann, 2009); (Albuquerque and Eisemann, 2011) para a visualização dos Scatter Plots com maiores propriedades de separação de classes. Neste projeto de mestrado propõe-se uma medida denominada Compactness Measure from ScatterPlots (CMS) para avaliar o comportamento das funções de distância empregadas nas consultas $k \mathrm{NN}$. É altamente recomendável usar a mesma função de distância na medida CMS e nas consultas $k \mathrm{NN}$ porque o desempenho das funções de distância altera-se segundo o contexto e aplicação (Bugatti and Traina, 2008). A Figura 4.2 mostra o ScatterPlot gerado pelo par de características $\left(f_{A}, f_{B}\right)$, onde as classes são representadas por diferentes 'sinais' e cores. Dado o centroide de 
cada classe $C_{k}$, usamos o ScatterPlot para calcular a média (average) de cada característica $f_{i}$ e $f_{j}$ na respectiva classe, onde $\sigma_{f_{i} C_{k}}$ e $\sigma_{f_{j} C_{k}}$ representam as médias para as características $f_{i}$ e $f_{j}$ respectivamente. Para obter uma melhor intuição, a Figura 4.2 ilustra um exemplo da obtenção do CMS, onde os centroides (representados por estrelas $\star$ ), são usados como centro de consulta pelas consultas $k \mathrm{NN}$ usando a função de distância Euclidiana. Assim, para cada ScatterPlot obtemos $m$ valores de compacidade representados como $\delta_{k}\left(f_{i} f_{j}\right)$, onde $k=\{1,2, \ldots, m\}$, e $m$ é o número de classes.

$$
\delta_{k}\left(f_{i} f_{j}\right)=\frac{\left|k N N\left[\left(\sigma_{\left(f_{i} C_{k}\right)}, \sigma_{\left(f_{j} C_{k}\right)}\right),\left|C_{k}\right|\right] \in C_{k}\right|}{\left|C_{k}\right|}
$$

A Equação 4.2 calcula os valores de CMS, onde a consulta $k \mathrm{NN}$ retorna $\left|C_{k}\right|$ elementos, considerando como centro de consulta o centroide da classe $k$. Em consequência, são considerados somente os elementos pertencentes à classe $C_{k}$. Assim, a proporção entre a quantidade de elementos retornados que efetivamente pertencem à classe recuperada e o valor $\left|C_{k}\right|$, dá a medida Compactness Measure from ScatterPlots (CMS). Um alto valor de CMS significa que as características $f_{i}$ e $f_{j}$ permitem separar a classe $C_{k}$ das outras classes no ScatterPlot. Um valor baixo de CMS significa que as características $f_{i}$ e $f_{j}$ se sobrepõem no ScatterPlot, e portanto, não são características que possam discriminar os elementos da classe $C_{k}$. A Figura 4.2 ilustra a medida CMS para as características $f_{A}$ e $f_{B}$, onde a classe $C_{1}$ (representada pelos pontos azuis) produz o maior valor CMS tomando como ponto de consulta a estrela azul devido à existência de apenas um outlier da classe verde, enquanto os demais pontos foram retornados corretamente na consulta $k \mathrm{NN}$. Por outro lado, a classe $C_{4}$ (representada pelos pontos verdes) recebe o menor valor CMS por conter no seu subespaço elementos da classe $C_{3}$ (representada pelos pontos pretos) e da classe $C_{5}$ (representada pelos pontos laranjas). A Figura 4.2 também mostra pontos fora dos círculos. Tais pontos representam a informação que não é considerada na medida, enquanto os outros pontos localizados em áreas de outras classes são considerados outliers.

\subsubsection{Ranking de ScatterPlots}

A medida CMS calcula os valores de compacidade $\left(\delta_{k}\right)$ de cada classe. Assim, o ranking de Scatter Plots usa como entrada os $d_{k}\left(f_{i} f_{j}\right)$ para gerar um ranking da separabilidade entre classes no ScatterPlot. O ranking dos Scatter Plots ajuda na busca dos pares de características com alta habilidade para separar as classes. Este processo gera as entradas para o processo "Ranking de características" (Seção 4.1.3). 


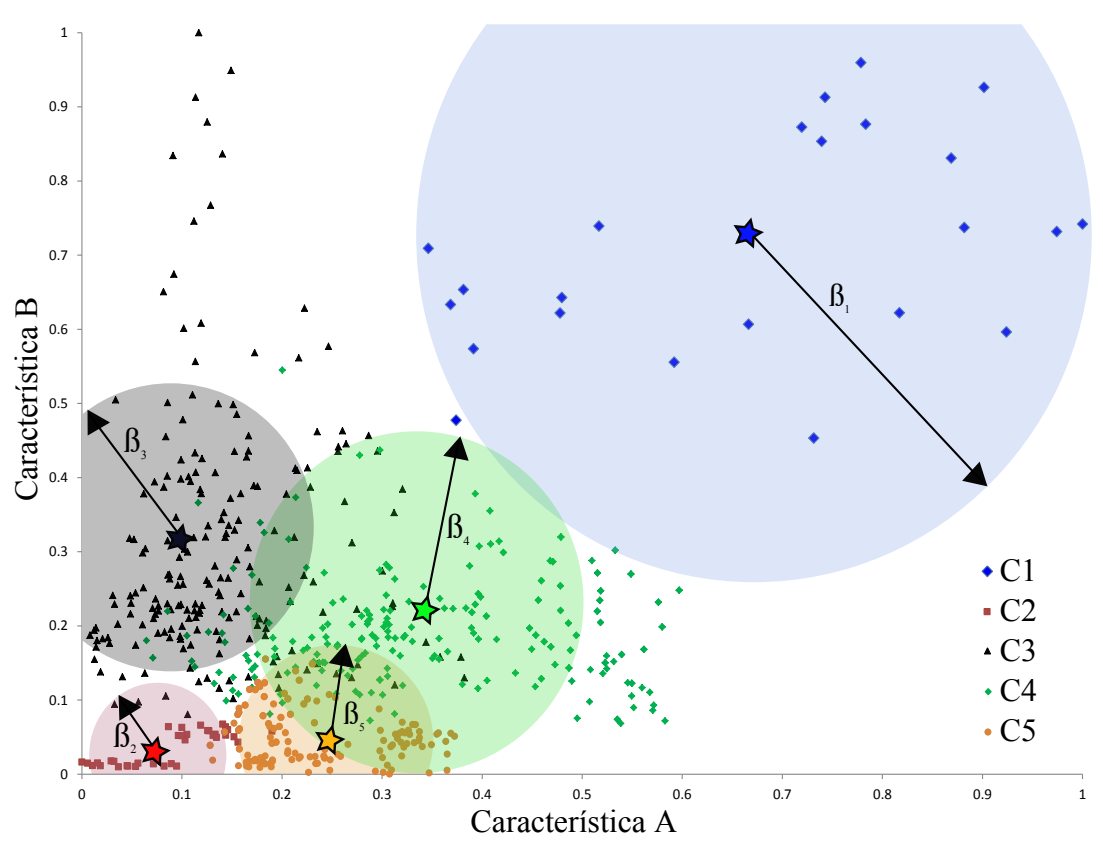

Figura 4.2: Exemplo de uma análise de ScatterPlot. Cada classe é representada por cores diferentes. A classe $C_{1}$ produz o maior valor CMS e a classe $C_{4}$ obtém o menor valor CMS devido aos outliers contidos na sua área de resposta da consulta $k \mathrm{NN}$. As extrelas ' $\star$ ' são os centroides de cada classe.

O Algoritmo 2 detalha a obtenção do Ranking dos ScatterPlots. Na linha 1, a variável rankValue é inicializada com o número total de ScatterPlots. Na linha 3 , o loop while verifica a condição de haver mais de zero elementos na tabela $\delta_{*}$. Em seguida, na linha 4 Max $\delta$ é inicializada com o valor máximo $\delta_{k}$ por cada classe, onde $f_{*}$ representa todas as características disponíveis para $\delta_{k}$. Na linha 5, a variável Pos é inicializada com o valor retornado pela função checkDuplicates, que verifica a existência de somente um valor máximo $\delta_{k}$ em cada classe, isto deve-se a que eventualmente mais de um $\delta_{k}$ pode ter o mesmo valor. Porém, a função checkDuplicates escolhe o máximo $\delta_{k}$ que tenha as maiores probabilidades de separabilidade e elimina os outros. Caso a função checkDuplicates encontre mais de um ScatterPlot com o mesmo valor máximo $\delta_{k}$, ela calcula o $\Psi_{f_{i} f_{j}}$ como um indicador interno para escolher o ScatterPlot mais relevante. O valor $\Psi_{f_{i} f_{j}}$ é calculado segundo a Equação 4.3 .

$$
\Psi_{\left(f_{i} f_{j}\right)}=\operatorname{avg}\left[\max \left(\delta_{*}\left(f_{i} f_{j}\right)\right), \operatorname{avg}\left(\delta_{*}\left(f_{i} f_{j}\right)\right)\right]
$$

A Equação 4.3 toma os valores máximos $\delta_{*}\left(f_{i} f_{j}\right)$ para ressaltar as classes mais separáveis. Desta forma, a média de $\delta_{*}\left(f_{i} f_{j}\right)$ representa o grau de separabilidade entre classes. Para obter $\Psi_{\left(f_{i} f_{j}\right)}$ calcula-se a média entre: o máximo valor e a média de $\delta_{*}\left(f_{i} f_{j}\right)$ para representar ambos valores. Para entender melhor o significado dos valores na Equação 4.3, tomamos como 


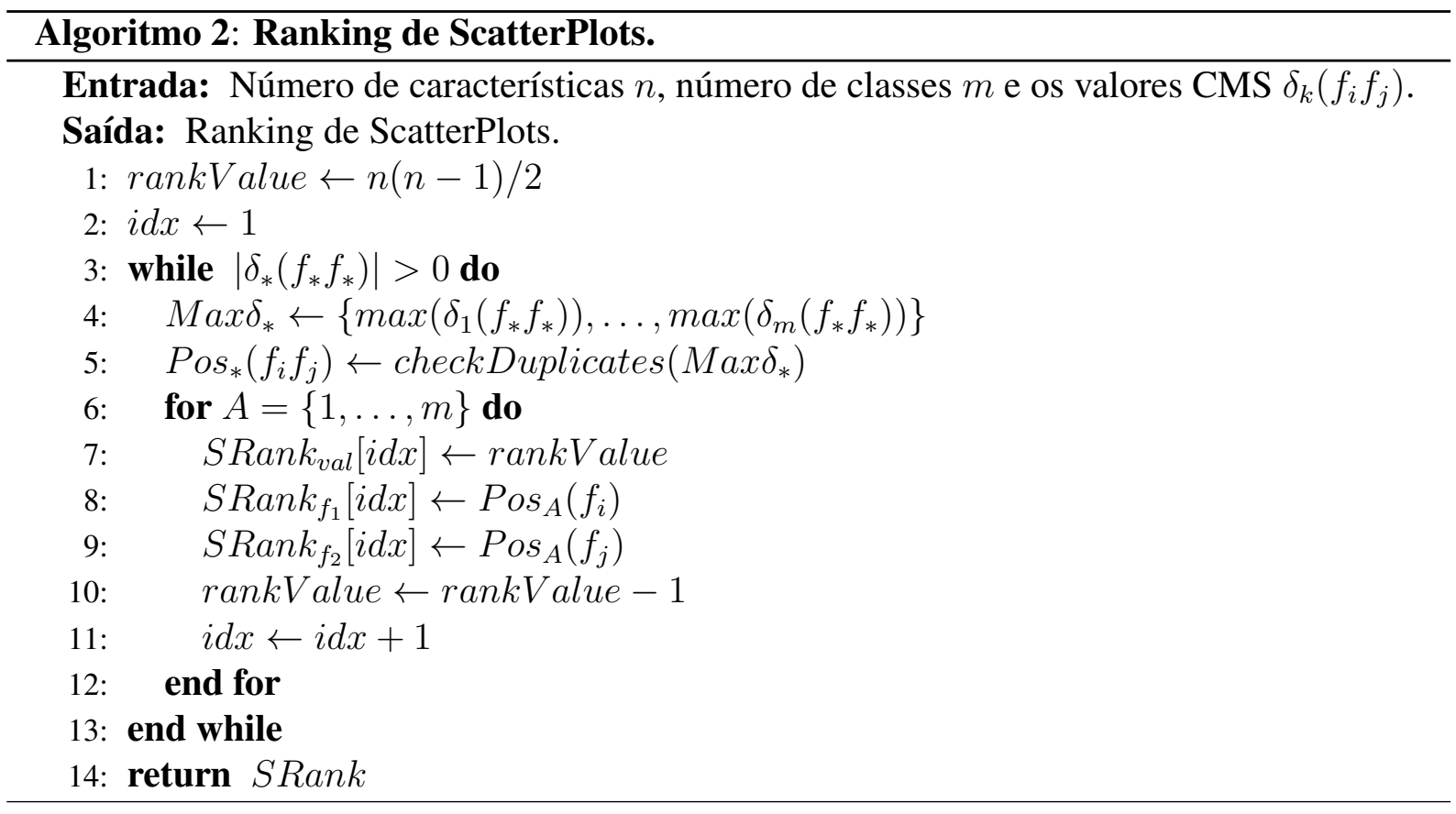

exemplo a Figura 4.2. O valor $\max \left(\delta_{*}\left(f_{i} f_{j}\right)\right)$ é dado pela classe $C_{1}$ (representada pelos pontos azuis) visto que esta classe apresenta maior valor CMS do que as outras quatro. Note-se que o valor $\operatorname{avg}\left(\delta_{*}\left(f_{i} f_{j}\right)\right)$ representa a média do CMS $\delta_{*}\left(f_{i} f_{j}\right)$ das cinco classes. Na função checkDuplicates, se existir mais de um ScatterPlot com o máximo valor $\max \left(\delta_{k}\left(f_{*} f_{*}\right)\right)$, o algoritmo escolhe aquele com o maior valor $\Psi_{f_{i} f_{j}}$ para garantir uma melhor separação das classes. Além disso, o algoritmo remove as posições $\operatorname{Max}_{*}$ da matriz $\delta_{*}\left(f_{i} f_{j}\right)$ e retorna as posições dos pares $\left(f_{i} f_{j}\right)$ ordenados em ordem decrescente de relevância.

Na linha 6, o loop for percorre todos os valores $m$, para iniciar o Ranking dos Scatter Plots na linha 7. As linhas 8 e 9 tomam a posição da característica em análise e a linha 10 diminui o valor do ranking para o ScatterPlot seguinte. Finalmente, a variável SRank guarda os valores de Ranking para Scatter Plots .

\subsubsection{Ranking de Características}

O processo anterior calcula o Ranking de Scatter Plots (Seção 4.1.2) para obter finalmente o Ranking de características. O Algoritmo 3 mostra de forma detalhada como é feita a atribuição de valores de ranking para as características. Nas três primeiras linhas, variáveis são iniciadas, e a variável FRank representa o Ranking de característica e é inicializado com zero (0). Na linha 4, o Ranking de Scatter Plots é ordenado em ordem decrescente. Na linha 5 percorre-se todos os Scatter Plots no loop for. Na linha 7 verifica se a característica $f_{j}$ ainda está com o valor zero (0), na linha 8 é designado o valor do ranking com a proporcionalidade entre $\lambda$ e $\Lambda$, 
onde $\Lambda$ representa o máximo valor do ranking e $\lambda$ toma valores entre $\{1, \ldots, \Lambda\}$. Finalmente, é gerado o ranking das características.

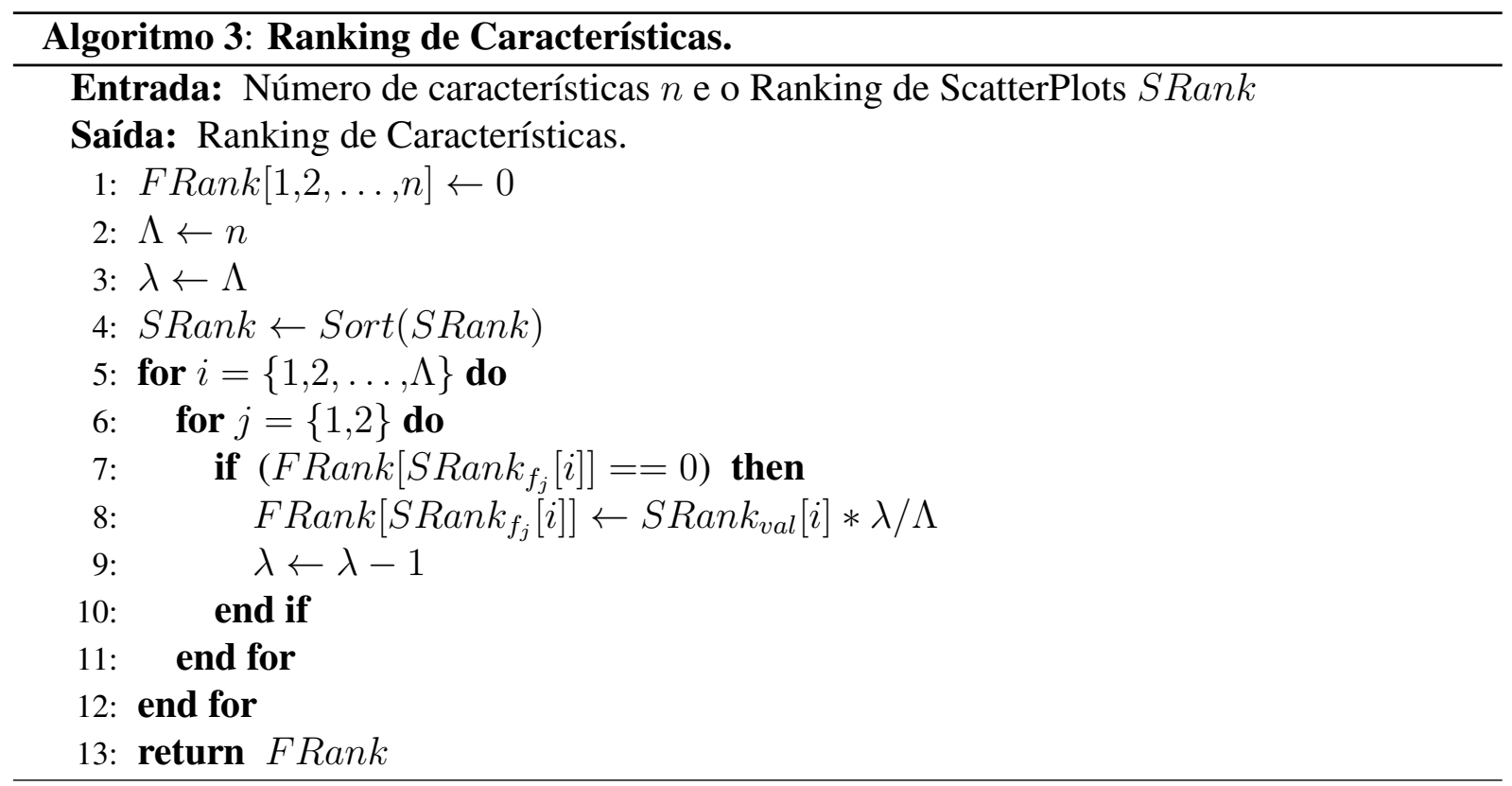

\subsection{Discussão de Experimentos}

Para gerar o vetor de características de entrada para os métodos de seleção de características temos usado os extratores $k$ Gabor, Gabor, Haralick, Histograms e FFS nas bases de imagens. Cada extrator de características gera um conjunto $F_{j}$, considerando $F_{j}=\left\{f_{1}, f_{2}, f_{3}, \ldots, f_{n}\right\}$, onde $f_{i}$ é uma característica. Para os experimentos, cada um dos cinco vetores de características $F_{i}$ criados pelos extratores foram concatenados em um único vetor de características $J_{f v}$ (Equação 4.4). Assim, a dimensionalidade do vetor de características $J_{f v}$ é igual à soma das dimensionalidades dos vetores de características, como mostra a Equação 4.5 .

$$
\begin{aligned}
J_{f v} & =\left\{F_{1} \cup F_{2} \cup \cdots \cup F_{p}\right\} \\
\operatorname{dim}\left(J_{f v}\right) & =\operatorname{dim}\left(F_{1}\right)+\operatorname{dim}\left(F_{2}\right)+\cdots+\operatorname{dim}\left(F_{p}\right)
\end{aligned}
$$

onde, a função dim calcula a dimensionalidade do vetor de características. Para trabalhar com métodos de seleção de características considera-se o vetor de características $J_{f v}$ como vetor de entrada. Adicionalmente, a dimensionalidade do vetor de características muda segundo a base de imagens, devido ao parâmetro $k$ do extrator de características $k$-Gabor. 
Um dos objetivos dos métodos de seleção de características é obter um vetor de características com uma menor dimensionalidade do que o vetor original $J_{f v}$ através da remoção de características irrelevantes. A Figura 4.3 mostra os procedimentos para todos os métodos de seleção de características. Métodos como CFS, StarMiner e o vetor de características "original" não precisam de uma análise de dimensionalidade por gerar subconjuntos com uma dimensionalidade fixa (constante). Por outro lado, métodos como $X^{2}$, IG e o nosso método proposto FSCoMS requerem uma análise da dimensionalidade para encontrar o número de características adequada que alcance o melhor desempenho em recuperação de imagens. A Figura 4.4 mostra uma análise da dimensionalidade para encontrar o subconjunto com um número de características apropriado (o melhor desempenho em recuperação de imagens). Esta análise é requerida pelos métodos $X^{2}$, IG e FSCoMS. O processo de geração de subconjuntos "ranqueia" as características por relevância para depois ser avaliado nas consultas $k \mathrm{NN}$ e obter o valor da precisão do subconjunto.

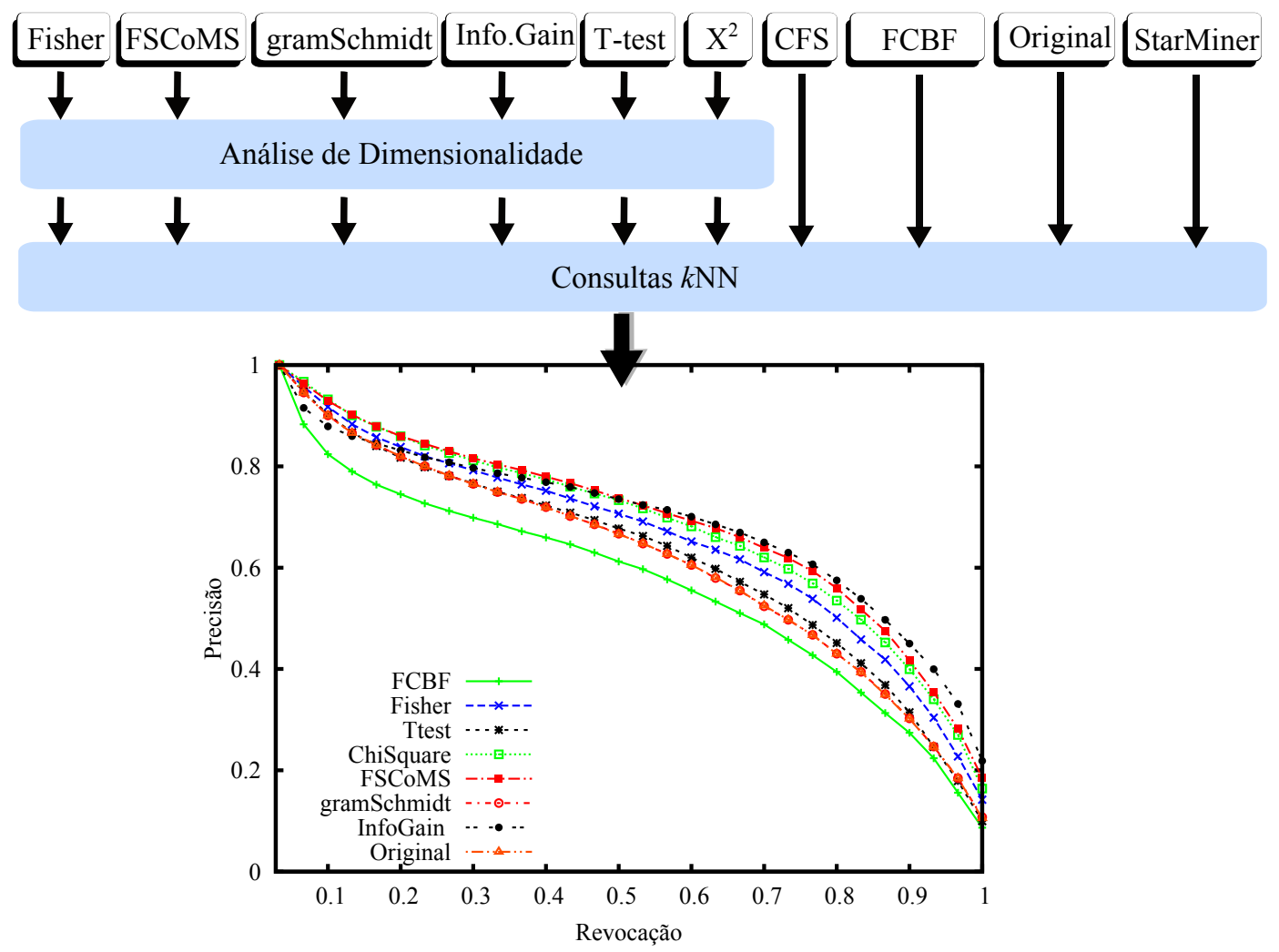

Figura 4.3: O diagrama mostra os processos necessários para os métodos de seleção de características, onde Fisher, FSCoMS, gramSchmidt, IG, T-test e $X^{2}$ precisam de uma análise (detalhada na Figura 4.4) para melhorar a qualidade nas consultas $k$ NN. Os resultados são apresentados em gráficos de Precisão e Revocação. 


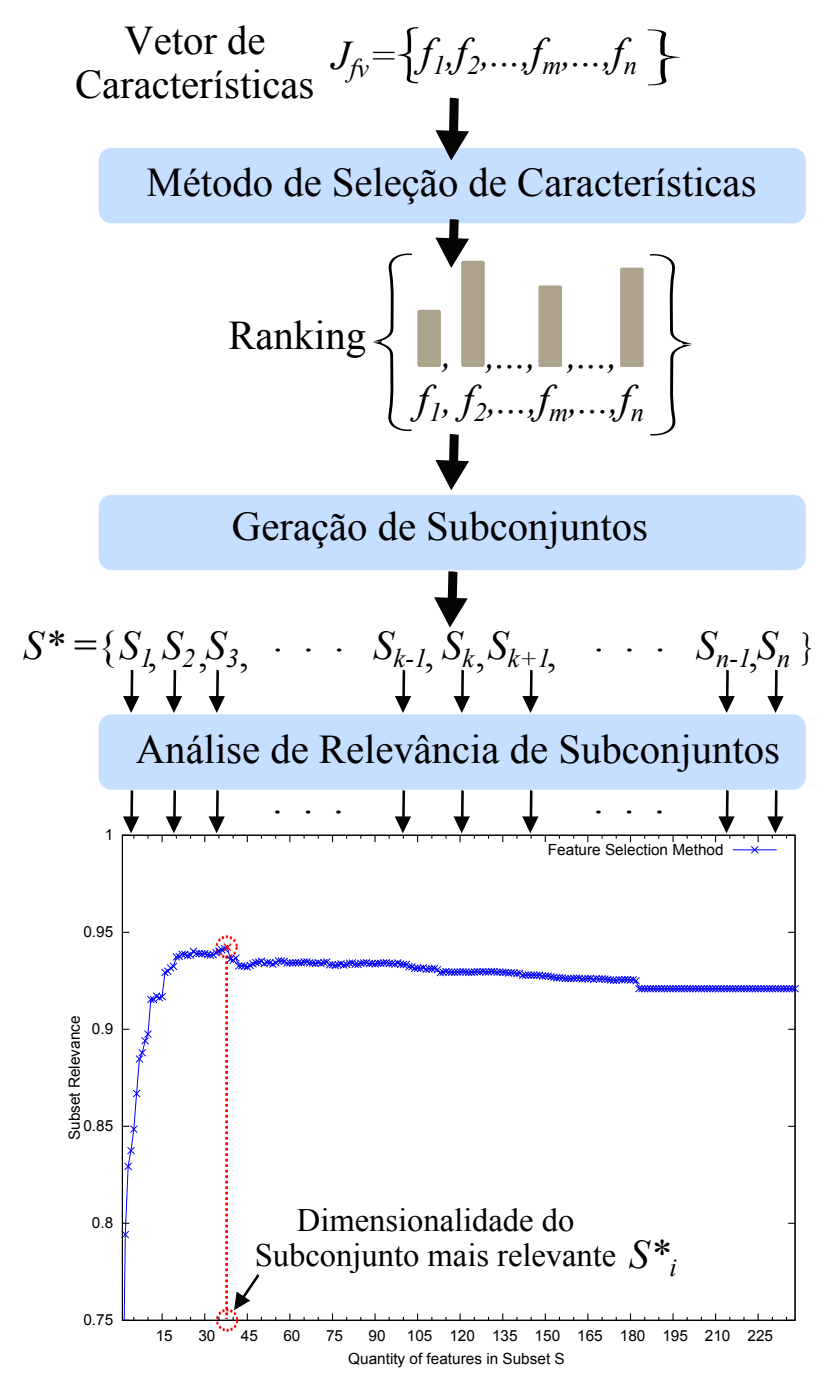

Figura 4.4: Diagrama da análise da dimensionalidade para os métodos $X^{2}$, IG e FSCoMS, onde a entrada para cada método é o vetor de características $J_{f v}$ para obter o ranking das características. Os subconjuntos são gerados heuristicamente para obter a relevância de cada um (detalhado na Figura 4.5). O subconjunto com o maior valor de relevância será considerado o melhor subconjunto.

A maneira mais fácil é gerar todas as combinações de subconjuntos usando força bruta, avaliando todas as dimensionalidades possíveis para o subconjunto de características. Nosso método não usa força bruta, como descreveremos nas seguintes subseções.

\subsubsection{Geração de Subconjuntos}

A abordagem da força bruta gera todos os possíveis subconjuntos usando o fatorial da dimensionalidade do vetor de características $\left(\operatorname{dim}\left(J_{f v}\right)\right)$. A seguir, cada subconjunto é avaliado para obter sua relevância e encontrar um subconjunto de características apropriado. 
A força bruta é aceitável apenas para valores baixos de dimensionalidade, mas o tempo de processamento requerido torna-se exponencialmente alto para altas dimensionalidades. Aproveitamos o ranking de características gerado pelos métodos de seleção de características para gerar heuristicamente subconjuntos. Esta abordagem permite reduzir significativamente o número de subconjuntos para avaliá-los. Assim, geramos subconjuntos segundo o ranking $R=\left\{f_{1}, f_{2}, f_{3}, \ldots, f_{n}\right\}$, considerando $f_{1} \triangleright \cdots \triangleright f_{k} \triangleright f_{k+1} \triangleright \cdots \triangleright f_{n}$, onde $\triangleright$ indica que a característica da direita é menos relevante que a característica da esquerda. Assim, geramos subconjuntos em ordem de relevância, sendo $S_{1}=\left\{f_{1}\right\}, S_{2}=\left\{f_{1}, f_{2}\right\}, \ldots, S_{n-1}=\left\{f_{1}, f_{2}, \ldots, f_{n-1}\right\}$ os subconjuntos de características, então $S^{*}=\left\{S_{1}, S_{2}, \ldots, S_{n-1}\right\}$ representa o conjunto de características relevantes $S_{i}$. Com essa restrição heurística, garantimos a geração de até $n$ subconjuntos, onde $n$ é o número de características. Como resultado, nosso processo de busca da dimensionalidade apropriada torna-se reduzido significativamente. A literatura (Cho et al., 2008; Geng et al., 2007; Yoon et al., 2005) recomenda fazer a análise para medir o desempenho dos subconjuntos para os métodos de seleção de características poderem encontrar a combinação apropriada de características.

\subsubsection{Análise de Relevância de Subconjuntos em Dimensionalidade}

Este processo é chamado também de variação do desempenho sob o número de características selecionadas (Cho et al. 2008). Assim, primeiro analisamos a dimensionalidade dos métodos de seleção de características $X^{2}$, IG e FSCoMS

O algoritmo de avaliação de subconjuntos, apresentado na Seção 1, obtém o melhor subconjunto usando a função $J$ (linha 1 do algoritmo). A função $J$ pode ser uma função de medida e, no nosso caso, avalia-se cada subconjunto com os gráficos de Precisão e Revocação. Os valores obtidos no gráfico são a entrada para a função de avaliação do ranking (função de relevância) (da Silva et al., 2011) apresentado na Equação 4.6.

$$
F R_{(P \& R)}=\sum_{i}\left(r(i) \frac{1}{A}\left(\frac{A-1}{A}\right)^{(i-1)}\right)
$$

onde $i$ representa o número de objetos em análise, $r(i)$ representa o valor obtido pelo gráfico de precisão e revocação na posição $i$. Assim, ' $A$ ' representa o valor de relevância de cada posição no ranking tomando valores maiores ou iguais que dois. Um exemplo é apresentado na Tabela 4.2 considerando $A=2$. 


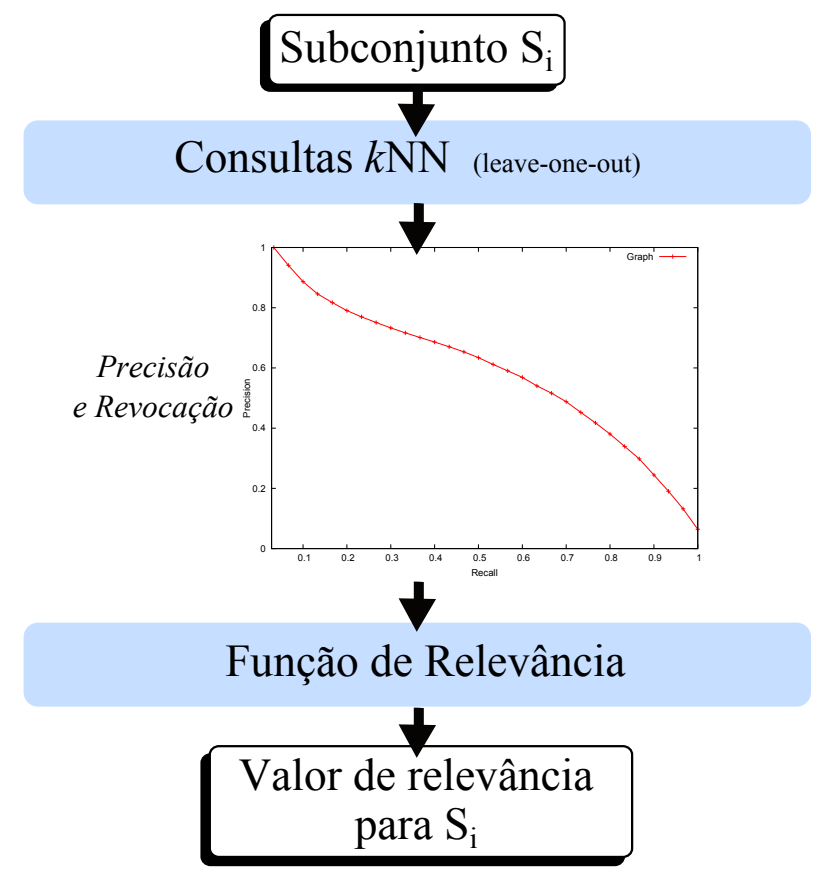

Figura 4.5: Obtenção do valor de relevância para um subconjunto $S_{i}$.

Tabela 4.2: Exemplo de valores de relevância do ranking usando a Equação $4.6 \operatorname{com} A=2$.

\begin{tabular}{c|c|c}
\hline $\mathbf{i}$ & $\mathbf{r ( i )}$ & Valor do Ranking \\
\hline 1 & 1 & 0.50000 \\
2 & 1 & 0.25000 \\
3 & 1 & 0.12500 \\
4 & 1 & 0.06250 \\
5 & 1 & 0.03125 \\
6 & 1 & 0.01563 \\
7 & 1 & 0.00781 \\
8 & 1 & 0.00391 \\
9 & 1 & 0.00195 \\
10 & 1 & 0.00098 \\
\hline & Soma & 1.0000 \\
\hline
\end{tabular}

\subsection{Resultados}

Esta seção apresenta resultados experimentais da execução de consultas de similaridade por relevância em quatro bases de imagens médicas reais. Para os experimentos usamos as características extraídas por Haralick, Histograms, FFS, Gabor e $k$-Gabor, onde os vetores gerados tem $23,17,8,48$ e $k^{*} 48$ como dimensionalidade respectivamente. A Tabela 4.3 sumariza as definições dos extratores de características utilizados nos experimentos. Além disso, a 
mesma tabela mostra a dimensionalidade do vetor de características gerado por cada extrator. A dimensionalidade do $k$-Gabor muda segundo o parâmetro $k$, o qual será especificado em cada base de imagens na descrição dos experimentos. Assim, os outros extratores de características também têm parâmetros detalhados a seguir. Para o extrator Haralick foram tomados os deslocamentos - 1 e 0 nos eixos $x$ e $y$ respectivamente. Para o extrator Histogramas foram usados 17 bins como características dos 255 valores do histograma em tons de cinza, cada bin representa a média de 15 características do histograma de 255 valores. Os bins foram usados para reduzir a dimensionalidade do vetor de características gerado pelo Histograma. Enquanto isso, o extrator $k$-Gabor está baseado no extrator Gabor, assim, foram usados os mesmos parâmetros base: 6 orientações e 4 escalas.

Tabela 4.3: Métodos de extração de características usados nos experimentos.

\begin{tabular}{|c|c|c|}
\hline $\begin{array}{l}\text { Nome do } \\
\text { Método }\end{array}$ & Descrição & $\begin{array}{l}\text { Número de } \\
\text { Componentes }\end{array}$ \\
\hline FFS & $\begin{array}{l}\text { O extrator FFS Costa et al. 2011 usa oito limiares para } \\
\text { decompor a imagem e extrair a dimensão fractal como ca- } \\
\text { racterística. }\end{array}$ & 8 \\
\hline Gabor & $\begin{array}{l}\text { O extrator Gabor (Manjunath, 1996) é amplamente usado } \\
\text { em diferentes aplicações, os parâmetros usados foram } 6 \\
\text { orientações e } 4 \text { escalas, gerando } 6^{*} 4 \text { filtros. A média e o } \\
\text { desvio padrão são calculados por cada filtro do Banco de } \\
\text { Filtros de Gabor. }\end{array}$ & 48 \\
\hline Haralick & $\begin{array}{l}\text { O extrator Haralick (Haralick et al. } 1973 \text { ) extrai caracte- } \\
\text { rísticas de textura como autocorrelação, brilho, contraste, } \\
\text { entropia, homogeneidade, entre outros das matrizes de } \\
\text { co-ocorrência. Nos experimentos foram usadas } 22 \text { carac- } \\
\text { terísticas. }\end{array}$ & 22 \\
\hline Histogramas & $\begin{array}{l}\text { O histograma (Swain and Ballard, 1991) de } 255 \text { valores foi } \\
\text { re-quantizado a } 17 \text { bins. }\end{array}$ & 17 \\
\hline$k$-Gabor & $\begin{array}{l}\text { O extrator } k \text {-Gabor (Humpire et al. } 2012 \mathrm{~b} \text { ), tem como } \\
\text { parâmetro o valor } k \text { que representa o número de clusters } \\
\text { que requere-se. Assim, a dimensionalidade do vetor de ca- } \\
\text { racterísticas é } k \text { vezes as características de Gabor. }\end{array}$ & $k^{*} 48$ \\
\hline
\end{tabular}

Adicionalmente, o método de mineração de regras StarMiner foi utilizado como método de seleção de características. Assim, o StarMiner precisa dos seguintes valores dos parâmetros que foram achados empiricamente: $\Delta \mu_{f_{i}}=0.22, \sigma_{\max }=0.1, Z_{1}=-4.7172$ e $Z_{2}=10.6232$ para todas as bases de imagens. Estes valores foram encontrados experimentalmente. Para avaliar nossa abordagem, usamos os gráficos de Precisão e Revocação $(P \& R)$. Os valores de Precisão 
e Revocação estão definidos a seguir:

$$
\begin{aligned}
\text { Precisão } & =\frac{\text { O número de imagens relevantes recuperadas }}{\text { O número de imagens recuperadas }} \\
\text { Revocação } & =\frac{\text { O número de imagens relevantes recuperadas }}{\text { O número de imagens relevantes na base }}
\end{aligned}
$$

Uma regra de ouro para entender os gráficos de $P \& R$ é a seguinte: quão mais próxima for a curva da parte superior do gráfico, melhor é o desempenho de recuperação do método. Para a comparação dos resultados obtidos usamos as consultas $k \mathrm{NN}$ para todas as bases de imagens, onde cada imagem foi usada como centro de consulta usando a função de distância Euclidiana. Uma imagem é considerada relevante quando sua classe é a mesma classe da imagem de consulta. As curvas de Precisão e Revocação foram construídas pela média das curvas resultantes de cada consulta.

\subsubsection{Experimento \#1: Base de Imagens 944-Body}

Este experimento usou a base de imagens fornecida pelo Hospital das Clinicas de Ribeirão Preto da Universidade de São Paulo. Esta base contém 944 imagens divididas em seis classes que descrevem regiões do corpo como abdômen coronal, angiografia, cabeça axial, cabeça coronal, cabeça sagital e coluna vertebral com 23, 36, 200, 236, 293 e 155 imagens respectivamente. Algumas amostras são ilustradas na Figura 4.6. Como parte da configuração dos extratores, o extrator $k$-Gabor usou o parâmetro $k$ com valor $k=2$ para esta base de imagens, sendo que o vetor de características do $k$-Gabor gerou $96(2 * 48)$ características. Assim, a dimensionalidade do vetor de características $J_{f v}$ (entrada para os métodos de seleção de características) é 191 (a soma dos elementos da tabela 4.3.
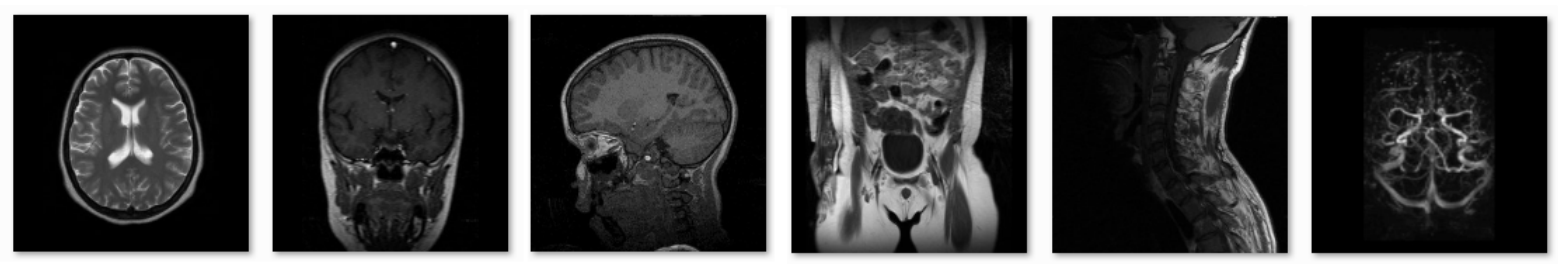

Figura 4.6: Amostras da base de imagens médicas 944-Body.

A Figura 4.7 mostra o processo de "Análise de relevância de subconjuntos" para os métodos de seleção de características Fisher, T-test, $X^{2}$, IG, gramSchmidt e o FSCoMS, onde a faixa de valores do eixo "Relevância do Subconjunto" foi alterada de 0.0 por 0.7 para permitir uma melhor visualização dos dados. Esta análise representa a proporcionalidade entre a quantidade de características no subconjunto $S_{i}$ e seu respectivo valor de relevância obtido usando 
a Equação 4.6. Assim, esta análise identifica o subconjunto com o maior valor de relevância e com propriedades apropriadas de recuperação de imagens para esta base de imagens. Portanto, a Figura 4.7 apresenta os subconjuntos $S_{102}, S_{176}, S_{145}, S_{127}, S_{162}$, e $S_{86}$ como os que obtiveram os maiores valores de relevância para os métodos Fisher, T-test, $X^{2}$, IG, gramSchmidt e FSCoMS respectivamente. Isso significa que o subconjunto $S_{86}$ contém apenas 86 características, ou seja, $S_{86}=\left\{f_{1}, f_{2}, \ldots, f_{86}\right\}$, onde a característica $f_{a}$ é mais relevante do que a característica $f_{a+1}$. Além disso, os métodos que não precisam da análise da dimensionalidade,

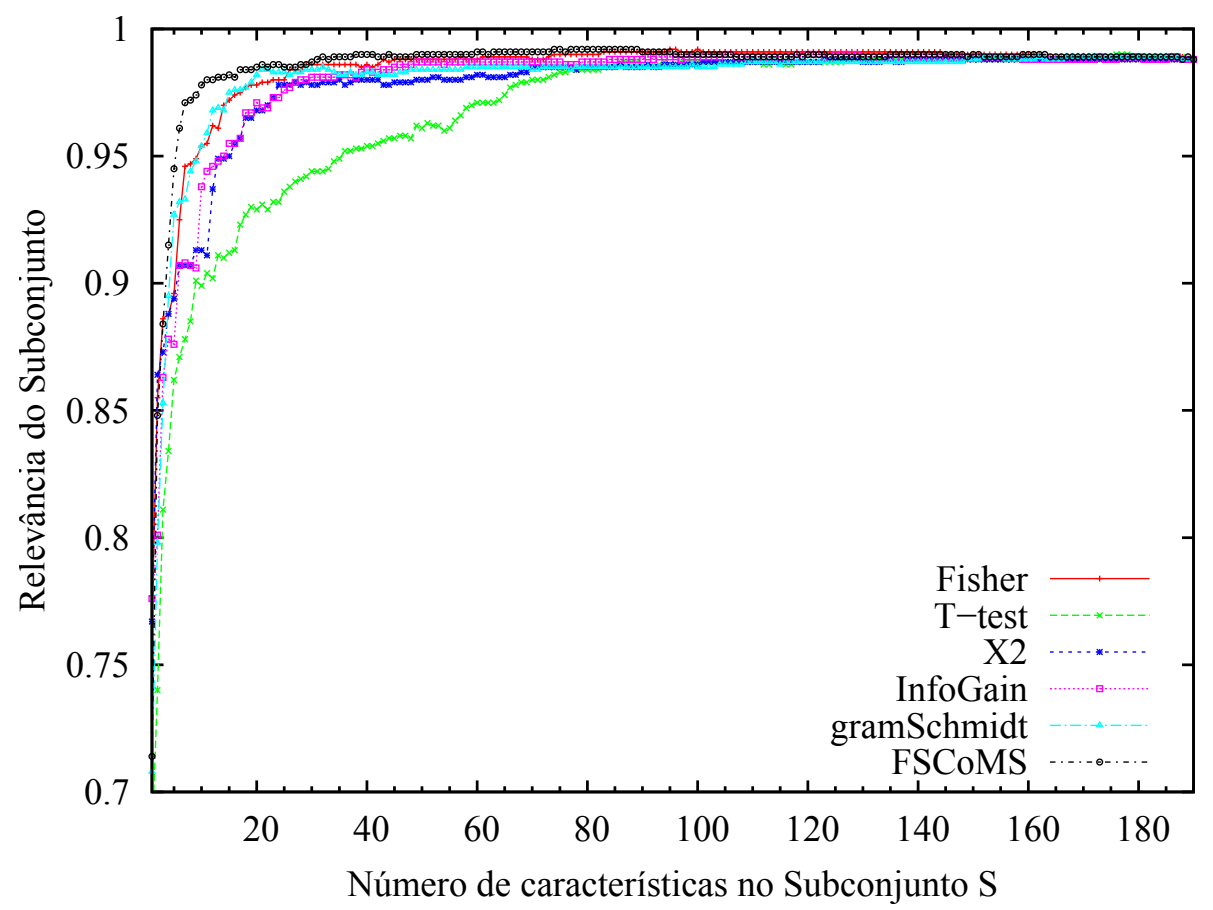

Figura 4.7: Análise de relevância de subconjuntos para a base de imagens 944Body. Os subconjuntos com o maior valor de relevância para os métodos Fisher, T-test, $X^{2}$, IG, gramSchmidt e FSCoMS possuem dimensionalidades 102, 176, 145, 127, 162, e 86 respectivamente.

como o CFS, FCBF e o StarMiner, obtiveram subconjuntos com dimensionalidades de 39, 22 e 113 respectivamente. Por fim, a Figura 4.8 ilustra o gráfico de Precisão e Revocação, comparando o desempenho de recuperação de todos os métodos de seleção de características com as dimensionalidades encontradas na Figura 4.7. No entanto, a Figura 4.8 apresenta a faixa alterada do eixo "Precisão" de 0.0 por 0.86 para permitir uma melhor visualização dos dados. Assim, o valor de recuperação do $J_{f v}$ é representado pelo método 'Original' (linha cinza com sinais ' $\boldsymbol{\Delta}$ '). Por outro lado, o FSCoMS (linha preta com sinais ' $\triangle$ ') mantém a superioridade até o valor 0.70 de revocação onde o CFS (linha vermelha com sinais '+') torna-se melhor. Por outro lado, o método Fisher (linha azul com sinais ' $*$ ') obtém resultados bem próximos ao FSCoMS e o CFS. No entanto, o CFS com apenas 39 características consegue ser um dos me- 


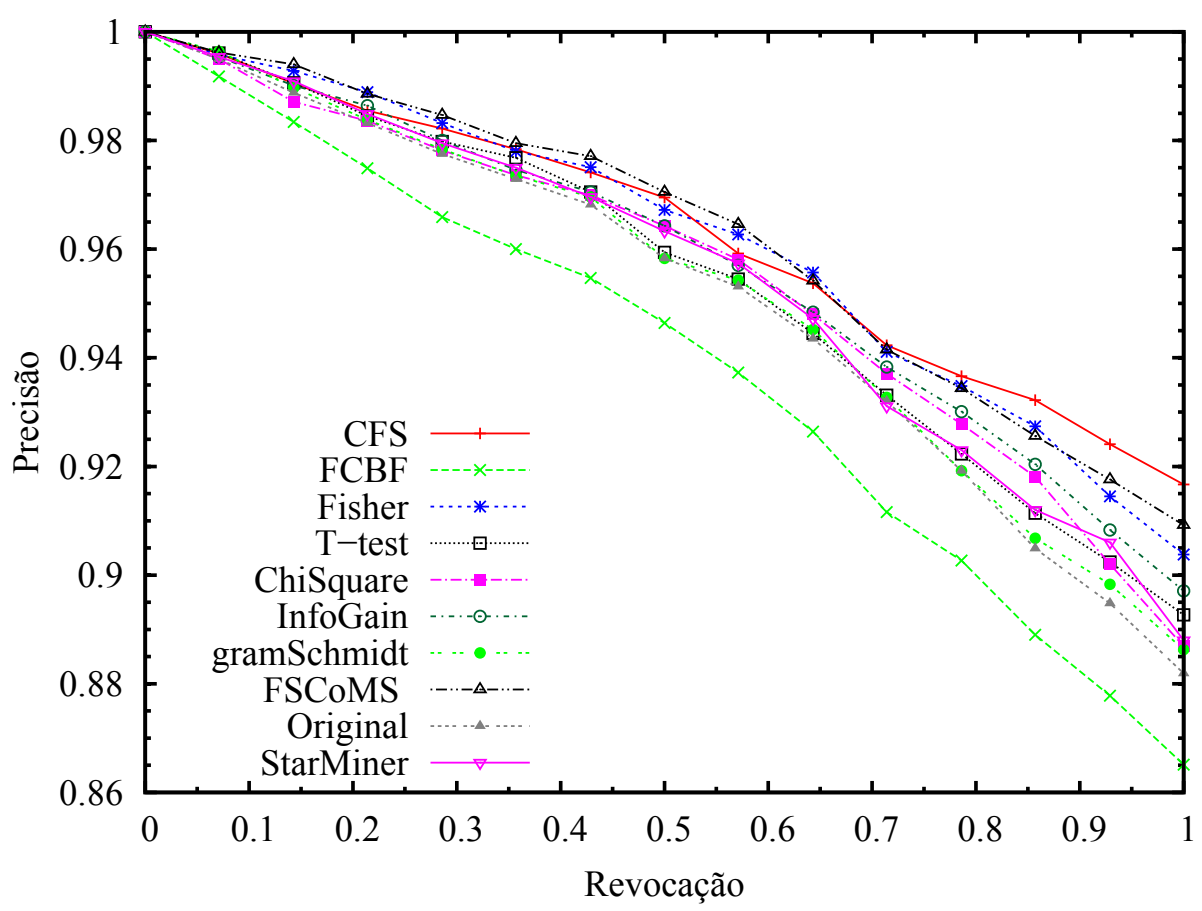

Figura 4.8: Gráfico P\&R para a base de imagens 944Body e consultas $k \mathrm{NN}$ com as $k=15$ imagens mais relevantes. O método FSCoMS (linha preta com sinais ' $\triangle$ ') obtém o melhor desempenho em recuperação de imagens para esta base. Apenas a partir do valor 0.7 de revocação que o CFS (linha vermelha com sinais ' + ') torna-se melhor do que o FSCoMS.

lhores métodos neste experimento, enquanto o FSCoMS com apenas 86 características obtém os melhores resultados de recuperação até quase o final das consultas por similaridade. Assim, o Fisher com 102 características consegue ficar próximo ao CFS e o FSCoMS. Por consequência, o FSCoMS com apenas $45 \%$ das características (86 das 191 características) obtém os melhores resultados de recuperação de imagens. Os outros métodos, gramSchmidt IG, StarMiner, T-test, e $X^{2}$ obtêm resultados similares, mas menores do que o FSCoMS. No entanto, o FCBF com apenas 22 características obteve os menores resultados de recuperação. Por outro lado, o vetor de características 'Original' é melhor apenas do que o FCBF mas com diferença de 191 e 22 características respectivamente. Mesmo assim, o vetor de características 'Original' apresenta no começo, em relação aos outros métodos, uma pequena diferença. Isto significa que os métodos de seleção de características estão satisfazendo a condição de melhorar a performance em desempenho de recuperação (precisão) do vetor de características $J_{f v}$. É importante lembrar que o FSCoMS usa apenas o $45 \%$ das características e ainda obtém um melhor desempenho do que os métodos convencionais (ver Figura 4.8). Assim, o método proposto é capaz de selecionar características que são pelo menos tão boas como os competidores, enquanto fornece um conjunto menor de características selecionadas do que os outros métodos. 


\subsubsection{Experimento \#2: Base de Imagens Lung CT ROIs}

Neste experimento foi usada a base de imagens Lung CT ROIs que contém tomografias computarizadas (CT) de pulmão e foi fornecida pelo Hospital das Clinicas de Ribeirão Preto da Universidade de São Paulo. Esta base contém seis classes, uma do pulmão normal (sem doenças) e cinco casos clínicos com anormalidades no pulmão como: consolidação, enfisema, espessamento, favo de mel e vidro fosco. A base de imagens contém 3258 imagens, em que cada imagem contém uma ROI de 64x64 pixels. Assim, algumas amostras são apresentadas na Figura 4.9. Como parte da configuração dos extratores, o extrator $k$-Gabor usou o parâmetro $k$ com valor $k=3$ para esta base de imagens, sendo que o vetor de características do $k$-Gabor gerou $144(3 * 48)$ características. Assim, a dimensionalidade para o vetor de características $J_{f v}$ é 239 (a soma dos elementos da tabela 4.3).
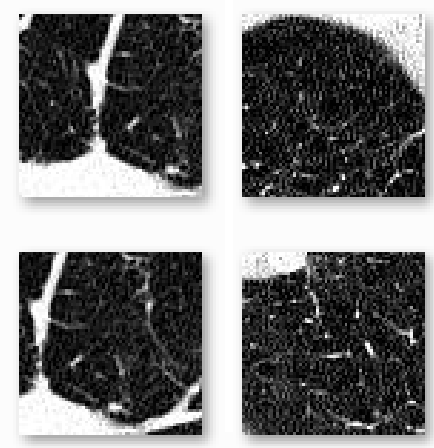
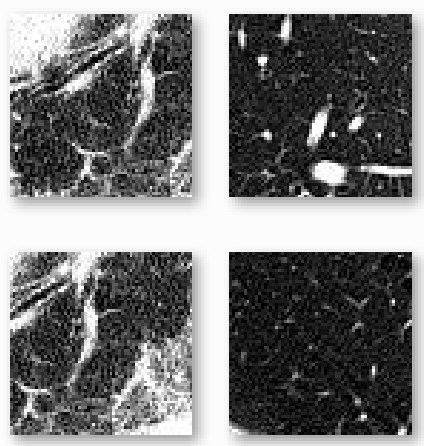
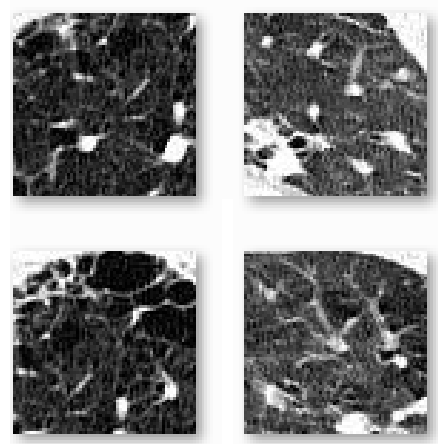

Figura 4.9: Amostras da base de imagens Lung CT ROIs com seis classes com diferentes doenças do pulmão humano.

A Figura 4.10 mostra a "análise de relevância de subconjuntos" dos métodos de seleção de características Fisher, T-test, $X^{2}$, IG, gramSchmidt e o FSCoMS com os subconjuntos mais relevantes $S_{153}, S_{97}, S_{127}, S_{125}, S_{226}$, e $S_{77}$ respectivamente. Onde, a faixa de valores do eixo "Relevância do Subconjunto" foi alterada de 0.0 por 0.6 para permitir uma melhor visualização dos dados. Além disso, os métodos que não precisam da análise da dimensionalidade como o CFS, FCBF e StarMiner obtiveram subconjuntos com dimensionalidades de 44, 6 e 67 respectivamente. Por fim, a Figura 4.11 ilustra o gráfico de Precisão e Revocação, comparando o desempenho de recuperação de todos os métodos de seleção de características com as dimensionalidades encontradas na Figura 4.10. No entanto, a Figura 4.11 apresenta a faixa alterada do eixo "Precisão" de 0.0 por 0.5 para ter uma melhor visualização dos dados. Lembre-se que o valor de recuperação do $J_{f v}$ é representado pelo método 'Original' (linha cinza com sinais ' $\Delta$ ') para tê-lo como ponto de referência. Assim, o gráfico de $P \& R$ representa o método FSCoMS (linha preta com sinais ' $\triangle$ ') com o seu maior desempenho. Esse desempenho torna-se ainda 
maior na parte final do gráfico (subconjuntos com maior número de características), apenas do valor 0.9 de revocação em diante que o CFS (linha vermelha com sinais '+') torna-se melhor.

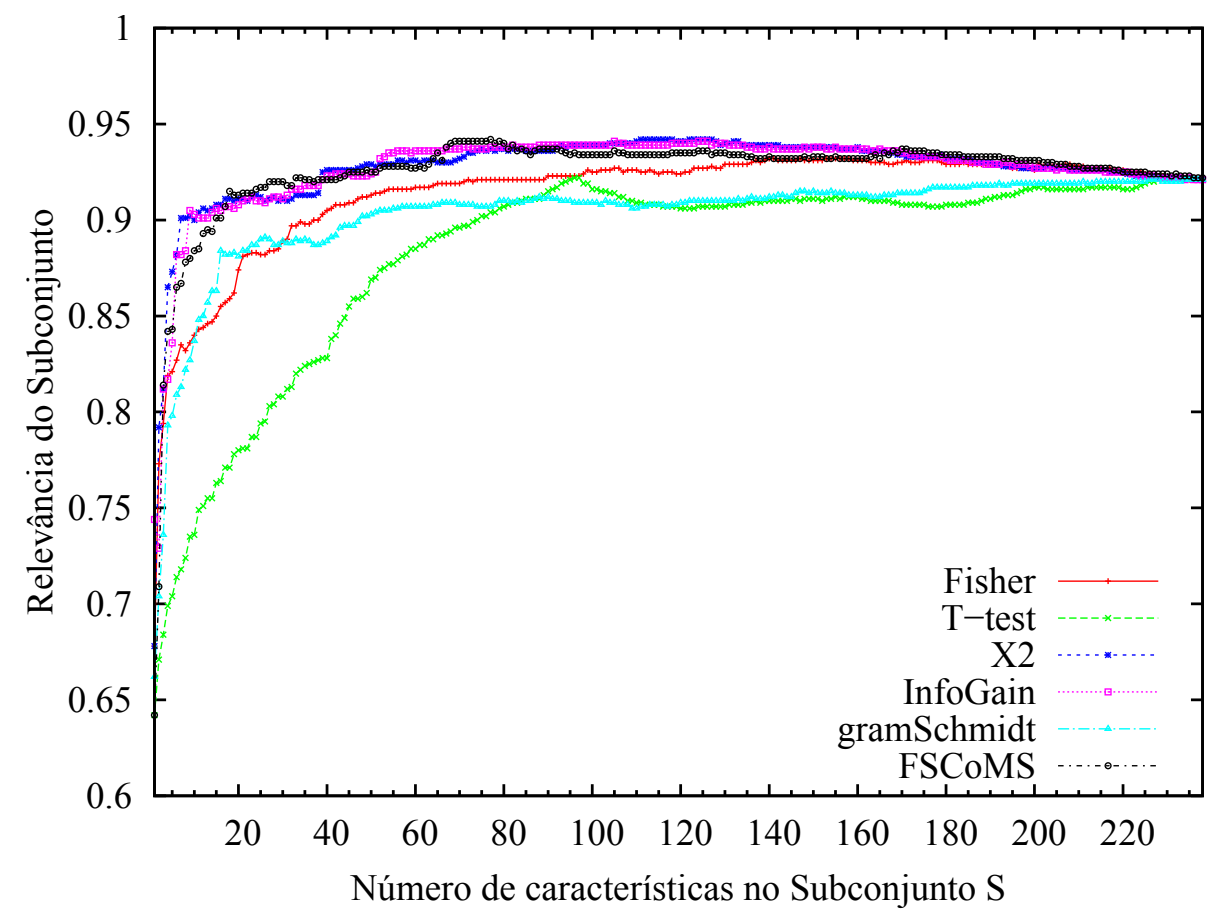

Figura 4.10: Análise de relevância de subconjuntos para a base de imagens Lung CT ROIs. Os subconjuntos com o maior valor de relevância para os métodos Fisher, T-test, $X^{2}$, IG, gramSchmidt e o FSCoMS possuem dimensionalidades 153, 97, 127, 125, 226, e 77 respectivamente.

Enquanto os métodos Information Gain (linha verde com sinais 'o') e chi-squared (linha rosa com sinais ' $\boldsymbol{\square}$ ') obtiveram resultados similares ao FSCoMS e CFS. No entando, o CFS com apenas 44 características consegue ser um dos melhores métodos de seleção neste experimento, enquanto o FSCoMS com apenas 77 características obtém em boa parte os melhores resultados de recuperação até quase o final das consultas por similaridade. Assim, os métodos Chi-squared e Information Gain, com 127 e 125 respectivamente, conseguem ficar próximos ao CFS e o FSCoMS. Por consequência, o FSCoMS com apenas o $32.21 \%$ das características (77 das 239 características) obtém os melhores resultados de recuperação de imagens. Os seguintes métodos de seleção de características Fisher, T-test, gramSchmidt, e StarMiner obtêm valores de desempenho em recuperação similares, sendo que o FCBF obtém novamente os menores resultados de recuperação de imagens. Por outro lado, o vetor de características 'Original' é melhor apenas do que o método FCBF, mas com a diferença de ter 239 e 6 características respectivamente. Além disso, o método 'Original' até o valor 0.15 de revocação é ligeiramente melhor do que o StarMiner. Isto significa que os métodos de seleção de características estão 
satisfazendo a condição de melhorar o desempenho de recuperação (precisão) do vetor de características $J_{f v}$. É importante lembrar que o FSCoMS usa apenas o $31.21 \%$ de características e ainda obtém um melhor desempenho do que os métodos de seleção de características convencionais (ver Figura 4.11). Assim, o método proposto é capaz de selecionar características que são pelo menos tão boas como os competidores, enquanto fornece um conjunto menor de características selecionadas do que os outros métodos.

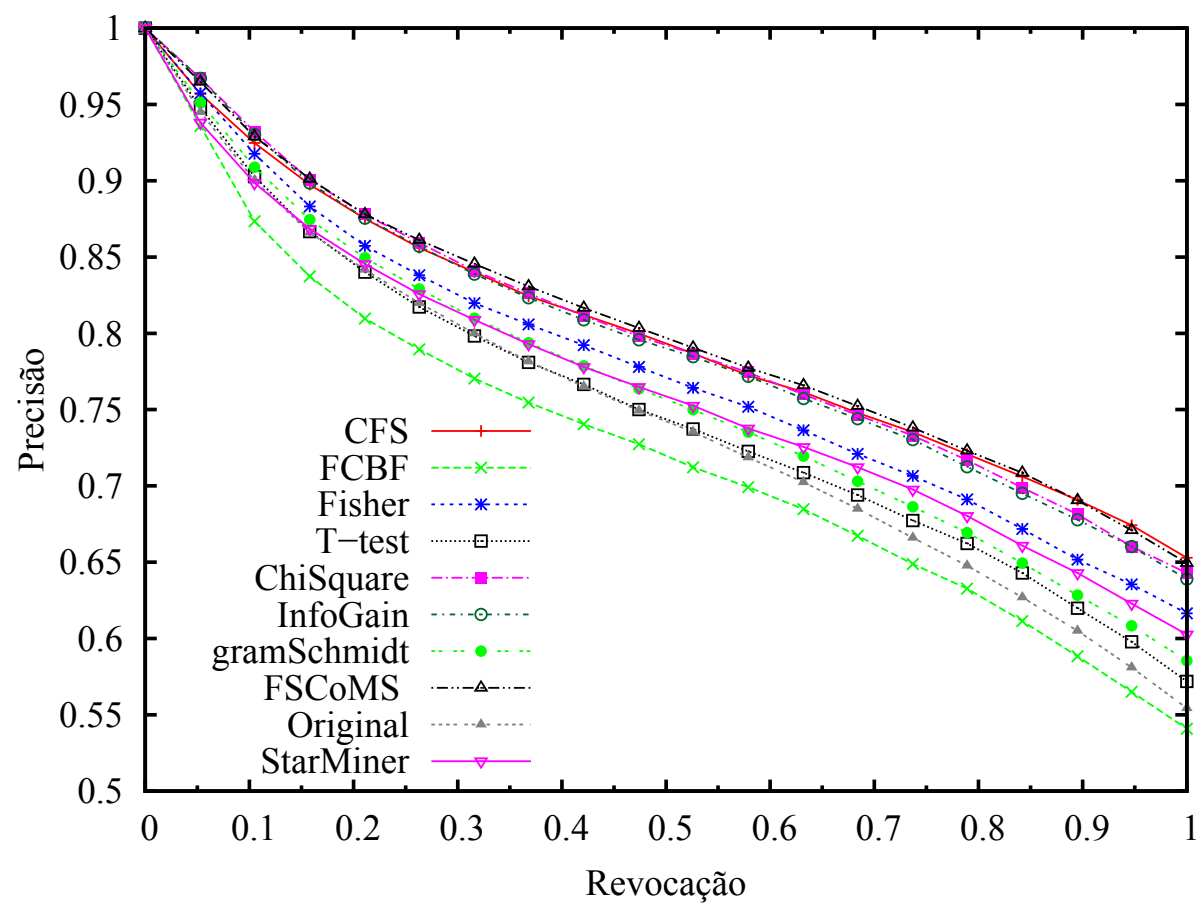

Figura 4.11: Gráfico de P\&R obtido da base de imagens Lung CT ROIs considerando $k=20$ para as consultas $k \mathrm{NN}$. O FSCoMS (linha preta com sinais ' $\triangle$ ') é o melhor método com uma ampla diferença em relação aos outros métodos a partir do valor 0.265 de revocação.

\subsubsection{Experimento \#3: Base de Imagens DDSM}

Esta base de imagens Digital Database for Screening Mammography (DDSM) contém 250 ROIs de mamografias e foram capturadas pela University of South Carolina (disponível no site http://marathon.csee.usf.edu/Mammography). Esta base de imagens tem duas classes: massas benignas e malignas com 99 e 151 imagens respectivamente. Amostras da base de imagens $D D S M$ são ilustradas na Figura 4.12. Como parte da configuração dos extratores, o extrator de características $k$-Gabor usou o parâmetro $k=10$ para esta base de imagens, sendo que o vetor de características do $k$-Gabor gerou $480(10 * 48)$ características. Assim, a dimensionalidade 

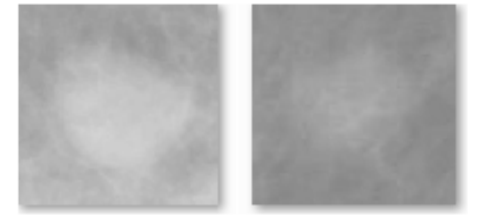

(a) Benigno
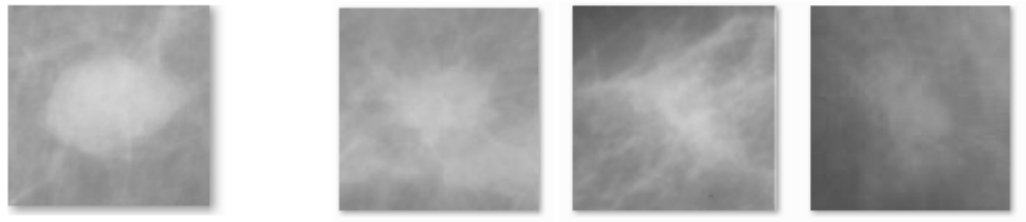

(b) Maligno

Figura 4.12: Amostras da base de imagens "DDSM" apresentam as duas classes: (a) benigno com 99 imagens e (b) a classe malignas com 151 imagens.

do vetor de características $J_{f v}$ (entrada para os métodos de seleção de características) é 575 (a soma dos elementos da tabela 4.37.

A Figura 4.13 mostra a análise de relevância de subconjuntos para os métodos Fisher, T-test, $X^{2}$, IG, gramSchmidt e o FSCoMS com os subconjuntos mais relevantes $S_{444}, S_{565}, S_{471}, S_{481}$, $S_{569}$, e $S_{482}$ respectivamente. Onde, a faixa de valores do eixo "Relevância do Subconjunto" foi alterada de 0.0 por 0.78 para ter uma melhor visualização dos dados. Além disso, os métodos que não precisam da análise da dimensionalidade como o CFS, FCBF e StarMiner obtiveram subconjuntos com dimensionalidades de 31,8 e 173 respectivamente.

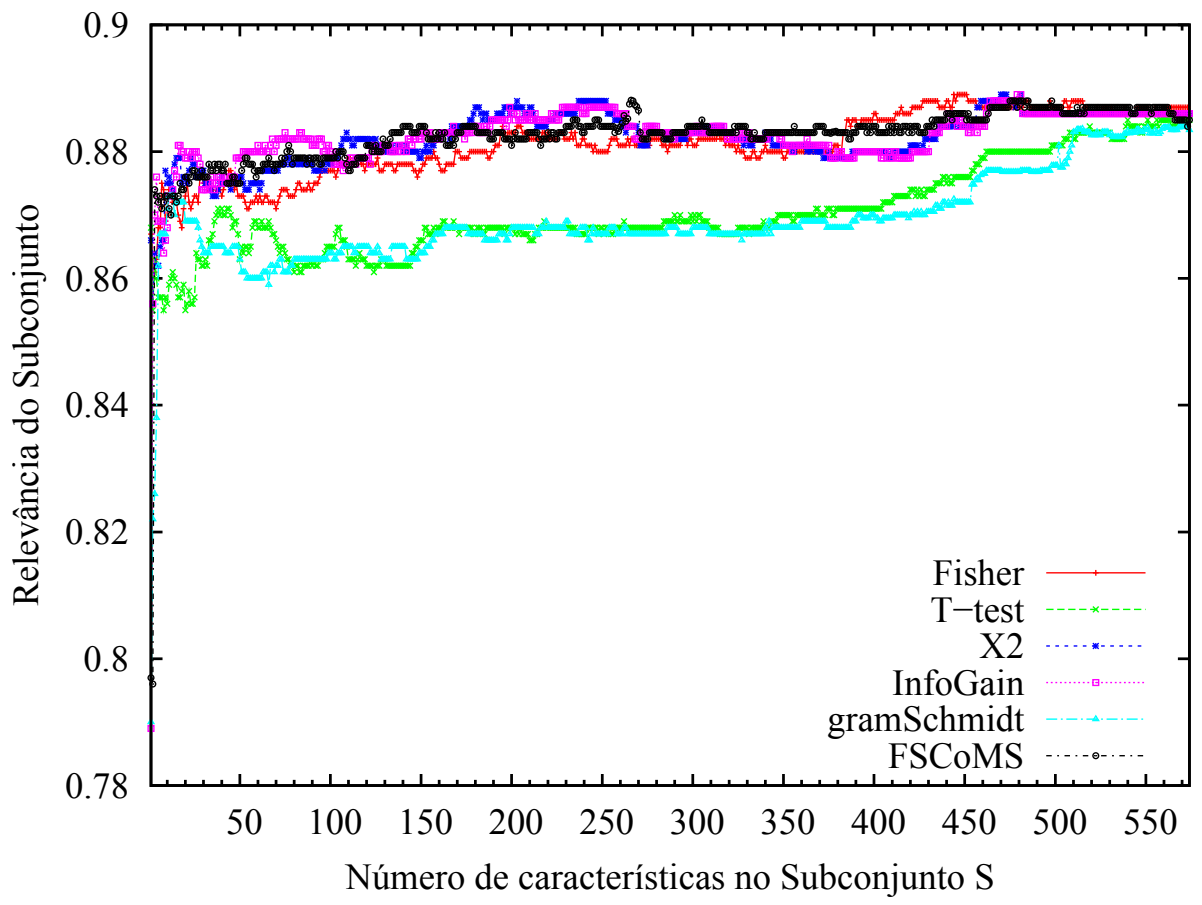

Figura 4.13: Análise de relevância de subconjuntos para a base de imagens DDSM. Os subconjuntos com o maior valor de relevância para os métodos Fisher, T-test, $X^{2}$, IG, gramSchmidt e o FSCoMS possuem dimensionalidades 444, 565, 471, 481, 569 e 482 respectivamente. 
Por fim, a Figura 4.14 ilustra o gráfico de Precisão e Revocação, comparando o desempenho de recuperação de todos os métodos de seleção de características com as dimensionalidades encontradas na Figura 4.13. No entanto, a Figura 4.14 apresenta a faixa alterada do eixo "Precisão" de 0.0 por 0.65 para ter uma melhor visualização dos dados. Lembre-se que

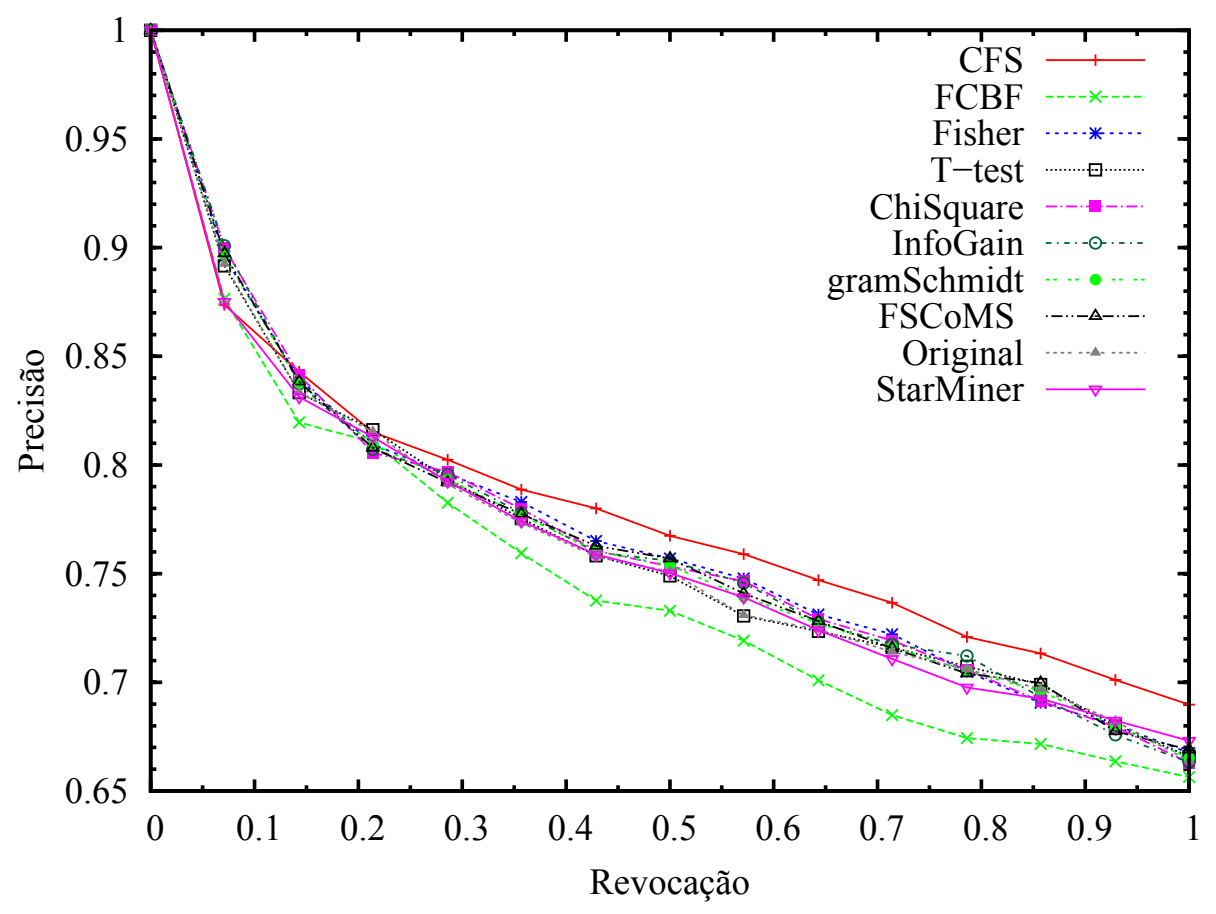

Figura 4.14: Gráfico de P\&R obtido da base de imagens $D D S M$ considerando $k=15$ para as consultas $k$ NN. O FSCoMS (linha preta com sinais ' $\triangle$ ') nesta base de imagens não obteve os melhores resultados a comparação dos outros métodos. No entanto, o CFS ressalta com uma ampla diferença a partir do valor 0.13 de revocação.

o valor de recuperação do $J_{f v}$ é representado pelo método 'Original' (linha cinza com sinais ' $\boldsymbol{\Delta}$ ') para tê-lo como ponto de referência. Assim, o gráfico $P \& R$ apresenta ao método CFS (linha vermelha com sinais ' + ') com os melhores resultados de recuperação de imagens. No entanto, neste experimento, o método FSCoMS (linha preta com sinais ' $\triangle$ ') não obteve os mesmos resultados como as outras bases de imagens, mas ficou com um comportamento similar aos métodos Chi-squared, Fisher, gramSchmidt, InfoGain, StarMiner e T-test. Assim, o método FCBF obteve o menor desempenho em recuperação das imagens neste experimento.

No entanto, o CFS com apenas 31 características tornou-se a partir do valor 0.13 de revocação como o melhor método de seleção de características. Assim, o FCBF obteve apenas 8 características, mas no gráfico de precisão e revocação (ver Figura 4.14) obteve o menor desempenho. Por outro lado, o método StarMiner com apenas 173 características é comparável com os outros métodos que obtiveram dimensionalidades de entre 444 e 481 características. Neste experimento, o método FSCoMS obteve 482 características. 


\subsubsection{Experimento \#4: Base de Imagens IRMA}

A base de imagens Image Retrieval for Medical Applications (IRMA) é de domínio público e foi obtida do site www.irma-project.org. Esta base de imagens foi obtida pelo projeto RWTH Aachen University (Lehmann and Thies, 2003). Esta base de imagens contém 12,069 imagens divididas em oito classes descrevendo diferentes partes do corpo: abdômen, braço, peito, cranio, perna, mama, pélvis e espinha dorsal. Algumas amostras são ilustradas na Figura 4.15. Como parte da configuração dos extratores, o extrator $k$-Gabor usou o parâmetro $k$ com valor $k=3$ para esta base de imagens, sendo que o vetor de características do $k$-Gabor gerou $144(3 * 48)$ características. Assim, a dimensionalidade do vetor de características $J_{f v}$ (entrada para os métodos de seleção de características) é 239 (a soma dos elementos da tabela 4.3).

A Figura 4.16 ilustra a análise de relevância de subconjuntos para os métodos Fisher, T-test, $X^{2}$, IG, gramSchmidt e o FSCoMS com os subconjuntos mais relevantes $S_{210}, S_{238}, S_{238}, S_{237}$, $S_{231}$, e $S_{159}$ respectivamente. Onde, a faixa de valores do eixo "Relevância do Subconjunto" foi alterada de 0.0 por 0.65 para ter uma melhor visualização dos dados.

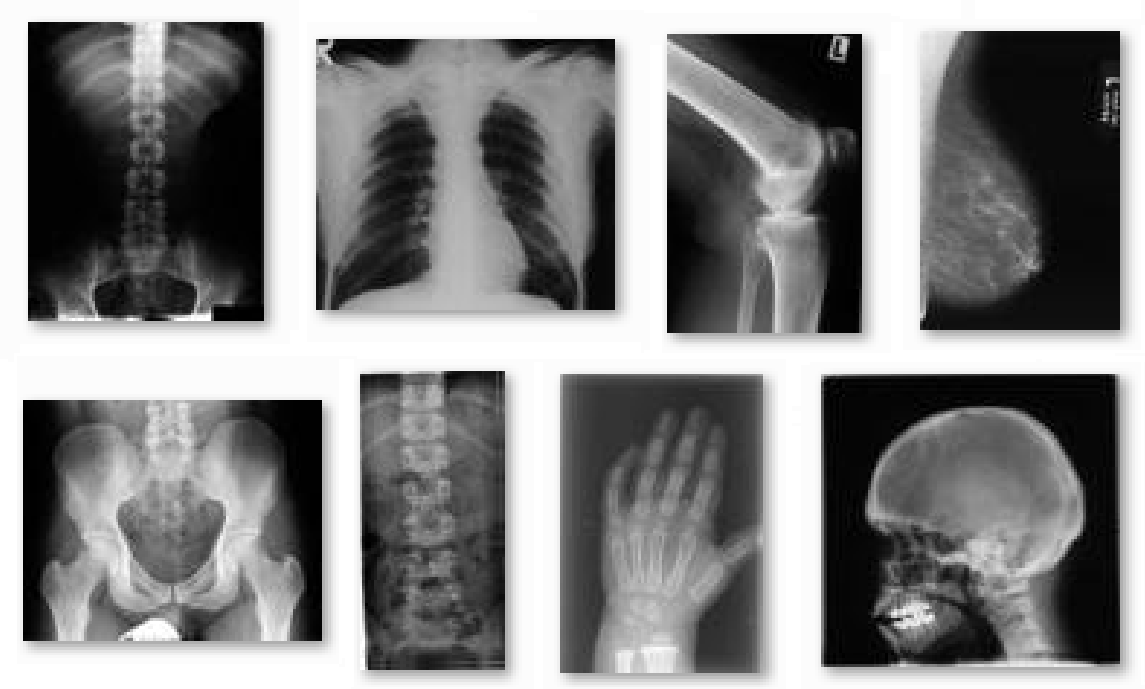

Figura 4.15: Amostras da base de imagens IRMA com oito classes (partes) diferentes do corpo humano.

Além disso, os métodos que não precisam da análise da dimensionalidade como o CFS, FCBF e StarMiner obtiveram subconjuntos com dimensionalidades de 54, 16 e 22 respectivamente. Por fim, a Figura 4.17 mostra o gráfico de Precisão e Revocação, comparando o desempenho de recuperação de todos os métodos de seleção de características com as dimensionalidades encontradas na Figura 4.16. No entanto, a Figura 4.17 apresenta a faixa alterada do eixo "Precisão" de 0.0 por 0.75 para ter uma melhor visualização dos dados. Lembre-se que 


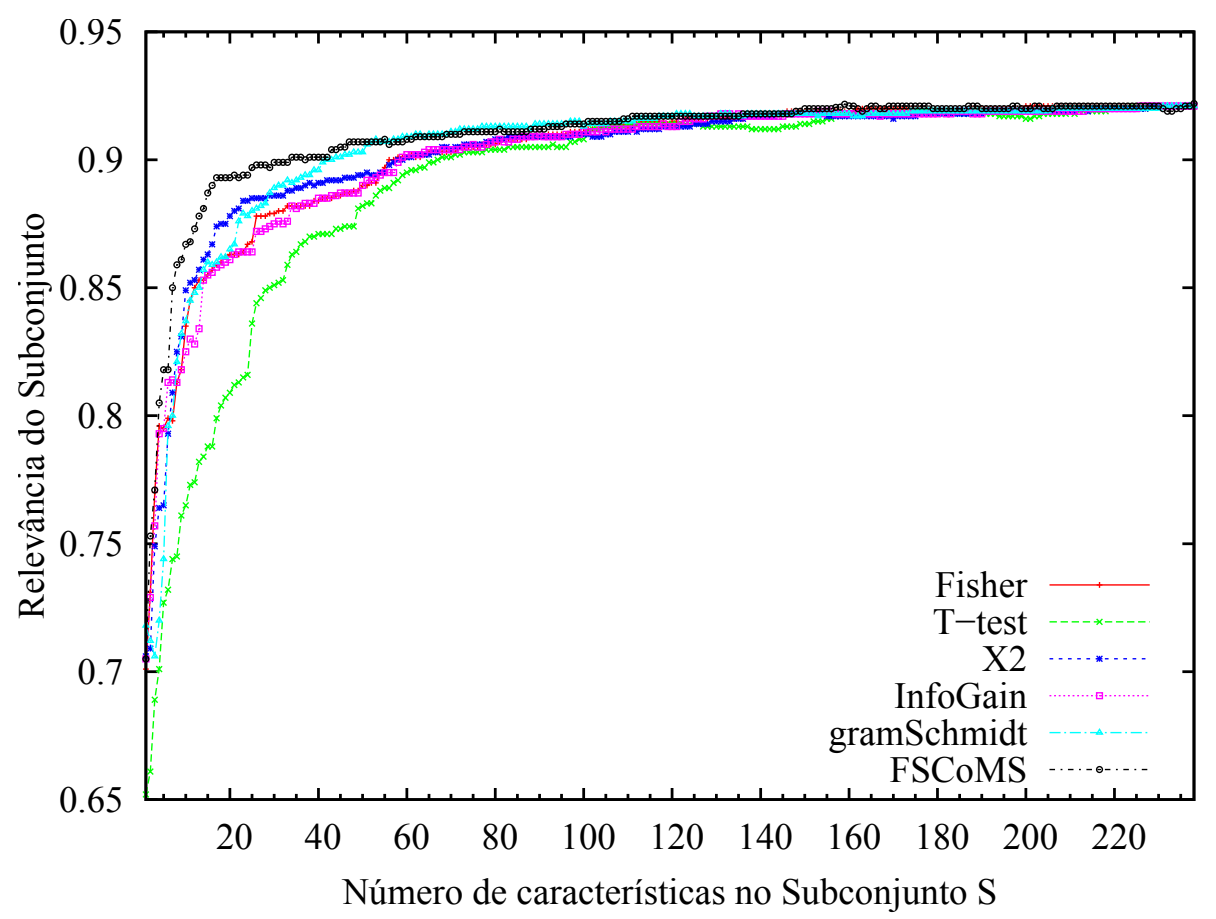

Figura 4.16: Análise de relevância de subconjuntos para a base IRMA. Os subconjuntos com o maior valor de relevância para os métodos Fisher, T-test, $X^{2}$, IG, gramSchmidt e o FSCoMS possuem dimensionalidades 210, 238, 238, 237, 231 e 159 respectivamente.

o valor de recuperação do $J_{f v}$ é representado pelo método 'Original' (linha cinza com sinais ' $\boldsymbol{\Delta}$ ') para tê-lo como ponto de referência. Assim, o gráfico P\&R mostra os métodos FSCoMS, gramSchmidt, Fisher, Chi-squared, T-test e IG bem próximos. Sendo que o FSCoMS é ligeiramente melhor do que os outros métodos. No entanto, o método FSCoMS consegue melhorar um pouco os resultados de recuperação com apenas 159 características, enquanto os outros métodos como gramSchmidt, Fisher, Chi-squared, T-test e IG obtiveram resultados de recuperação similares ao FSCoMS com 231, 210, 238, 238, e 237 características respetivamente. Ou seja, muitos dos métodos convencionais não conseguiram remover características irrelevantes. Por consequência, o FSCoMS com apenas $66.52 \%$ das características (159 das 239 características) consegue por pouco melhorar os resultados dos outros métodos de seleção de características, e ainda, reduzir a dimensionalidade. Os métodos CFS e StarMiner não obtiveram bons resultados de recuperação, mas ficaram acima do método FCBF. No entanto, é importante ressaltar que esses métodos obtiveram as menores dimensionalidades nos subconjuntos. Assim, o CFS obteve 54 características, o FCBF apenas 16 características e o StarMiner 22 características.

Esta base de imagens tornou-se complexa pela quantidade de imagens (12,069 imagens), por conseguinte, os métodos de seleção não conseguiram melhorar muito no desempenho de 


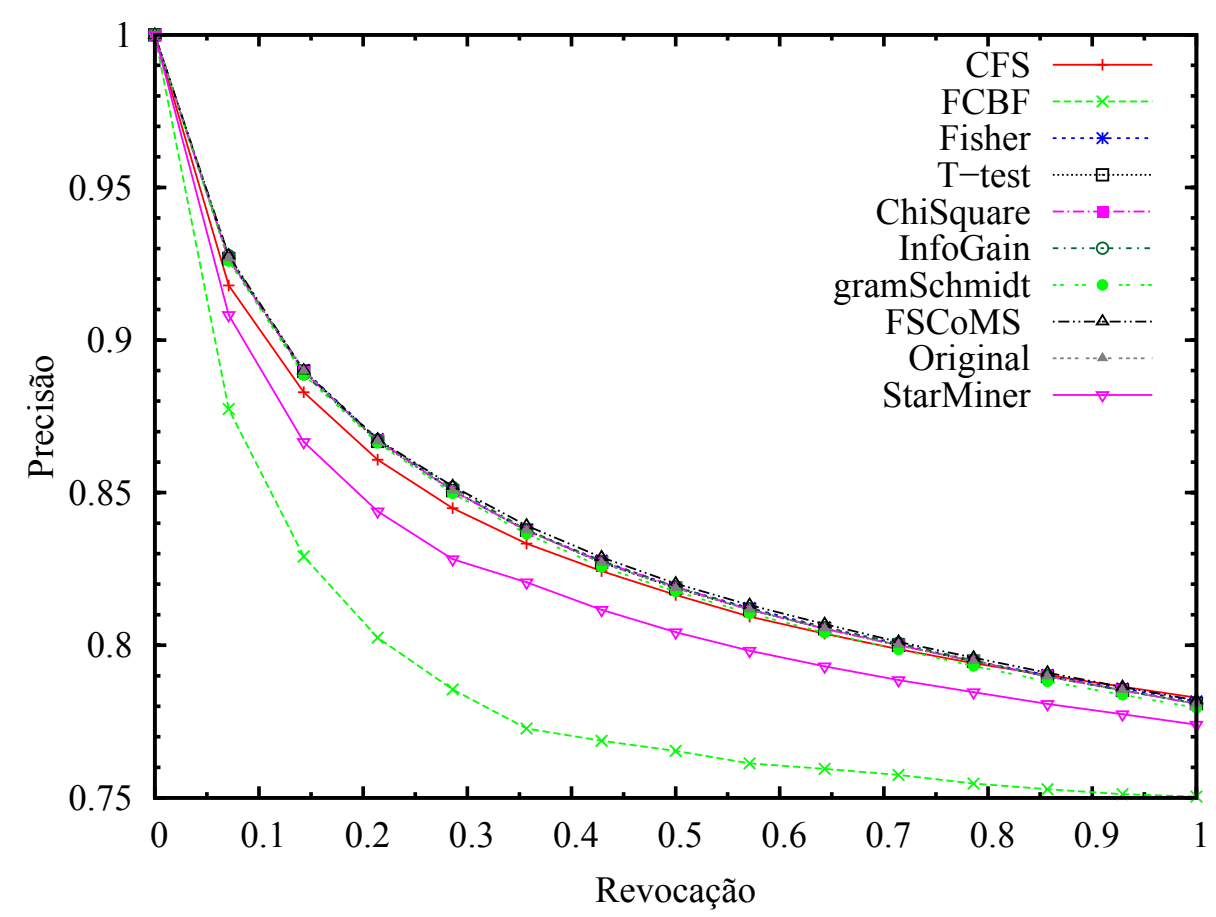

Figura 4.17: Gráfico de P\&R para a base de imagens IRMA e consultas $k \mathrm{NN}$ com $k=15$. O FSCoMS (linha preta com sinais ' $\triangle$ ') obtém o maior valor de precisão para esta base de imagens.

recuperação de imagens (ver Figura 4.17). Apenas o método FSCoMS que reduziu de 239 a 159 (redução de $33.47 \%$ ), e ainda conseguiu melhorar um pouco o desempenho.

\subsection{Considerações Finais}

Neste Capítulo foram usadas quatro bases de imagens médicas do mundo real, cada uma delas com complexidades diferentes segundo o objetivo de detecção de doenças. No entanto, a discussão dos resultados foi feita considerando cada base de imagens em cada experimento.

Assim, nesta Seção serão apresentadas as conclusões gerais dos experimentos. Além disso, serão apresentados os diagramas radar para discutir os resultados de relevância por proporcionalidade do vetor de características do $k$-Gabor em cada um dos métodos de seleção. Por outro lado, a Tabela 4.4 sumariza a informação obtida pelos experimentos mostrando as dimensionalidades obtidas por cada método nas quatro bases de imagens médicas. Os resultados obtidos pelo método de seleção de características FSCoMS foram os melhores para três das quatro bases de imagens, sendo que para a base de imagens DDSM não foi o melhor, pelo fato de que a classificação de ROIs de mamas demandarem características de forma e não de textura, como foi o enfoque deste trabalho. 
Tabela 4.4: Tabela comparativa de dimensionalidade alcançada por cada método de seleção de características nas quatro bases de imagens avaliadas.

\begin{tabular}{l|c|c|c|c}
\hline & 944Body & Lung CT & DDSM & IRMA \\
\hline Original & 191 & 239 & 575 & 239 \\
CFS & 39 & 44 & 31 & 54 \\
ChiSquared $\left(X^{2}\right)$ & 145 & 127 & 471 & 238 \\
Information Gain & 127 & 125 & 481 & 237 \\
gramSchmidt & 162 & 226 & 569 & 231 \\
FCBF & 22 & 6 & 8 & 16 \\
Fisher & 102 & 153 & 444 & 210 \\
T-test & 176 & 97 & 565 & 238 \\
FSCoMS & $\mathbf{8 6}$ & $\mathbf{7 7}$ & $\mathbf{4 8 2}$ & $\mathbf{1 5 9}$ \\
StarMiner & 113 & 67 & 173 & 22 \\
\hline
\end{tabular}

Para a base de imagens 944Body o método CFS produz o menor número de características, porém, o gráfico P\&R mostrado na Figura 4.8 mostra que o FSCoMS é o melhor em recuperação de imagens, é apenas no final do gráfico que o CFS torna-se melhor do que o FSCoMS. Assim, ambos métodos de seleção (o CFS e o FSCoMS) obtêm uma menor dimensionalidade do que os outros métodos de seleção de características.

Enquanto para a base de images Lung CT, o método CFS ainda é o método com menor número de características, o FSCoMS é o segundo. No entanto, o gráfico de P\&R mostrado na Figura 4.11 ilustra que o FSCoMS é o melhor em recuperação das imagens.

Por outro lado para a base de imagens DDSM, o FCBF é o método com menor dimensionalidade, mas no gráfico $\mathrm{P} \& \mathrm{R}$ mostrado na Figura 4.14 é o método com o menor desempenho. No entanto, para a mesma base DDSM, o método CFS é o melhor em desempenho com apenas 31 características a partir do valor 0.13 de revocação. Além disso, o método FSCoMS não obteve resultados relevantes nesta base de imagens.

Para a base de imagens IRMA, o FSCoMS com apenas 159 características obteve ligeiramente melhores resultados em P\&R (ver Figura 4.17) do que os métodos convencionais. A base de imagens IRMA é complexa pelo número de imagens $(12,069)$, assim, diversos métodos de seleção de características não conseguiram reduzir consideravelmente o número de características como nas outras bases de imagens (ver Tabela 4.4).

Finalmente, são apresentados os gráficos radar para sumarizar os resultados obtidos dos métodos de seleção com respeito à proporcionalidade de características selecionadas de cada extrator. Por exemplo, o vetor de características $F_{\text {vect }}$ (resultado de algum método de seleção de características) foi composto por três vetores de características gerados pelos extratores ' $\mathrm{A}$ ', ' $\mathrm{B}$ ' e 'C'. Assumindo as dimensionalidades dos extratores 'A', 'B' e 'C' com 35, 40 e 25 caracterís- 
ticas respectivamente, teríamos a dimensionalidade do vetor $F_{\text {vect }}$ com valor 100 (pela soma de 35,40 e 25). Portanto, a proporcionalidade do extrator ' $A$ ' no vetor $F_{\text {vect }}$ é de 0.35 (pela divisão de $35 / 100$ ), e para os extratores ' $\mathrm{B}$ ' e 'C' de 0.40 e 0.25 respectivamente.

Assim, os valores $0.35,0.40$ e 0.25 serão plotados em um eixo do diagrama radar para representar a proporcionalidade de composição do vetor de características $F_{\text {vect }}$ obtido pelo método de seleção de características para uma base de imagens em específico. Assim, o diagrama radar neste caso apresenta quatro eixos, cada eixo (linha preta) representa uma das bases de imagens usadas nos experimentos e estão na faixa de valores de 0 a 1 . No entanto, a linha que representa um extrator de características intersecta um eixo para representar a proporcionalidade de características selecionadas de cada extrator. Portanto, aquele método que produz o maior polígono no diagrama é considerado o mais relevante para todas as bases de imagens. As Figuras 4.18, 4.19, 4.20, 4.21 e 4.22 ilustram os diagramas radar para todos os métodos de seleção de características. Como foi visto na Tabela 4.3, o método $k$-Gabor tem o maior número de características do que os outros extratores, mas os diagramas radar ilustram que os métodos de seleção incluíram nos seus resultados em maior parte as características do $k$-Gabor. Isso quer dizer que as características do $k$-Gabor são relevantes e, portanto, devem ser consideradas nos vetores dos métodos de seleção. Como resultado comum para todas as figuras, o $k$-Gabor (linha azul) gerou a maior proporcionalidade de características em todas as bases de imagens e para todos os métodos de seleção de características.

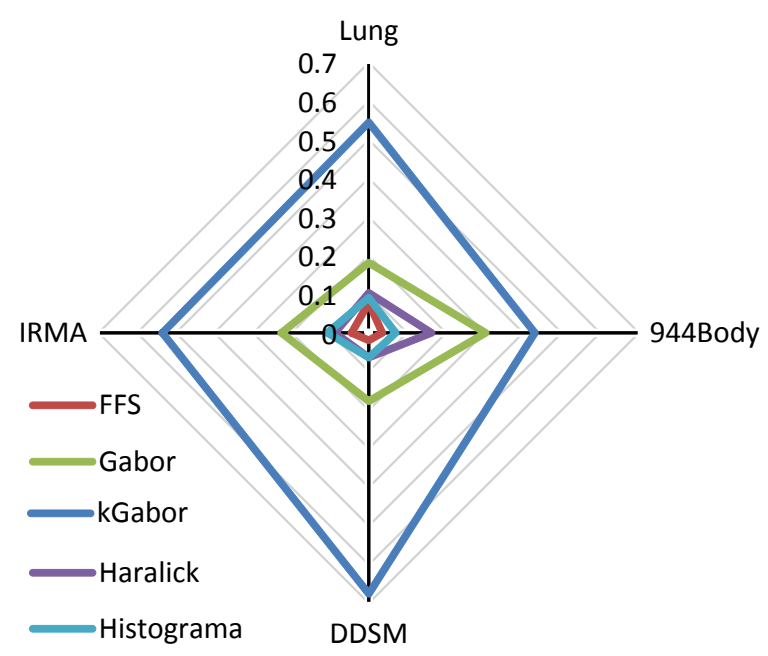

(a) Radar para o FSCoMS

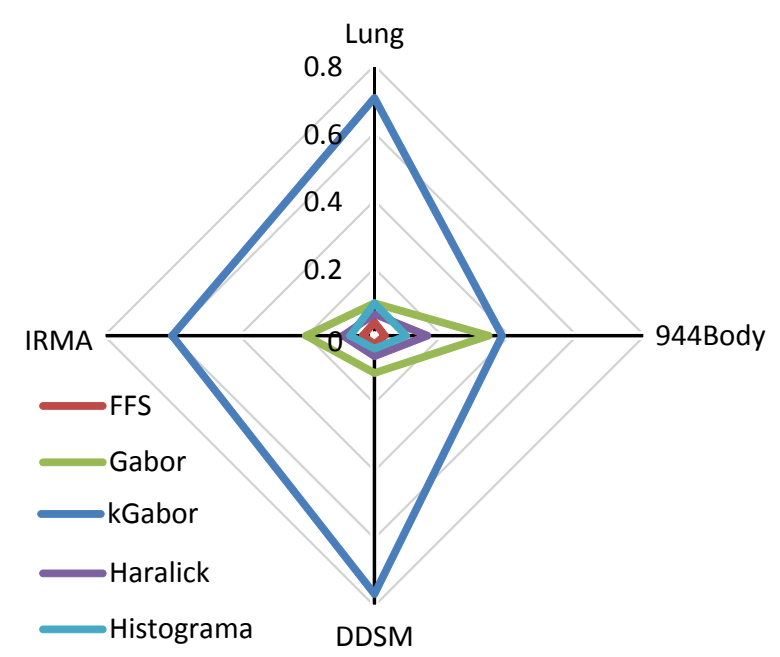

(b) Radar para o Information Gain

Figura 4.18: Diagrama radar do desempenho do FSCoMS e o Information Gain em cada Base de imagens. 
Além disso, o extrator Gabor (linha verde) foi o segundo extrator com maior número de características, foi apenas para o método StarMiner (ver Figura 4.21a) onde para as bases de imagens IRMA e DDSM que não foram selecionadas as características de Gabor. No entanto, o método FCBF (ver Figura 4.22) considerou mais características de Histograma (linha de cor ciano) do que as características de Gabor (linha verde). Enquanto o extrator FFS (linha vermelha) é um dos extratores que tem o menor número de características. No entanto, o método StarMiner considerou poucas características do FFS (ver Figura 4.21a).

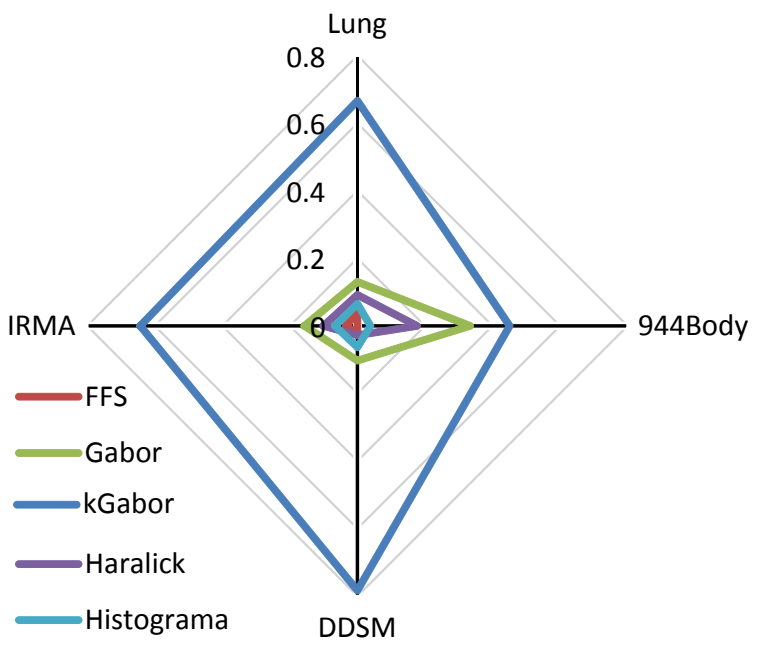

(a) Radar para o Fisher

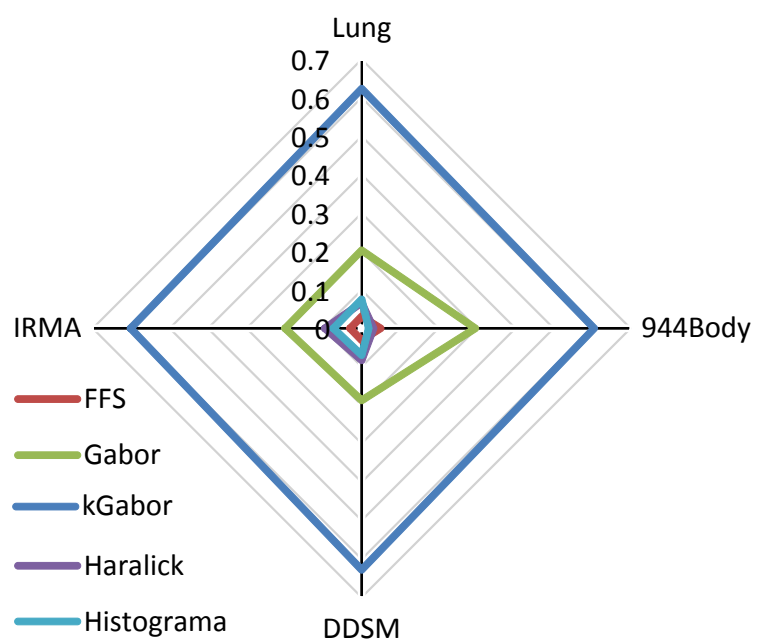

(b) Radar para o gramSchmidt

Figura 4.19: Diagrama radar do desempenho do Fisher e gramSchmidt em cada Base de imagens.

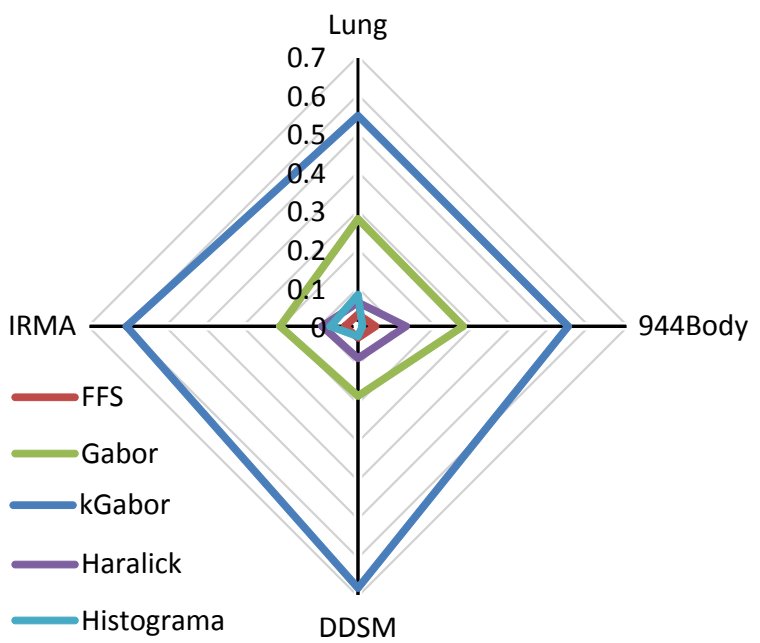

(a) Radar para o T-test

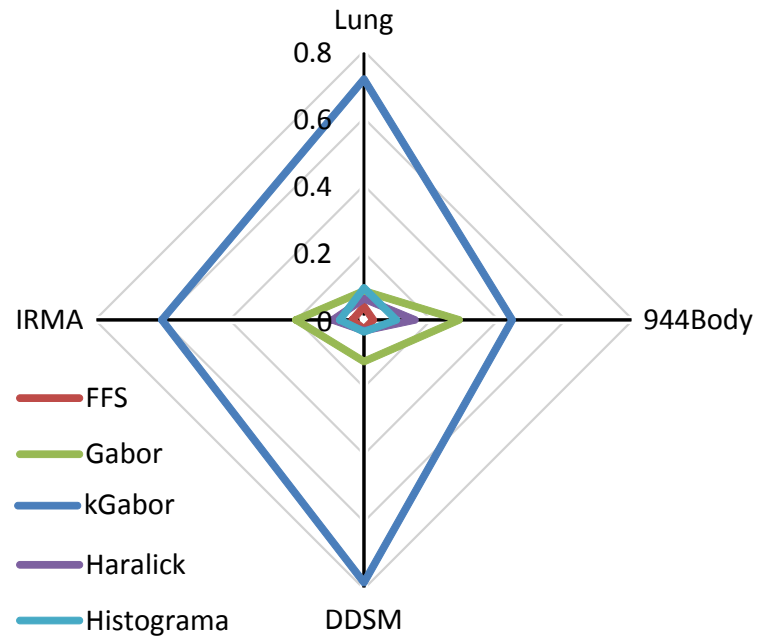

(b) Radar para o $X^{2}$

Figura 4.20: Diagrama radar do desempenho do T-test e o $X^{2}$ em cada Base de imagens. 
Finalmente, os gráficos radar ajudam na visualização das proporcionalidades dos dados, nesta dissertação, foram utilizados para ressaltar a proporcionalidade de características obtidas em cada uma das bases de imagens considerando cada método de seleção de características (nove no total). Assim, o extrator de características $k$-Gabor, proposto nesta dissertação, gerou o maior número de características selecionadas em todos os métodos de seleção de características.

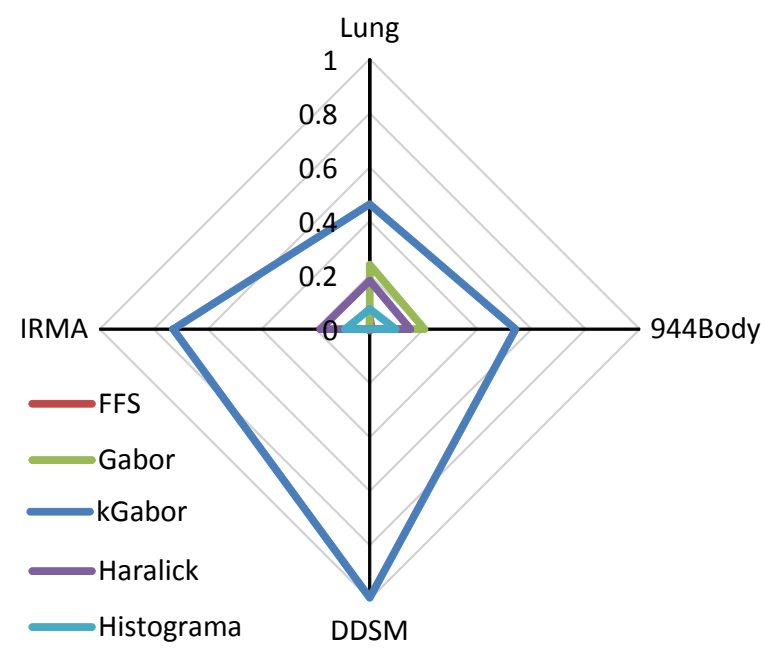

(a) Radar para o StarMiner

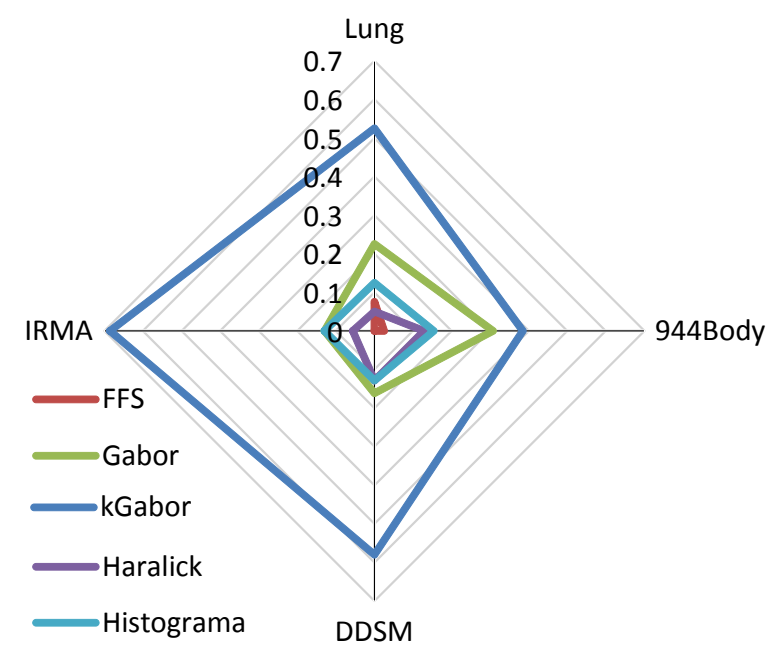

(b) Radar para o CFS

Figura 4.21: Diagrama radar do desempenho do StarMiner e o CFS em cada Base de imagens.

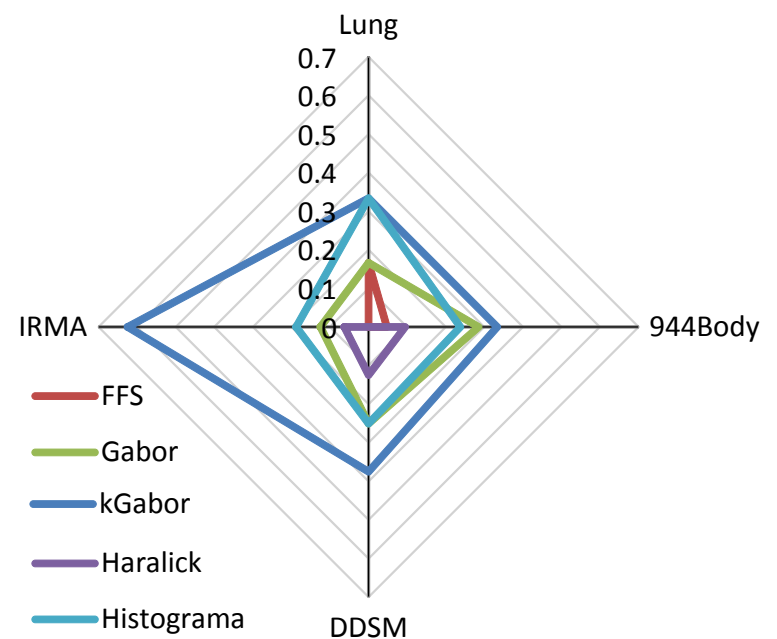

Figura 4.22: Diagrama radar do desempenho do FCBF em cada Base de imagens. 


\section{CAPÍTULO \\ 5 \\ Conclusões Gerais e Linhas de Pesquisas Futuras}

Nesta dissertação de mestrado foram desenvolvidos dois métodos para aprimorar os resultados de precisão dos sistemas CBIR, um método de extração de características e um método de seleção de características. Ambos os métodos são detalhados a seguir.

O extrator de características $k$-Gabor: $\mathrm{O} k$-Gabor emprega a decomposição da imagem para ressaltar características que na imagem global não são perceptíveis. A imagem decomposta por níveis de cinza gera máscaras, a partir das quais o extrator Gabor extrai as características para cada máscara. O vetor de características do método $k$-Gabor é uma composição dos vetores extraídos por cada máscara. Este método consegue superar os extratores encontrados na literatura para imagens médicas.

O método de seleção de características FSCoMS: O FSCoMS baseia-se na análise das projeções bidimensionais (ScatterPlots) das características para associar valores de relevância a cada uma delas. Assim, este método gera um ranking das características. 
Em conclusão, o método $k$-Gabor extrai características internas das imagens médicas ressaltando informação relevante como órgãos, tecidos ou malformações produzindo melhores resultados do que outros extratores. Enquanto o método FSCoMS obtém projeções das características que conseguem separar as classes para sua classificação. Esses dois métodos permitem alcançar o objetivo desta dissertação melhorando os resultados das consultas por similaridades dos sistemas de recuperação.

\subsection{Linhas de Pesquisas Futuras}

A pesquisa realizada ao longo deste projeto de mestrado possibilita o desenvolvimento de novos métodos com extensões de técnicas como clustering ou de projeção de dados. As principais linhas de futuras pesquisas são listadas a seguir:

Avaliar os Métodos Propostos para Diferentes Domínios de Aplicações: Tanto os métodos $k$-Gabor como o FSCoMS foram avaliados neste projeto de mestrado com imagens médicas. No entanto, os métodos apresentam vantagens sobre os outros métodos por ter uma melhor distinção das classes. Enquanto o $k$-Gabor mistura informação baseada na forma e extrai características de textura o FSCoMS faz uma análise das características para reduzir a redundância de dados obtendo um ranking de características. Assim, ambos os métodos podem ser úteis em outros domínios de aplicações.

Reduzir o Número de Características para $k$-Gabor e o Tempo de Resposta dos Métodos : Atualmente o $k$-Gabor obtém $k$ vezes as características do extrator Gabor. Embora essas características possibilitem um maior desempenho, elas também podem gerar problemas relacionados à maldição da dimensionalidade. Assim como os outros extratores, o $k$-Gabor também é afetado pelo tamanho da imagem de entrada por ter uma maior informação para processar, incrementando o tempo de resposta. Como uma possível solução é possível paralelizar o método durante a extração das características de Gabor. Outra possível solução é tentar realizar menos cálculos para reduzir o tempo de resposta do algoritmo. Enquanto o FSCoMS faz uma análise intensiva, o método poderia melhorar em tempo de resposta evitando avaliar todos os ScatterPlot. Um algoritmo de ranking de ScatterPlots rápido para sua pre-seleção ajudaria nesta tarefa.

Avaliar Outros Métodos de Clustering para o $k$-Gabor: Atualmente é usado o $k$-means para clusterizar a imagem, mas outros métodos de clustering podem gerar conteúdo mais semântico fornecendo assim uma maior precisão. 
Automatizar o valor $k$ para o $k$-Gabor: O valor $k$ é um valor que, neste trabalho, foi obtido empiricamente entre $2,3, \ldots, 10$, mas essa análise pode demorar muito dependendo da quantidade de imagens na base. Uma possível solução é aproximar o valor $k$ segundo os valores $k$ obtidos para outras bases de imagens.

Permitir ao usuário definir pesos às máscaras do $k$-Gabor: As saídas do método $k$-means contém as máscaras, ou seja, informação relevante da imagem por níveis. Mas nem sempre todas essas máscaras são relevantes. Assim, uma interação com o usuário, onde ele possa escolher o peso para cada máscara, poderia dar melhores resultados para uma consulta personalizada.

Avaliar Outros Métodos de Projeção de Dados para o FSCoMS: O método de seleção de características FSCoMS está baseado na análise dos ScatterPlots para a obtenção do ranking de características. Porém existem diferentes métodos de projeção e visualização de dados. Os ScatterPlot podem ser substituídos por algum outro método que permita a projeção em duas dimensões. 

APÊNDICE

\section{$A$}

\section{Equações das Características de}

Haralick

As características de Haralick apresentadas na Secção 2.1.1, são apresentadas 22 possibilidades. Essas características são calculadas de forma separável. Porém, cada característica tem uma equação para poder ser calculada. As características consideradas são as seguintes:

- $f_{1}$ : Autocorrelação (Autocorrelation).

- $f_{2}$ : Destaque do Aglomerado (Cluster Prominence).

- $f_{3}$ : Mancha do Aglomerado (Cluster Shade).

- $f_{4}$ : Dissimilaridade (Dissimilarity).

- $f_{5}$ : Homogeneidade (Homogeneity).

- $f_{6}$ : Probabilidade Máxima (Maximum probability).

- $f_{7}$ : Coeficiente de Máxima Correlação (Maximal correlation coefficient).

- $f_{8}$ : Momento Normalizado da Diferença Inversa (Inverse difference moment normalized).

- $f_{9}$ : Diferença Inversa Normalizada (Inverse difference normalized - INN). 
- $f_{10}$ : Segundo Momento Angular (Angular second moment).

- $f_{11}$ : Diferença da Variância (Difference variance).

- $f_{12}$ : Correlação (Correlation).

- $f_{13}$ : Soma dos quadrados da Variância (Sum of squares variance).

- $f_{14}$ : Momento da Diferença Inversa (Inverse difference moment).

- $f_{15}$ : Soma das Médias (Sum average).

- $f_{16}$ : Soma das Variâncias (Sum variance).

- $f_{17}$ : Soma da Entropia (Sum entropy).

- $f_{18}$ : Entropia (Entropy).

- $f_{19}$ : Contraste (Contrast).

- $f_{20}$ : Diferença da Entropia (Difference entropy).

- $f_{21}$ : Medida de Correlação 1 (Information measure of correlation 1).

- $f_{22}$ : Medida de Correlação 2 (Information measure of correlation 2).

$$
\begin{aligned}
& f_{1}=\sum_{i} \sum_{j}(i, j) p(i, j) \\
& f_{2}=\sum_{i} \sum_{j}\left(i+j-\mu_{x}-\mu y\right)^{4} p(i, j) \\
& f_{3}=\sum_{i} \sum_{j}\left(i+j-\mu_{x}-\mu y\right)^{3} p(i, j) \\
& f_{4}=\sum_{i} \sum_{j}|i-j| * p(i, j) \\
& f_{5}=\sum_{i}\left(\frac{\sum_{j} p(i, j)}{1+(i-j)^{2}}\right) \\
& f_{6}=M A X_{i, j} p(i, j) \\
& f_{7}=\sqrt{\text { Segundo maior eigenvalores de } \mathrm{Q}}
\end{aligned}
$$




$$
\begin{aligned}
& f_{8}=\sum_{i} \sum_{j}\left(\frac{p(i, j)}{1+\left(\frac{i-j}{d}\right)^{2}}\right) \\
& f_{9}=\sum_{i} \sum_{j}\left(\frac{p(i, j)}{1+\frac{|i-j|}{d}}\right) \\
& f_{10}=\sum_{i=1}^{N_{g}} \sum_{j=1}^{N_{g}} p(i, j)^{2} \\
& f_{11}=\sum_{k=0}^{N_{g}-1} k^{2} p_{x-y}(k) \\
& f_{12}=\frac{\sum_{i=1}^{N_{g}} \sum_{j=1}^{N_{g}}(i j) p(i, j)-\mu_{x} \mu_{y}}{\sigma_{x} \sigma_{y}} \\
& f_{13}=\sum_{i} \sum_{j}(i-\mu)^{2} p(i, j) \\
& f_{14}=\sum_{i} \sum_{j} \frac{1}{1+(i-j)^{2}} p(i, j) \\
& f_{15}=\sum_{i=2}^{2 N_{g}} i p_{x+y}(i) \\
& f_{16}=\sum_{i=2}^{2 N_{g}}\left(i-f_{8}\right)^{2} p_{x+y}(i) \\
& f_{17}=-\sum_{i=2}^{2 N_{g}} p_{x+y}(i) \log \left(p_{x+y}(i)\right) \\
& f_{18}=-\sum_{i} \sum_{j} p(i, j) \log (p(i, j)) \\
& f_{19}=\sum_{n=0}^{N_{g}-1} n^{2}\left\{\sum_{i=1}^{N_{g}} \sum_{j=1}^{N_{g}} p(i, j)\right\},|i-j|=n \\
& f_{20}=-\sum_{i=0}^{N_{g}-1} p_{x-y}(i) \log \left(p_{x-y}(i)\right) \\
& f_{21}=\frac{f_{9}-H X Y 1}{\max (H X, H Y)} \\
& f_{22}=\sqrt{1-\exp ^{-2\left(H X Y 2-f_{9}\right)}}
\end{aligned}
$$


onde $N_{g}$ é a quantidade de níveis de cinza considerados para construir a matriz de co-ocorrência, $Q(i, j)=\sum_{k} \frac{p(i, k) p(j, k)}{p_{x}(i) p_{y}(k)}$ para a equação A.7. E HX e HY são entropias de $p_{x}$ e $p_{y}$ respectivamente e para as equações A.22 e A.23 os valores de HXY1 e HXY2 são:

$$
\begin{aligned}
& H X Y 1=-\sum_{i} \sum_{j} p(i, j) * \log \left(p_{x}(i) * p_{y}(j)\right) \\
& H X Y 2=-\sum_{i} \sum_{j} p_{x}(i) * p_{y}(j) * \log \left(p_{x}(i) * p_{y}(j)\right)
\end{aligned}
$$




\section{Referências Bibliográficas}

Abraham, R. H. (1994). Fractals, chaos, power laws: Minutes from an infinite paradise : Manfred schroeder, (w.h. freeman, new york, ny, 1991). Journal of Economic Dynamics and Control, 18(5):1041-1043. Citado na página 12.

Albregtsen, F. and Others (1995). Statistical Texture Measures Computed from Gray Level Coocurrence Matrices. Image Processing Laboratory, Department of Informatics, University of Oslo, pages 1-14. Citado na página 7 .

Albuquerque, G. and Eisemann, M. (2009). Quality-based visualization matrices. Proc. Vision, Modeling and Visualization. Citado na página 40.

Albuquerque, G. and Eisemann, M. (2011). Perception-based visual quality measures. Visual Analytics Science. Citado na página 40 .

Arimura, H., Magome, T., Yamashita, Y., and Yamamoto, D. (2009). Computer-Aided Diagnosis Systems for Brain Diseases in Magnetic Resonance Images. Algorithms, 2(3):925-952. Citado na página 6 .

Baeza-Yates, R., Ribeiro-Neto, B., and Others (1999). Modern information retrieval, volume 463. ACM press New York. Citado na página 27

Balan, A., Traina, A. J., Traina, C., and Azevedo-Marques, P. (2005). Fractal analysis of image textures for indexing and retrieval by content. In Computer-Based Medical Systems, 2005. Proceedings. 18th IEEE Symposium on, pages 581-586. IEEE. Citado na página 11.

Bjorck, A. (1967). Solving linear least squares problems by gram-schmidt orthogonalization. $B I T, 7$. Citado na página 20 .

Buciu, I. and Gacsadi, a. (2009). Gabor wavelet based features for medical image analysis and classification. 2009 2nd International Symposium on Applied Sciences in Biomedical and Communication Technologies, pages 1-4. Citado na página 9.

Bugatti, P. H. and Traina, A. J. (2008). On the Effects of Distance Functions to Improve. (Icmc):105-112. Citado nas páginas $18 \mathrm{e} 40$. 
Cho, B. H., Yu, H., Kim, K.-W., Kim, T. H., Kim, I. Y., and Kim, S. I. (2008). Application of irregular and unbalanced data to predict diabetic nephropathy using visualization and feature selection methods. Artificial intelligence in medicine, 42(1):37-53. Citado na página 47.

Cho, Z.-H. Y.-D. S. Y.-B. K. S.-S. (2010). Fusion of PET and MRI for Hybrid Imaging. In Deserno; Thomas, editor, Biomedical Image Processing, chapter 2, pages 55-77. Springer, Berlin Heidelberg. Citado na página 10.

Cope, J., Remagnino, P., and Barman, S. (2010). Plant texture classification using gabor co-occurrences. Advances in Visual. Citado na página 9.

Costa, A., Humpire, G., and Traina, A. (2012). An efficient algorithm for fractal analysis of textures. Citado na página 12 .

Costa, A. F., Tekli, J., and Traina, A. J. (2011). Fast Fractal Stack : Fractal Analysis of Computed Tomography Scans of the Lung. In International ACM Workshop on Medical Multimedia Analysis and Retrieval. Citado nas páginas $12 \mathrm{e} 49$.

da Silva, S. F., Ribeiro, M. X., Batista Neto, J. a. D. E., Traina-Jr., C., Traina, A. J., and Traina, C. (2011). Improving the ranking quality of medical image retrieval using a genetic feature selection method. Decision Support Systems, pages 1-11. Citado na página 47.

Datta, R., Joshi, D., Li, J., and Wang, J. Z. (2008). Image retrieval ideas influences and trends of the new age. ACM Computing Surveys, 40(2):1-60. Citado na página 5 .

Deselaers, T., Keysers, D., and Ney, H. (2007). Features for image retrieval: an experimental comparison. Information Retrieval, 11(2):77-107. Citado nas páginas $6 \mathrm{e} 11$.

Deserno, T. M. (2010). Biomedical image processing., volume 5. Springer. Citado na página 6.

Ding, S., Zhu, H., Jia, W., and Su, C. (2011). A survey on feature extraction for pattern recognition. Artificial Intelligence Review, 37(3):169-180. Citado na página 38.

Duangsoithong, R. and Windeatt, T. (2010). Bootstrap feature selection for ensemble classifiers. Citado na página 19.

Duchesnay, E., Cachia, A., Boddaert, N., Chabane, N., Mangin, J.-F., Martinot, J.-L., Brunelle, F., and Zilbovicius, M. (2011). Feature selection and classification of imbalanced datasets: application to PET images of children with autistic spectrum disorders. NeuroImage, 57(3):1003-14. Citado nas páginas $14 \mathrm{e} 16$.

García-Gómez, J. M. (2009). Pattern Recognition Approaches for Biomedical Data in Computer-Assisted Cancer. $\mathrm{PhD}$ thesis, Universidad Politecnica de Valencia. Citado na página 5 .

Geng, X., Liu, T.-Y., Qin, T., and Li, H. (2007). Feature selection for ranking. Proceedings of the 30th annual international ACM SIGIR conference on Research and development in information retrieval SIGIR 07, (49):407. Citado nas páginas $38 \mathrm{e} 47$. 
Ghosh, P., Antani, S., and Long, L. (2011). Review of medical image retrieval systems and future directions. Computer-Based Medical Systems. Citado na página 5 .

Ghurye, S. (1949). On the use of student's t-test in an asymmetrical population. Biometrika, 36. Citado na página 20 .

Gu, Q., Li, Z., and Han, J. (2010). Generalized Fisher Score for Feature Selection A Brief Review of Fisher Score. Ratio. Citado na página 19.

Guyon, I. (2006). Feature extraction: foundations and applications. Soft Computing. Citado nas páginas $6 \mathrm{e} 14$.

Hall, M. and Smith, L. (1999). Feature selection for machine learning: comparing a correlation-based filter approach to the wrapper. In Proceedings of the Twelfth International Florida Artificial Intelligence Research Society Conference, volume 235, page 239. AAAI Press. Citado na página 17.

Haralick, R., Shanmugam, K., and Dinstein, I. (1973). Textural features for image classification. Systems, Man and Cybernetics, IEEE Transactions on, 3(6):610-621. Citado nas páginas 7 e 49 .

He, L., Long, L. R., Antani, S., and Thoma, G. R. (2011). Multiphase Level Set Model with Local K-means Energy for Histology Image Segmentation. 2011 IEEE First International Conference on Healthcare Informatics, pages 32-39. Citado na página 25.

Hinneburg, A. and Keim, D. (1999). Optimal grid-clustering: Towards breaking the curse of dimensionality in high-dimensional clustering. Citeseer. Citado na página 13.

Huang, C. and Liao, W. (2003). A comparative study of feature selection methods for probabilistic neural networks in cancer classification. Artificial Intelligence, pages 0-7. Citado nas páginas $17 \mathrm{e} 38$.

Huang, D.-Y. and Wang, C.-H. (2009). Optimal multi-level thresholding using a two-stage otsu optimization approach. Pattern Recognition Letters, 30(3):275 - 284. Citado na página 12.

Humpire, G., Traina, A., and Traina, C. (2012a). Fscoms: Feature selection of medical images based on compactness measure from scatterplots. HISB2012, The second IEEE Conference on Healthcare Informatics, Imaging, and Systems Biology - HISB, California-USA, (2). Citado na página 37 .

Humpire, G., Traina, A., and Traina, C. (2012b). k-gabor: A new feature extraction method for medical images providing internal analysis. CBMS, Computer-Based Medical System, Roma-Italia, (25). Citado nas páginas $23 \mathrm{e} 49$.

Kim, Y. and Street, N. (2007). Feature Selection in Data-Mining, volume $3 . \quad$ Citado na página 13 .

Lehmann, T. and Thies, C. (2003). The irma project: A state of the art report on content-based image retrieval in medical applications. Medical Image. Citado nas páginas 32 e 58. 
Liu, H. (1997). Feature selection via discretization. Knowledge and Data Engineering, IEEE, 9(4):1995-1998. Citado na página 16.

Liu, H. and Setiono, R. (1995). Chi2: Feature selection and discretization of numeric attributes. In Tools with Artificial Intelligence, 1995. Proceedings., Seventh International Conference on, pages 388-391. IEEE. Citado nas páginas $16 \mathrm{e} 38$.

Lo, D., Cheng, H., Han, J., Khoo, S., and Sun, C. (2009). Classification of software behaviors for failure detection: a discriminative pattern mining approach. Knowledge discovery and data mining. Citado na página 19 .

Manjunath, B. (1996). Texture features for browsing and retrieval of image data. Pattern Analysis and Machine, 18(8):837-842. Citado nas páginas 8 e 49.

Manjunath, B. and Ma, W.-Y. (2002). Texture features for image retrieval. In Image Databases, volume 8, chapter 12, page 32. John Wiley \& Sons, Inc. Citado na página6.

Mingqiang, Y., Kidiyo, K., Joseph, R., Yang, M., Kpalma, K., and Ronsin, J. (2008). A survey of shape feature extraction techniques. Pattern Recognition, (November). Citado na página9.

Movellan, J. (2002). Tutorial on gabor filters. Open Source Document. Citado na página 8.

Mukras, R., Wiratunga, N., Lothian, R., Chakraborti, S., and Harper, D. (2007). Information gain feature selection for ordinal text classification using probability re-distribution. In Proceedings of the Textlink workshop at IJCAI, volume 7. Citeseer. Citado nas páginas $16 \mathrm{e} 38$.

Pagel, B.-U., Korn, F., and Faloutsos, C. (2000). Deflating the dimensionality curse using multiple fractal dimensions. In icde, page 589. Published by the IEEE Computer Society. Citado na página 13 .

Reunanen, J. (2012). Overfitting in Feature Selection: Pitfalls and Solutions. PhD thesis, Aalto University. Citado na página 14.

Ribeiro, M. X. (2008). Suporte a sistemas de auxílio ao diagnóstico e de recuperação de imagens por conteúdo usando mineração de regras de associação. Citado nas páginas 18 e 39.

Saeys, Y., Inza, I. n., and Larrañaga, P. (2007). A review of feature selection techniques in bioinformatics. Bioinformatics (Oxford, England), 23(19):2507-17. Citado na página 16.

Saipullah, K. M. and Kim, D.-H. (2011). A robust texture feature extraction using the localized angular phase. Multimedia Tools and Applications. Citado na página 7.

Sips, M., Neubert, B., and Lewis, J. (2009). Selecting good views of high Řdimensional data using class consistency. Computer Graphics, 28(3). Citado nas páginas 38 e 40.

Stoppiglia, H. and Dreyfus, G. (2003). Ranking a random feature for variable and feature selection. The Journal of Machine Learning Research, 3. Citado na página 20.

Suy, Y., Muraliy, T. M., Pavlovic, V., Schaffer, M., and Kasif, S. (2003). Rankgene: Identification of diagnostic genes based on expression data. Bioinformatics. Citado na página 20. 
Swain, M. J. and Ballard, D. H. (1991). Color indexing. International Journal of Computer Vision, 7(1):11-32. Citado nas páginas $10 \mathrm{e} 49$.

Tahmoush, D. (2009). Image Similarity to Improve the Classification of Breast Cancer Images. Algorithms, 2(4):1503-1525. Citado na página 9.

Tibshirani, R., Hastie, T., Narasimhan, B., and Chu, G. (2002). Diagnosis of multiple cancer types by shrunken centroids of gene expression. Proceedings of the National Academy of Sciences. Citado na página 20.

Wang, J., Mohammed J. Zaki, Hannu T.T. Toivonen, and Shasha, D. (2005a). Data mining in Bioinformatics. Springer, London, 1 edition. Citado na página 13

Wang, L., Chu, F., and Xie, W. (2007). Accurate cancer classification using expressions of very few genes. IEEE/ACM Transactions on Computational, 4(1). Citado na página 20.

Wang, X., Ding, X., and Liu, C. (2005b). Gabor filters-based feature extraction for character recognition. Pattern Recognition, 38(3):369-379. Citado na página9.

Ward, M. O. (1994). XmdvTool: Integrating Multiple Methods for Visualizing Multivariate Data. Visualization 94 Proceedings, pages 326-333. Citado na página 38.

Yoon, H., Yang, K., and Shahabi, C. (2005). Feature Subset Selection and Feature Ranking for Multivariate Time Series. Knowledge Creation Diffusion Utilization, 17(9):1-13. Citado na página 47 .

Yu, L. (2003). Feature selection for high-dimensional data: A fast correlation-based filter solution. Machine Learning-International Workshop. Citado nas páginas $18 \mathrm{e} 19$.

Yu, L. and Liu, H. (2004). Efficient feature selection via analysis of relevance and redundancy. The Journal of Machine Learning Research, 5:1205-1224. Citado na página 13.

Yuan, J., Li, Y., Liu, C., and Zha, X. (2010). Leave-One-Out Cross-Validation Based Model Selection for Manifold Regularization. Advances in Neural Networks-ISNN 2010, pages 457-464. Citado na página 27.

Zhao, Z., Morstatter, F., Sharma, S., Alelyani, S., Anand, A., and Liu, H. (2010). Advancing Feature Selection Research. ASU Feature Selection Repository, Arizona State University. Citado nas páginas $16 \mathrm{e} 17$.

Zhou, N. and Wang, L. (2007). A modified t-test feature selection method and its application on the hapmap genotype data. Genomics, proteomics \& bioinformatics. Citado na página 20. 